\title{
History, philosophy, and sociology of sport recommendations for physical education teacher education
}

Amanda A. Metcalf

West Virginia University

Follow this and additional works at: https://researchrepository.wvu.edu/etd

\section{Recommended Citation}

Metcalf, Amanda A., "History, philosophy, and sociology of sport recommendations for physical education teacher education" (2010). Graduate Theses, Dissertations, and Problem Reports. 3092.

https://researchrepository.wvu.edu/etd/3092

This Dissertation is protected by copyright and/or related rights. It has been brought to you by the The Research Repository @ WVU with permission from the rights-holder(s). You are free to use this Dissertation in any way that is permitted by the copyright and related rights legislation that applies to your use. For other uses you must obtain permission from the rights-holder(s) directly, unless additional rights are indicated by a Creative Commons license in the record and/ or on the work itself. This Dissertation has been accepted for inclusion in WVU Graduate Theses, Dissertations, and Problem Reports collection by an authorized administrator of The Research Repository @ WVU.

For more information, please contact researchrepository@mail.wvu.edu. 
History, Philosophy, and Sociology of Sport

Recommendations for Physical Education Teacher Education

Amanda A. Metcalf

Dissertation submitted to the

College of Physical Activity and Sport Sciences

at West Virginia University

in partial fulfillment of

the requirements for the degree of

Doctor of Philosophy in

Kinesiology with an emphasis in

Physical Education Teacher Education

Andrew Hawkins, Ph.D., Chair

Dallas Branch, Ph.D.

Sean Bulger, Ed.D.

Reagan Curtis, Ph.D.

Robert Wiegand, Ed.D.

Department of Coaching and Teaching Studies

Morgantown, West Virginia

2010

Keywords: Professional Preparation; Teacher Education; Curriculum Design; Higher Education Copyright 2010 Amanda A. Metcalf 


\author{
ABSTRACT \\ History, Philosophy, and Sociology of Sport \\ Recommendations for Physical Education Teacher Education
}

Amanda A. Metcalf

The purpose of this study was to determine the essential history, philosophy, and sociology of sport competencies to be used to inform the physical education teacher education undergraduate curriculum. A two-round modified Delphi procedure involved the repeated circulation of a questionnaire to a panel of content experts. The study sample included specialists in history of sport, philosophy of sport, and sociology of sport, experts in the field of physical education teacher education, and school-based physical education practitioners. The Delphi panel members rated each questionnaire item in terms of its theoretical importance and pedagogical relevance using a five-point Likert scale. The data collected during the second round of the questionnaire were used to provide a final measure of group consensus regarding the strength of each history, philosophy, and sociology of sport competency. Five Delphi panel members, one from each of the three subject matter areas, one physical education teacher educator, and one K-12 physical education teacher were also asked to complete a subsequent telephone interview concerning their recommendations regarding the most effective delivery method of history, philosophy, and sociology of sport to prospective physical education teachers. The results from this research study, which includes a final list of recommended history, philosophy, and sociology of sport competencies and suggested methods of delivery, provide a conceptual framework upon which physical education teacher educators can make future curricular decisions in the areas of history, philosophy, and sociology of sport. 


\section{DEDICATION}

This manuscript is dedicated to Dr. Tom Coates and Dr. Peter Shoun. Thank you for your support over the years; it was no coincidence our paths crossed. You both have inspired me to go above and beyond; I could never repay you for all you have done! Your approach to teaching and belief in your students both inspires and guides me through my journey. 


\section{ACKNOWLEDGEMENTS}

It is impossible to appropriately give thanks to so many people who have supported me along my WVU PETE journey, but here goes...

To my dissertation committee-Dr. Andrew Hawkins, Dr. Sean Bulger, Dr. Robert Wiegand, Dr. Reagan Curtis, and Dr. Dallas Branch...thank you! You all have been especially helpful in planning both my research and doctoral plan of study. A special thank you to Dr. Sean Bulger who focused my attention on this subject matter three years ago and again one year ago. Thank you for being relentless! I am sure I would still be searching for the magical dissertation topic to smack me in the face had you not been the little angel on my shoulder.

To Dr. Andrew Hawkins, my dissertation committee chair, advisor, and golf buddy. Thank you for sharing your expert teaching knowledge throughout my journey at WVU. Your assistance along the way has lightened the load as well as made me smile and laugh countless times over.

To Dr. Reagan Curtis, I am so thankful to have had you as a teacher for so many statistics classes. You made learning statistics easy to understand and made the all important light bulb come on countless times.

To Dr. Robert Wiegand, thank you for all of the smiles and laughter.

To a true Super Woman, A.K.A. Dr. Amy Sidwell. You have been there through it all my friend with constant support and a listening ear. Bless you dearly! The bond we have created at WVU will continue through the years. To Jack Sager for your encouragement and help from day one. You paved the way buddy! To Justine Vosloo for your friendship, support, and laughter at just the right moment.

To my best friend Susan Ross, thank you for EVERYTHING...your friendship, laughing until the point of crying all too hard, unwavering support in all sense of the word, etc., etc.

I would also like to thank the Delphi panel for their timely efforts and expert knowledge.

What a memorable journey this has been! 


\section{TABLE OF CONTENTS}

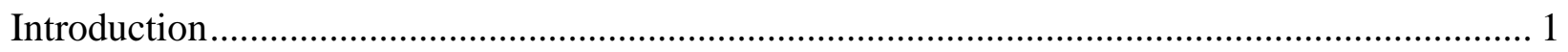

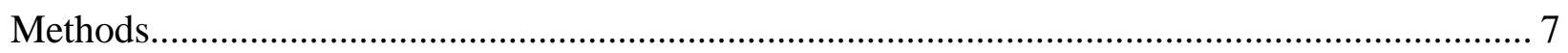

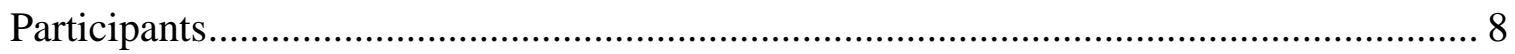

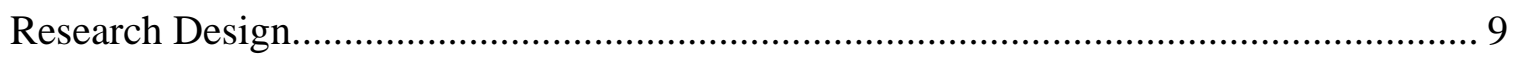

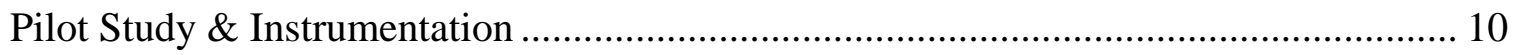

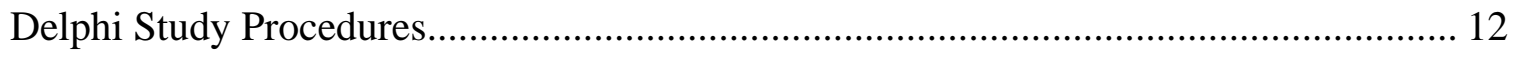

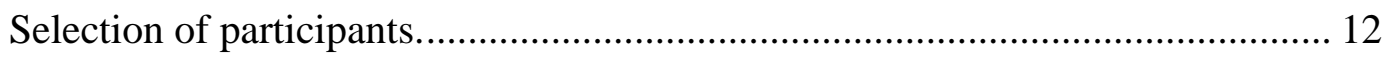

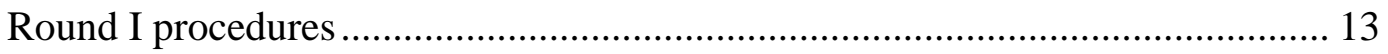

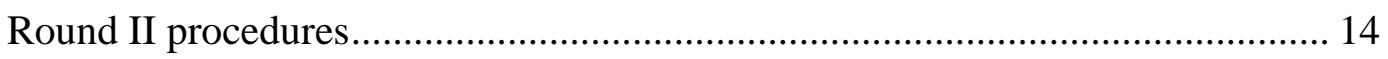

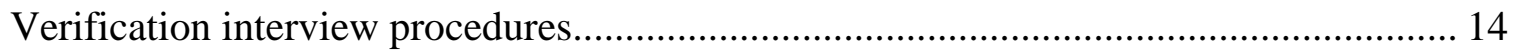



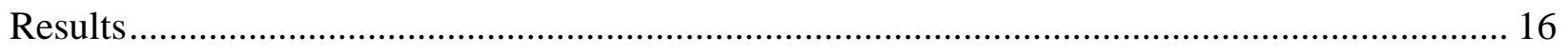

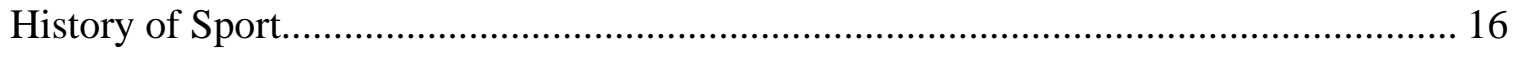



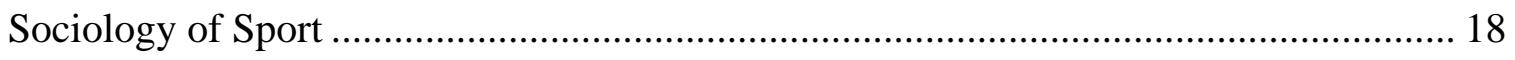

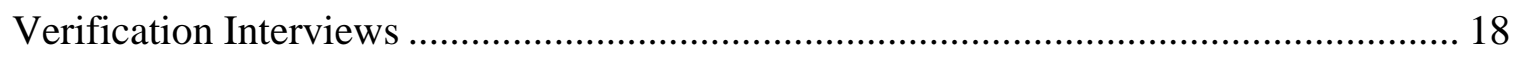

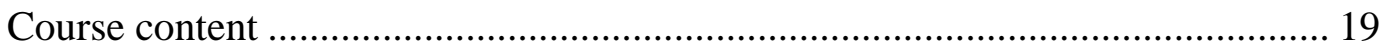



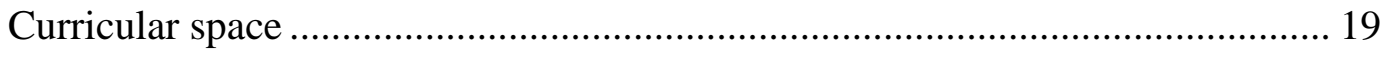

Additional competency .................................................................... 20

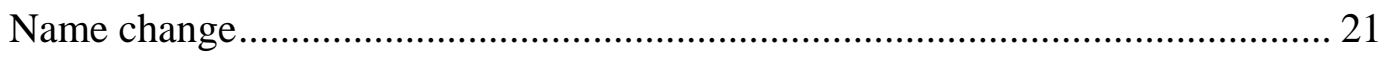






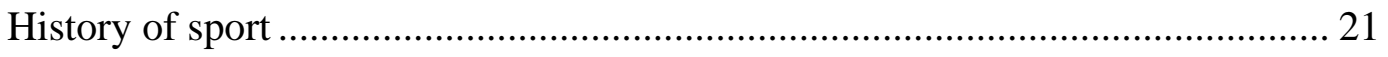

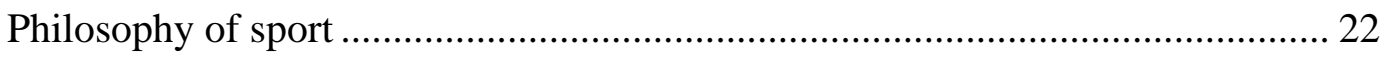

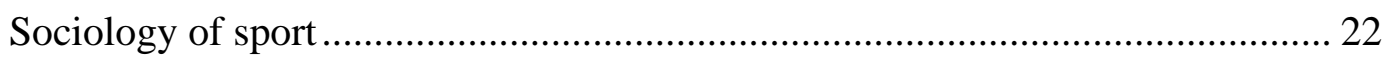

Verification interviews...................................................................................... 23

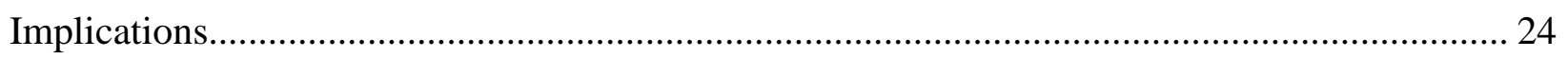



Instructional Context............................................................................................. 26

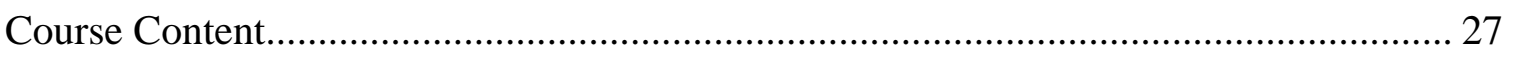

Physical Activity and Sociocultural Content ................................................................. 30

Curricular Space.................................................................................................. 32

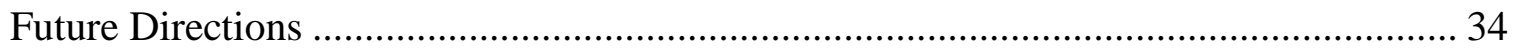

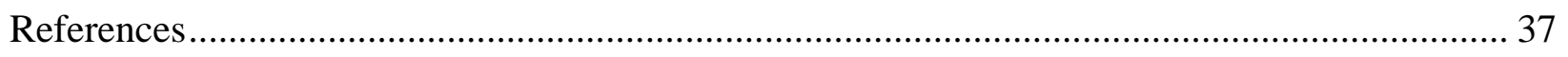

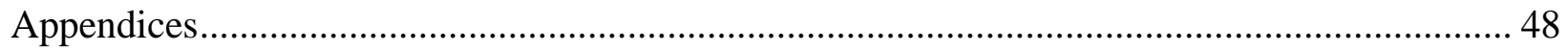

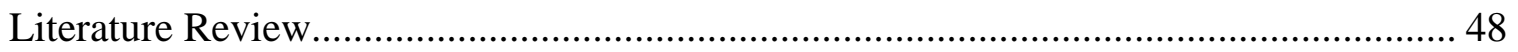

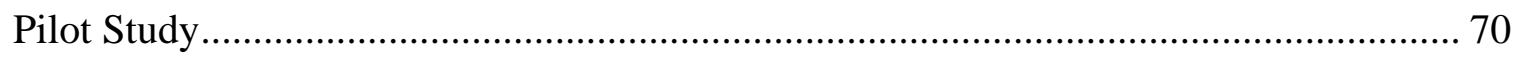

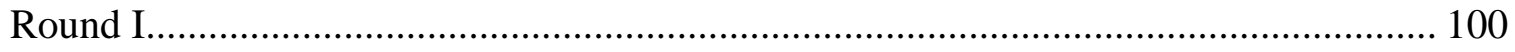

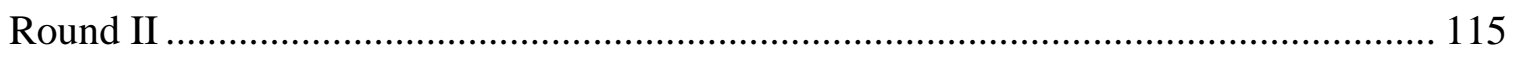

Verification Interview Protocol ................................................................................. 138 


\section{LIST OF TABLES}

Table 1. Final list of essential history, philosophy, and sociology of sport competencies............42

Table 2. Sub-discipline Delphi Studies..........................................................................44

Table 3. Verification interviews - course content ..........................................................45

Table 4. Summary of theoretical and applied history, philosophy, and sociology of sport PETE competencies. 


\section{Introduction}

Course work in the area of history, philosophy, and sociology is recognized as an important foundational component of the physical education teacher education (PETE) curriculum (NASPE, 2008a). It has been proposed that a physical educator's knowledge of history, philosophy, and sociology of sport (sociocultural sphere) concepts may enrich the prospective teacher's understanding of physical education content (Siedentop, 2009). However, little is known about how a physical educator’s understanding of history, philosophy, and sociology nurtures students towards valuing and adopting physical activity behaviors. The limited research suggests course work in the sociocultural sphere has been unable to find a way into a curriculum promoting skill development and lifetime physical activity initiatives. While changing values, ideologies, and needs of our culture (history, philosophy, and sociology) have influenced what physical educators teach and how they behave morally and ethically, content related to the sociocultural sphere (Hoffman, 2005) has diminished from numerous PETE programs. Kretchmar (1990) contends “physical educators are given very little historical, sociocultural, and linguistic context against which to understand our problems and identify potential solutions" (p. 331).

The sociocultural sphere content has also been traditionally delivered as components of the PETE curriculum within introduction to physical education/sport studies courses, or in specific history, philosophy, and sociology courses taught within various departments throughout a university. This disciplinary disconnect suggests PETE programs have been unable to conceptualize the relevance of theoretical knowledge from the sociocultural sphere in the preparation of prospective physical education teachers. Because of this unrecognized

relationship, PETE institutions may be eliminating potentially worthwhile foundational 
knowledge in the sociocultural sphere from the teacher preparation curriculum. Looking across PETE institutions, it is evident how curricula vary in terms of how history, philosophy, and sociology of sport content are delivered due to differing views of what constitutes quality physical education programming. For example, a History of Sport in America course is required at the University of Maryland; Elementary Physical Education Curriculum Philosophy and Theory is required at the University of Alabama; and Social Aspects of Physical Activity is a requirement at the University of Central Missouri. West Virginia University offers an Introduction to Physical Education course as well as provides philosophical content within its Student Teaching Seminar.

The curricular model employed by PETE departments typically influences the focus given to theoretical content in the sociocultural sphere. For example, greater emphasis is placed on the history, philosophy, and sociology of sport within PETE programs utilizing the sport education model because two central goals of the model are to produce literate and enthusiastic sports persons. According to Siedentop (1994) a literate sport person is knowledgeable about the rules, traditions, and values associated with specific sports, and can distinguish between good and bad sport practices. An enthusiastic sport person participates and behaves in ways that preserve, protect, and enhance the culture of sport. Prospective physical educators exposed to the sport education model have the opportunity to develop a deeper understanding of the cognitive, social, and affective aspects of game play because they are engaged in comprehensive study of sport. Conversely, PETE programs utilizing the multi-activity model may place less emphasis on history, philosophy, and sociology concepts in an attempt to expose prospective teachers to a wide variety of individual, dual, and team sports, as well as lifetime physical activities. 
The preparation of physical education teachers in the midst of a changing society has been a longstanding topic of discussion by planning committees at national conferences for decades. The American Association for Health, Physical Education, and Recreation (AAHPER) held a National Conference on Undergraduate Professional Preparation in 1963 with the goal of generating ideas among a group of professionals for PETE programmatic improvement (AAHPER, 1974). This national conference marked the initial efforts to generate concepts and competencies for physical education teacher preparation programs (AAHPER, 1974). Franklin Henry’s (1964) declaration of physical education as an academic discipline initiated the beginning of the sub-disciplinary movement, and sparked a series of events that would revise the original competencies set forth at the AAHPER conference. It was conceived by the planning committee and task force members that the structure of knowledge within PETE involved "research and application of the meaning and significance of movement as reflected in the sociocultural, historical, and philosophical aspects of movement; the growth and development of the individual; and, the physical, biological and behavioral factors influencing movement” (AAHPER, 1974, p. 23). The final professional preparation document endorsed by AAHPER yielded a general set of concepts and competencies that would provide guidance for curricular planning, evaluation, and teacher preparation. The final AAHPER conference report clearly defined historical, philosophical, and sociocultural concepts and paralleling competencies in the study of human movement for physical education teacher preparation. It was generally conceived that the sociocultural sphere would help physical educators understand the meaning and significance of physical activity within various cultures, as well as the impact of society from the work of physical educators (AAHPER, 1974). 
Although history, philosophy, and sociology of sport were initially perceived to make important contributions to physical education teacher preparation, it has become increasingly evident a stronger emphasis was placed on the physical sciences, rather than the social sciences and cultural foundations of human movement behavior, within the PETE curriculum. A notable shift fueling curricular changes occurred in the late 1970s and early 1980s when applicants to teacher education programs dropped due to an increase in non-teaching majors within kinesiology departments (Marett, Siler, Pavlacka, \& Shapiro, 1984). This drop in enrollment led to many colleges and university PETE departments looking for more attractive curricula in order to appeal to more students. Thus, a stronger sport science emphasis in teacher preparation programs eventually led to an under representation of the sociocultural sphere content within the PETE curriculum. By 1978, significant changes had been made by the National Council for the Accreditation of Teacher Education (NCATE) with respect to the content and process for evaluation of accreditation guidelines. To this effect, NCATE invited learned societies in the subject matter areas, such as NASPE, to develop their content and evaluative process (Douglas \& Wiegand, 1987). Thus in 1987, NASPE established their first set of guidelines for the preparation of physical education teachers.

Moving into the $21^{\text {st }}$ century, the NASPE Sport History, Philosophy, and Sociology Academy followed the lead of the biomechanics and motor development academies by developing and publishing Minimum Competencies for Teaching Undergraduate Sport Philosophy Courses (NASPE, 2004). The proposed philosophy of sport competencies are primarily intended for faculty responsible for teaching a standalone undergraduate philosophy of sport course without having an extensive background (NASPE, 2004). Currently, the Sport History, Philosophy, and Sociology Academy is in the process of developing competencies for 
both history and sociology of sport (P. Rodriguez, personal communication, December 11, 2008). Although there is merit in establishing undergraduate preparation competencies, it remains to be seen if the competencies proposed by the Sport History, Philosophy, and Sociology Academy will serve as a relevant source of theoretical knowledge in the preparation of physical education teachers. A closer examination of the initial PETE standards as well as Concepts and Principles of Physical Education: What Every Student Needs to Know endorsed by NASPE (Mohnsen, 2003) may bring to light what is considered a relevant source of knowledge for prospective physical education teachers.

NASPE and NCATE require teacher educators to have a thorough training in content and theoretical knowledge in all of the different disciplines. Beginning physical educators should be able to "identify historical, philosophical, and social perspectives of physical education issues and legislation” (NASPE, 2008b, p.1). Accordingly, there is a need for PETE to clearly define what concepts and associated competencies within the sociocultural sphere are essential in preparing physical educators. It is important for PETE scholars to take the responsibility for examining what disciplinary content is essential in helping physical education graduates achieve the NASPE/NCATE standards.

Scholarly investigations focused on identifying critical concepts, themes, or perspectives in the areas of history, philosophy, and sociology are long overdue in physical education teacher education. While insufficient physical educator preparation in the foundational sub-disciplines has been a highly discussed issue, the associated theory to practice gap problem is often exposed though ineffective K-12 physical education practices. Making progress as a discipline and/or profession in the $21^{\text {st }}$ century will require greater consensus among physical education teacher educators regarding a core body of knowledge in the sociocultural sphere upon which PETE can 
base its practice. Specifically identifying what physical educators should learn in history, philosophy, and sociology of sport will inform the curriculum development process, which includes the content, instruction, and assessment triad.

Achieving this goal will require PETE scholars to move from a unitary focus and join forces across disciplinary and practice landscapes. Additionally, there is a need to support and incorporate alternative research designs when addressing PETE curriculum issues that cannot be solved through experimental approaches. This study will bring together content area specialists to evaluate what critical competencies in the areas of history, philosophy, and sociology should be incorporated in the PETE undergraduate curriculum. This study is a part of an existing line of research looking at all sub-disciplinary areas. More specifically, this study followed the pattern of a previous modified Delphi study examining PETE competencies related to exercise science for undergraduate education by using a panel of experts to determine theoretical and applied teaching competencies (Bulger \& Housner, 2007). However, unlike the Bulger and Housner study, this research utilized an online modified Delphi methodology. Through experts in the PETE sub-disciplines, teacher education, and practicing physical education teachers, these PETE professionals were examining what needs to be included in the PETE curriculum. See Table 2 for a timeline of studies within this line of research.

The purpose of this study was to generate a consensus of expert judgment regarding the most important and pedagogically relevant theoretical and applied history, philosophy, and sociology of sport competencies that prospective physical educators need to learn within the PETE curriculum. A secondary aim of this study was to determine where history, philosophy, and sociology of sport content should be delivered within the PETE curriculum to prospective physical educators. The results of this research project will hopefully provide a framework upon 
which PETE faculty members can make future history, philosophy, and sociology of sport curricular decisions.

\section{Methods}

According to Ludwig (1997), when using geographically dispersed experts, a method of involvement allowing for participation within the experts' respective locations is necessary. In situations where group meetings are believed to be unsuitable due to logistical limitations, the Delphi method is a useful research tool in synthesizing expert judgments and deriving consensus (Clayton, 1997). The underlying assumption of the Delphi method is that informed, collective judgment of a group of experts is more accurate and reliable than individual judgment (Clayton, 1997; Ziglio, 1996). The structured process of the modified Delphi method utilizes a series of questionnaires (or rounds) to gather information and provide controlled feedback; this process continues until group consensus is obtained (Beretta, 1996; Green, Jones, Hughes, \& Williams, 1999). The Delphi method is noted as preserving the separate power of each person's opinion, unlike group discussion, where one dominant leader might persuade the group member’s opinions (Cyphert \& Gant, 1971). Participants remain anonymous to each other, thereby avoiding influences of affiliation, reputation, or authority, and this enables panel members to change their opinions without losing face (Martino, 1993).

The modified Delphi method is a variation of the Delphi method developed by Dalkey and Helmer (1963) at Rand. It utilizes multiple rounds of a survey, with questions being eliminated, new questions added, and expert panel members being able to view anonymous responses from the other participants and alter their responses accordingly. The modified Delphi method described in this study used electronic mail (e-mail) to gather information, provide 
feedback, and report conclusions. The effective selection of a Delphi panel not only gives the results of the study credibility, but it also maximizes the quality of responses (Martino, 1993).

\section{Participants}

Because the selection of appropriate experts who are qualified in their subject area determines the success of a Delphi study, an expert panel was convened to examine history, philosophy, sociology of sport, PETE, and the practical application of teaching physical education in a school-based setting. Expert panel members for these five areas were recruited using snowball sampling. Snowball sampling is a technique used to recruit participants into a sample via expert recommendation (Lang, 1998). This technique begins with an established expert in a specified field of study, usually declared as an expert or specialist from a national governing body, followed by the initial expert specifying other individuals recognized as experts in their field. For this study, the individuals who identified the history, philosophy, and sociology of sport, and PETE participant pool were identified as experts due to their ranking of specialist in the specified areas of interest by the American Academy of Kinesiology and Physical Education (AAKPE). These specialized areas of interest included: history of sport/exercise, philosophy of sport, sociology of sport, and pedagogy/teacher education.

Once these experts were identified, they were contacted via telephone in order to gather recommendations regarding the nomination of fellow specialists in the respective fields of PETE and history, philosophy, and sociology of sport. The combined list of aforementioned experts and those they nominated made up the expert list (population pool) from which experts were randomly selected to be participants in the Delphi study. The K-12 physical education teachers sample was selected based upon their status as district or national teachers of the year as recognized by NASPE (2008b). 
The initial list of prospective panel members included 13 history of sport specialists, 8 philosophy of sport specialists, 9 sociology of sport specialists, 58 physical education teacher educators, and 64 physical education teachers. From this participant pool, a group of 25 experts were randomly selected and recruited from three groups of qualified individuals representing the following levels of expertise:

1. History (5), philosophy (5), and sociology (5) of sport specialists ( $n=15)$ who were nominated by either the history, philosophy, or sociology specialists of the AAKPE or by History, Philosophy, and Sociology of Sport Academy board members of NASPE.

2. Physical education teacher educators $(n=5)$ who were nominated by either the pedagogy/teacher education specialists of the AAKPE or by Curriculum and Instruction Academy board members of NASPE.

3. K-12 physical education teachers $(n=5)$ who have held District or National Teacher of the Year status through NASPE.

\section{Research Design}

This study utilized a, Modified Delphi, quantitative-qualitative (QUAN-qual) research design. Numeric data were collected through the use of questionnaire, and follow-up interviews provided qualitative data to support the quantitative findings.

Two rounds of questioning were used to achieve group consensus among the experts. Numerous authors within the Delphi literature have found the use of two round survey sampling to be sufficient in generating final consensus (Anglin, 1991; Dalkey, Rourke, Lewis, \& Snyder, 1972; Weaver, 1971). During each round of the present study, expert panel members were asked 
to rate a series of history, philosophy, and sociology of sport competencies in terms of their theoretical importance and pedagogical relevance for prospective K-12 physical educators.

A verification telephone interview following the second round asked a randomly selected group of Delphi panel members (one from each of the five areas represented) to recommend the best instructional context for delivering history, philosophy, and sociology of sport content to prospective physical educators.

\section{Pilot Study \& Instrumentation}

The survey instrument was derived from a current list of 32 philosophy of sport competencies recommended by the Sport Philosophy Academy of NASPE (2004). Additionally, 9 history, 21 sociology, and 9 philosophy of sport competencies were derived from a list of competencies recommended by AAHPER (1974).

Following approval from the Institutional Review Board for the Protection of Human Subjects, a pilot study was conducted in order to: (a) evaluate the initial survey items for importance and completeness, (b) examine the feasibility of the administrative procedures, and (c) test the usability of the online survey instrument, SurveyMonkey. The pilot study included a panel of seven experts with demonstrated expertise in their respective area (i.e., history, philosophy, and sociology of sport, physical education teacher educators, and K-12 physical education teachers). These seven experts who met the aforementioned criteria for Delphi panel selection included one history of sport specialist, one sociology of sport specialist, one philosophy of sport specialist, two physical education teacher educators, and two K-12 physical education teachers. It should be noted that the pilot study panel members were not utilized in the actual study. 
The pilot study participants were asked to rate the importance of 71 history, philosophy, and sociology of sport competencies using a five-point Likert scale. A rating of four or five indicated the item was a valid theoretical or applied history, philosophy, sociology of sport competency that could potentially be incorporated into the PETE undergraduate curriculum. A rating of three meant the respondent was neutral or undecided. A rating of two or one meant the item should be removed from the final version of the questionnaire because it lacked curricular importance. Participants were also asked to add any competencies that would provide a higher level of content validity, keeping in mind the ultimate goal of producing a comprehensive list of theoretical and applied history, philosophy, and sociology of sport competencies that could potentially be incorporated into the PETE undergraduate curriculum.

The pilot study data were used to construct a list of history, philosophy, and sociology of sport competencies to be included in Round I of the study. Each competency had to meet the following criteria for consensus (Bulger \& Housner, 2007; Jacobs, 1996): (a) the competency needed to receive a mean rating of at least four or higher in the areas of importance and relevance, and (b) the competency needed to receive at least $75 \%$ of all individual ratings at the four level or higher. Any competency that failed to meet these criteria was considered nonessential in nature. Four competencies failed to meet these criteria; however, no competencies were eliminated in order to produce the most inclusive list of history, philosophy, and sociology of sport competencies as possible. Alternatively, if any one expert panel member recommended the addition of a new competency in one of the three categories (history, philosophy, or sociology of sport), it was added to the survey. This resulted in three new competencies being added to the initial list based on the pilot study expert recommendations. These new competencies related to human movement and the development of political, social, economic, 
and cultural patterns of historical societies; responsibility of one’s actions, opinions, and outcomes when engaging in sports; and the way sport interfaces with race, ethnicity, gender, and class.

The items resulting from these criteria were again organized into a questionnaire (Round I) that required the actual Delphi expert panel members to rate each item regarding its theoretical importance within the PETE undergraduate curriculum and pedagogical relevance regarding the instruction of school-based physical education. Each item's theoretical importance and pedagogical relevance were rated using the following five-point Likert scale: (5) Strongly Agree, (4) Agree, (3) No Opinion, (2) Disagree, and (1) Strongly Disagree.

\section{Delphi Study Procedures}

The administrative procedures were adapted from the research protocol outlined by Bulger and Housner (2007) and are divided into the following sections: (a) Selection of Participants, (b) Round I Procedures, and (c) Round II Procedures.

Selection of participants. According to Andrews and Allen (2002), e-mail panel selection over traditional recruitment approaches has two primary advantages: time and cost. Therefore, the means by which this study’s participants were asked to participate was via e-mail. A follow-up telephone conversation, prompted by a phone script (see Appendix E), was used to encourage participation in the study and to answer any questions from the potential expert panel member. Following any decline to participate, another name was randomly selected from the appropriate expert participant pool until the expert panel selection was complete. Three history of sport specialists, one sociology of sport specialist, three physical education teacher educators, and three K-12 physical educators declined invitations to serve on the Delphi panel. 
In the 2007 Bulger and Housner study, the researchers recommended a preset experimental mortality standard to determine the effects of participant attrition on the results of the study. If $20 \%$ or more of the panel members who returned the Round I questionnaire failed to complete the Round II questionnaire the results of the study would be considered compromised. Of this study's 25 Delphi panel sample, 24 panel members completed both rounds of questionnaire circulation; therefore, participant attrition was not considered a negative factor in this study. One telephone call was made and four e-mails were sent (two survey deadline reminders and two survey deadline extensions) in order to attempt to get in touch with the PETE faculty member who failed to complete the second round questionnaire. No reply was received.

Round I procedures. An e-mail regarding the questionnaire was sent to the 25 expert panel members. The e-mail contained: (a) a study overview, (b) an explanation of why they were selected to participate in the study, (c) an explanation of their rights and responsibilities, (d) instructions on accessing the online survey, and (e) a thank you for agreeing to participate in the study (see Appendix C). Once at the survey website, participants were provided the instructions for completing the survey, the actual survey instrument, and they were thanked once again for their participation.

Because participants were required to input their name at the beginning of the online survey, determining whether participants had completed the survey could be tracked at any time through SurveyMonkey. Within two weeks after the aforementioned e-mail was sent to the participants, the Delphi expert panel members who failed to complete the Round I survey each received a telephone call to answer any questions and to request the survey be returned in a timely fashion. Following the completion of all online Round I questionnaires, participant 
responses were recorded in a Microsoft Office Excel database where mean group ratings were calculated for each survey item.

Round II procedures. Round II followed the same administrative procedures as Round I. The primary difference between the Round I questionnaire and Round II was the inclusion of individual and mean group rating scores as to the importance of each survey item determined from Round I. These scores were indicated in columns next to each survey item (see Appendix D). Each expert panel member was asked to reevaluate and again rate their Round I responses for each survey item based on the participant's individual ratings and mean group ratings. The return time table and follow-up procedures followed the same protocol as Round I. Following the successful completion and data analysis tabulation of all Round II online questionnaires, a final research report was sent to each Delphi panel member.

Verification interview procedures. Following the completion of Round II survey document analysis, follow up interviews were conducted on a random sample of five panel members from within each represented group of the 25 Delphi panel member participant pool:

1. History (1), philosophy (1), sociology (1) of sport specialists (n=3)

2. Physical education teacher educators $(n=1)$

3. K-12 physical education teachers $(n=1)$

The verification interviews were conducted via telephone and focused on extending the results from the Delphi study in order to determine how the newly revised history, philosophy, and sociology of sport competencies would best be incorporated into an undergraduate PETE curriculum. Verification interview panel members were asked seven questions (see Appendix E for verification interview protocol) in order to establish confirmability and dependability of the data. Interview protocol consisted of open-ended questions related to the following: Should 
history, philosophy, and sociology of sport be taught together or separately?; Should history, philosophy, and sociology of sport be taught as stand alone courses (if so, where in sequence)? or, Should these competencies be stranded throughout the curriculum (and if so, how should they be integrated into curriculum)?

\section{Data Analysis}

Data analysis was performed following a sequential explanatory approach to evaluating the qualitative and quantitative data. First, all quantitative data were gathered via the online survey instrument, SurveyMonkey. The following outline for conducting a Delphi study was utilized in this study: repetition with controlled feedback, anonymity, and statistical representations of group response (Martino, 1993). The data collected in Round II were used to arrive at group consensus in regard to the importance of each history, philosophy, and sociology of sport competency. These data were also analyzed to compare the history, philosophy, and sociology of sport disciplinary specialists with the physical education teacher educators and K-12 physical education teachers in order to determine differences of opinion with regard to the competencies.

Second, telephone interviews were conducted in order to identify the expert panel members' views on which instructional context they believed were the best method for delivery of the history, philosophy, and sociology of sport competencies and why they believed their preferred instructional context would be the best approach to instruction of these competencies. As recommended by Fleming and Monda-Amaya (2001), content analysis can be used to triangulate Delphi panel members' responses to open-ended questions. Because data analyzed in a quantitative manner cannot explain participants’ curricular beliefs, a sequential explanatory approach was used in order to expand on the quantitative findings. Interview data were 
transcribed and initially coded according to each interviewee's group member designation. Later, open coding was used in repeated rounds of transcript document analysis in order to determine whether there were themes related to Delphi members' curricular beliefs.

\section{Results}

Upon completion of the pilot study, three additional competencies were added to the original 71 competencies for a total of 74 history, philosophy, and sociology of sport competencies. Following the second and final round, 27 history, philosophy, and sociology of sport competencies met the previously described criteria (history of sport, $n=1$; philosophy of sport, $\mathrm{n}=17$; and sociology of sport, $\mathrm{n}=9$ ). Only the second round analysis is presented because it is the final round, and it is reflective of group consensus. The results are presented in the following categories: (a) History of Sport, (b) Philosophy of Sport, (c) Sociology of Sport, (d) Verification Interviews, and (e) Group Comparisons. The final list of competencies in all areas is reported in Table 1.

\section{History of Sport}

As indicated in Table 1, the Delphi panel members reached a consensus of agreement regarding one of the ten history of sport competencies that were included in the questionnaire. The only history of sport competency considered to be of essential importance and relevance related to how physical education has developed as a profession and is intimately related to the development of play, games, dance, and sport. This competency's group mean for theoretical importance was 4.08 , and 4.17 for pedagogical relevance. The percentage of panel members who rated those competencies as being of essential importance and relevance was 92\%. 


\section{Philosophy of Sport}

The Delphi panel members reached a consensus of agreement regarding 17 of the 41 philosophy of sport competencies that were included in the questionnaire. These essential items are reported in Table 1. These competencies’ group means ranged from 4.04 to 4.79 for theoretical importance and from 4.00 to 4.75 for pedagogical relevance. The percentage of panel members who rated those competencies as being of essential importance and relevance ranged from $79-100 \%$.

The essential competencies reflected the following competency categories: (a) understanding how sport philosophy contributes to the practice of sport and physical education; (b) identifying the importance of sport and physical education to the educational process; (c) identifying games and play and its significance to society; (d) the role of society in sport; (e) identifying the difference between intrinsic and extrinsic values; (f) ethical aspects of sports; (g) general skills as a result of knowledge; and (h) formulate a personal philosophy of human movement. The remaining competency categories not considered essential addressed (a) nature of philosophy and sport philosophy; (b) branches of philosophy and asking philosophical questions; (c) philosophers of science, education, and physical education (past and present); (d) physical education professional discipline and the academic discipline; (e) mind versus body argument; (f) philosophical difference between games and play; (g) social values in relationship to their philosophical thinking; (h) ethical aspects of sports; (i) ability to read and comprehend philosophical writings; (j) philosophic systems of thought and their relationship to human movement; (k) express individuality and uniqueness; (l) opportunities for individuals to inquire and discover their own nature; (m) human movement reflects the nature of the universe; (n) relationships between man and the universe; and (o) behaviors reflect philosophical attitudes. 
Five of the remaining items satisfied the required criteria for theoretical importance, but were not considered to be highly relevant for those preparing to teach physical education in a K12 setting.

\section{Sociology of Sport}

As indicated in Table 1, the Delphi panel members reached a consensus of agreement regarding nine of the 23 sociology of sport competencies that were included in the questionnaire. These competencies' group means ranged from 4.00 to 4.33 for theoretical importance, and from 4.00 to 4.29 for pedagogical relevance. The percentage of panel members who rated those competencies as being of essential importance and relevance ranged from 75-92\%.

The competencies considered essential related to: (a) cultural influence; (b) influence of sub-cultures (ethnic, racial, socioeconomic, etc.); (c) sport and its utilization to facilitate change; (d) individual actions, opinions, and outcomes when engaging in sports; (e) current practices and trends; (f) socialization; (g) changing social practices; and (h) the way sport interfaces with race, ethnicity, gender, and class.

\section{Verification Interviews}

Following completion of the second round survey, five Delphi panelists (one from each of the represented subject areas) were randomly selected and asked to recommend the best instructional context for delivering history, philosophy, and sociology of sport content to prospective K-12 physical education teachers within the PETE curriculum. Due to the nature of the interview, the panelists were free to express and expand on any topics that could influence the delivery of the subject matter. As a result, the following categories were revealed: (a) Course Content, (b) Instructor Preference, (c) Additional Competencies, and (d) Name Change. In the following section, descriptions of recommendations made by the panelists are provided. 
Course content. Of the five panel members selected for verification interviews, one panelist conveyed the course content represented within history, philosophy, and sociology of sport should be taught together within one course. Two panelists believed history and philosophy of sport content should be taught together with sociology of sport being a separate course. Additionally, two of the above mentioned panelists believed the content should be taught as stand alone courses and have the information reiterated in methods courses throughout the curriculum. One panelist believed it would be "garbage if stranded" throughout the curriculum. See Table 3 for course content interview responses.

Instructor preference. A lack of passion by PETE instructors was mentioned by three of the five panelists (philosophy, history, and PETE) in reference to who should teach these three courses. This lack of passion for these content areas by PETE translates into the need for specialists in history, philosophy, and sociology of sport to teach these content areas. The history of sport specialist stated the following with reference to how to fit history, philosophy, and sociology of sport back into the curriculum:

This is a school by school thing as to what to include in the curriculum and if there is room. Usually specialists are needed to teach these areas; however, PETE tends to have people trained in pedagogy teach these courses that have no passion or interest in these areas. Therefore, it is difficult to prove these areas need to remain in the curriculum.

Curricular space. It was noted that history, philosophy, and sociology of sport specialists are fighting for their space within the curriculum even if institutions have taught this content for several years if not decades. The philosophy of sport interviewee stated these content area specialists have done a poor job in promoting their own value to PETE and therefore are 
suffering the consequences of getting squeezed out of the curriculum to make room for yet more skill-related courses. While the content area specialists are fighting for their right to remain in the PETE curriculum, physical educators at both the university and K-12 arenas believe the curricular need is for more skill-related and health-related content in order to further contribute to the development of health-related skills students will be able to use for the rest of their lives.

When asked why they believe history, philosophy, and sociology of sport were not currently in the PETE curriculum at most institutions, the panelists stated unanimously it was due to lack of curricular space. The PETE panelist added to this by stating "We have to meet NCATE standards and there is barely room for all of that information and then you add a semester taken away by student teaching, where do we put it?”

Additional competency. The sociology of sport specialist was the only panelist to recommend an additional competency. The following competency was recommended, along with three sub-areas, but not added to the final list:

Identify the role and understand the cultural and ethnic influence games, sport, and play have in determining the meaning of the experience of physical activity.

(a) identify and interpret meaning and experiences of physical activity for various race and ethnic groups;

(b) relate experiences of games, sport, and play for race and ethnic groups to society; and

(c) identify significant persons and events which contribute to present day understanding of games, sport, and play to race and ethnic groups.

The removal of competencies from the final list was not recommended by any panel members during the interviews. 
Name change. All panel members believed the term "sport" should be changed to "physical activity”, "physical education”, or "human movement”; for example, the new terminology should be history, philosophy, and sociology of physical activity. The term sport should be used to complement rather than define these content areas. The PETE panelist declared:

I believe sport is a limiting name. Physical education deals with meeting needs of individuals across a lifespan and sport and skills do not relate to life skills. So physical activity would better address the life skill needs to include wellness, nutrition, and make things more relevant for students.

\section{Group Comparisons}

This study included specialists from history, philosophy, and sociology as well as physical education practitioners and individuals who prepare those practitioners. An interesting aspect of the study is that we were able to examine to what degree these experts agree with each other and if there were any of these groups that varied significantly from the consensus. Even though the history, philosophy, and sociology specialists differed from the rest of the groups, the competencies rejected by PETE and K-12 physical educators still made it to the final list based on the criteria for acceptance. The criteria for acceptance states each item had to receive a mean rating of at least four or higher in the areas of importance and relevance and the item had to receive at least $75 \%$ of all individual ratings at the four level or higher.

History of sport. The following competencies were considered both important and relevant by PETE faculty, but not by the other panelists: (a) Be familiar with the historical debate between the academic and professional disciplines of physical education (i.e., Is the purpose of the discipline of physical education to generate new "scientific" knowledge to advance the 
academic discipline or to generate "applied knowledge" to serve the public's need for school physical education and/or sport opportunities?); (b) Understand why physical education has been renamed with new identifiers such as exercise science, human movement, sport science, and kinesiology; and (c) Develop a familiarity with various types of dualistic and holistic arguments, such as whether the body can be trained and/or educated without impacting the mind and viceversa.

Philosophy of sport. Although rated essential by history, philosophy, and sociology of sport specialists and K-12 physical education teachers, the following philosophy of sport competencies were rated as non-essential by PETE faculty: (a) understand how sport philosophy contributes to the practice of sport and physical education; (b) be familiar with history of sport and physical education as it relates to the changing values and philosophies in sport and physical education; (c) ethical issues in sport and physical education (e.g., intimidation, illicit performance enhancing drugs, commercialization in college athletics, burnout and dropout, sportsmanship, and gender equity); (d) ability to cogently argue (verbal and written) for or against a variety of issues in sport and physical education; (e) ability to offer new viewpoints on competitive and/or educational practices in sport and physical education in order to ultimately improve practices in sport and physical education; and (f) ability to formulate a personal philosophy of human movement.

Sociology of sport. Four sociology of sport competencies, although rated essential by history, philosophy, and sociology of sport specialists and K-12 physical education teachers, were rated as non-essential by PETE faculty: (a) describe cultural influence upon developmental patterns of play, games, dance, and sport; (b) explain how play, games, dance, and sport may be utilized to facilitate change; (c) identify the nature and interpret the role and importance of 
socialization and (d) describe and interpret the sociological trinity (the way sport interfaces with race, ethnicity, gender, and class).

Although rated as non-essential by history, philosophy, and sociology of sport specialists and K-12 physical education teachers, the following sociology of sport competencies were the only competencies rated as essential by PETE faculty: (a) identify and evaluate the problems which arise in cooperation and competition in group movement experiences; and (b) demonstrate and evaluate various roles in group movement activities (e.g., facilitator, blocker, information source, recorder).

Verification interviews. It is clear from the verification interviews that the panelists were split between the history, philosophy, and sociology of sport specialists and the physical educators in their opinions. The physical educators, both PETE faculty and K-12 teachers, believed the information was not relevant enough to evoke a curricular change throughout the various PETE programs. The history, philosophy, and sociology of sport specialists, on the other hand, strongly believed the information from these content areas could only serve to enhance the PETE curriculum and thus its undergraduate students. However, the specialists in these three areas are representative of few PETE university departments who have stand alone history, philosophy, or sociology courses with the United States. With the addition of PETE educators wanting to add more movement related content, it appears even though the final list of competencies found through this study were deemed as being both pedagogically relevant and important, history, philosophy, and sociology of sport may be on its way out the PETE curricular door. 


\section{Implications}

This research study was designed to initiate meaningful discussion among various experts within five fields of study. The information gathered does not provide an all-inclusive list of history, philosophy, and sociology of sport competencies and associated instructional context that need to be adopted by all PETE programs. The curricular content within PETE programs is best left to each individual department as these faculty members know based on their own curricular model what content knowledge best fits their program. However, the information offered in this article can be used to inform curricular decisions in relation to course content and instructional context in the areas of history, philosophy, and sociology of sport. The following section will provide a description of these areas: (a) PETE Curriculum, (b) Instructional Context, (c) Course Content (d) Physical Activity and Sociocultural Content, (e) Curricular Space, and (f) Future Directions.

\section{PETE Curriculum}

In 1970, college physical education curricula would have looked similar across institutions; today there are a variety of curriculum models that make colleges look more distinguishable. Some of these curriculum models include sport education, fitness education, movement education, social-development physical education, adventure education, and the traditional multi-activity program (Siedentop, 2009). Siedentop explains that each curriculum model has a different view of the physical education subject matter.

Throughout this article the term "sport" has been used in conjunction with history, philosophy, and sociology based on the AAHPERD and NASPE terminology. The verification interviews suggest the term "sport” should be changed to "physical activity" in order to be more inclusive of various other activities and movement forms that are not categorized as "sport”. 
After all, is physical education not more than just sport? Is it not also inclusive of movement, fitness education, social development, and development through adventure and risk? No single definition of physical education has gained widespread acceptance in contemporary professional circles (Siedentop, 2009). If PETE cannot define who it is, what hope does it have of staking claim on exactly what should be taught within the undergraduate PETE curriculum? More discussion through studies such as this could help lead PETE curricula down a path to a national curriculum instead of the various PETE curricula which currently exist in institutions.

Physical education itself has undergone numerous name changes and has appeared to have found its new home with kinesiology. In Hoffman’s (2005) book, Introduction to Kinesiology, the sub-disciplines which make up kinesiology that are dominant at the present are biomechanics, physiology of physical activity, sport and exercise psychology, motor behavior, history of physical activity, philosophy of physical activity, and sociology of physical activity. Hoffman claims that in many kinesiology departments each sub-discipline is represented by a separate course or in some cases two or more sub-disciplines are combined into one course. For example, most universities who do not have specialists in the areas of history, philosophy, or sociology of sport will combine these into an introduction to physical education course. Often this course is the only interaction with these three sub-disciplines most PETE undergraduates receive unless connections are made during the student's final semester during a student teaching seminar. Keep in mind teaching each of these three sub-disciplines as separate courses can lead to fragmentation in student thinking (Lawson, 1991), and therefore can cause students to forget how history, philosophy, and sociology of sport fits into the discipline as a whole if they are not, for example, reiterated in future methods courses. Students who are best able to make 
connections between knowledge and practice will be in the best position to make significant contributions to the field (Bulger \& Housner, 2007).

Bulger, Mohr, Carson, Robert, and Wiegand (2000) believe there is a need to infuse subdisciplinary curricular strands in the PETE curriculum. Based on the literature reviewed and the aforementioned study, a stranded approach is recommended to infusing history, philosophy, and sociology of sport knowledge into the PETE curriculum in order to allow prospective physical educators to make more meaningful connections between the content and its actual application in a school-based setting. In order for more cross-disciplinary relationships to be made, the need for research to support alternative pedagogical approaches within PETE is needed.

PETE students need to be educated on understanding the learning, performance, psychological, physiological, and pedagogical foundations of physical activity (Zelaznik \& Harper, 2007). At the center of our discipline is physical activity and skill, yet the PETE curriculum lacks in sociocultural theoretical knowledge which is needed to truly educate undergraduate PETE students about the learner as a whole. PETE should be producing teachers who want to make their students knowledgeable and skillful movers. It appears that Franklin Henry’s vision to establish physical education as an academic discipline may have led to some fragmentation of the discipline and while this is problematic, at the same time these subdisciplines need to be re-infused into the PETE curriculum.

\section{Instructional Context}

The NCATE/NASPE beginning teacher standards represent what teacher candidates should know and be able to do to facilitate student learning. The NCATE/NASPE beginning teacher standard one (scientific and theoretical knowledge) states "Physical education teacher candidates know and apply discipline-specific scientific and theoretical concepts critical to the 
development of physically educated individuals” (NASPE, 2008b). Thus PETE institutions need to ensure their graduates master disciplinary knowledge for the purpose of teaching effectively to a diverse group of learners. The beginning teacher standards serve as a framework in which decisions about curricular content should be made. Therefore, PETE institutions are faced with the issue of deciding what content is most important and relevant in preparing teachers to facilitate K-12 learning. The expanding knowledge base of the sub-disciplines has made achieving Franklin Henry’s vision, of physical education as an academic discipline, a challenging feat.

This study is a part of an existing line of research looking at all sub-disciplinary areas. Once these sub-disciplinary studies are completed, each of the five elements within standard one will be examined thus providing PETE programs with a guide for knowing exactly what students should know and be able to do for each of the following sub-disciplines: exercise physiology; history, philosophy, and sociology of sport; biomechanics; motor development; motor learning; and sport and exercise psychology.

\section{Course Content}

The kinesiology sub-disciplines of history, philosophy, and sociology of sport have not grown because there are few programs that emphasize this liberal arts approach, and consequently, the trend has moved toward programs that are vocationally-oriented. The view has been that history, philosophy, and sociology of sport are not immediately relevant to students' preparation, and therefore, are squeezed out of the PETE curriculum. However, these areas not only stimulate interest but also promote students' abilities to think critically about the work they do and thus extend their appreciation for the importance and complexity of their work (Siedentop, 2009). 
Most students enroll in PETE because they were good at sports in school and want to learn more about sport and exercise. What they receive however, is a collection of different, more-or-less independent courses, from which to know about physical activity. Although this information is valuable, undergraduates struggle to see the big picture. PETE students should learn to value other disciplines and have a sense of how various areas of study complement one another (Ward \& Kretchmar, 2008). The study results indicate several history, philosophy, and sociology of sport competencies that can complement and become an interactive aspect of the PETE curriculum as a whole. This notion is also exclaimed by Corbin and McKenzie (2008) who stated, "We believe that the disciplinary classes for physical education teacher education need to be reviewed and subsequently brought into line with the specific needs of future teachers” (p. 48).

A relevant question to ask is how might history, philosophy, and sociology of sport information be incorporated into the PETE curriculum? An example using sociology might be, a preservice physical educator does not have to know all of the sociocultural sub-disciplines in depth, but the more information a preservice physical educator has, the more insightful they will be about the social side of physical activity. For example, if something is known about socialization it will be easier to understand how young boys become socialized into participating in sports or how certain people become members of subcultures centered in activities such as surfing, triathlons, mountain climbing, or skateboarding. However, if a lot of information is known about socialization, a physical education teacher will likely notice many more details when they study socialization into physical activity. This additional knowledge might lead a teacher to ask questions about the extent and ways to which children contribute to socializing their parents into participating in physical activity, rather than being content to think that 
socialization only flows from parent to child (Harris \& Duncan, 2005). By examining physical activity from another standpoint, new insights are brought to the understanding of the experience of being physically active.

Physical activity involves the mind as well as the body. Key issues such as understanding what motivates children and adolescents intrinsically and extrinsically to participate or not participate in physical activity show an understanding of philosophy of sport. If obesity is the prime topic amongst physical education today, more of a focus needs to be on philosophy in order to truly understand the meaning behind why some students do not choose to participate in physical activity.

Hoffman (2005) suggests separate sub-disciplinary courses can make it difficult for students to develop an integrated knowledge base for use in their professional practice. Although the knowledge of history, philosophy, and sociology of sport has been deemed by many specialists as being of vital importance to the physical educator (Eitzen \& Sage, 2008; Harris \& Kretchmar, 2005; Mechikoff \& Estes, 2005), many departments choose to combine these three courses into one introduction to the profession course. Few institutions remain which place such importance on these three sub-disciplines that individual courses are incorporated into the kinesiology curriculum. Hoffman reminds physical educators that dividing up the discipline into separate courses can lead to fragmentation in the student's thinking about physical activity and cause the student to forget that kinesiology is one unified body of knowledge with each part helping students to better understand the discipline as a whole. This will allow students to make correlations as a whole when in their professional practice, since the professional world does not have problems to solve in tidy little boxes the way many curricula are developed but rather the novice physical educator must be able to integrate their knowledge as a whole in order to relate 
separately taught courses to specific problems. Students who are able to make connections between facts, concepts, and the many sub-disciplines will be best prepared for their professional careers.

\section{Physical Activity and Sociocultural Content}

A physical educator not only utilizes the knowledge within PETE, but also significantly contributes to the knowledge of human movement. The physical educator must have an understanding of the meaning of the growth and development of the individual; the significance of movement; and the practical application of physical, biological, and behavioral sciences to assist individuals in reaching awareness of themselves and others (AAHPER, 1974). PETE programs provide prospective teachers with the subject matter knowledge, pedagogical knowledge, and pedagogical content knowledge (Shulman, 1987) needed to effectively develop the psychomotor, cognitive, and affective characteristics that will enable a child to enjoy a healthy, physically active lifestyle into adulthood (Bulger \& Housner, 2007). The nation’s growing concern for the obesity crisis and the role physical activity plays in the maintenance of good health (U.S. Department of Health and Human Services, 2000) should be used to help determine the course content and instructional methodologies employed within the PETE curriculum. This would in turn better prepare physical educators to instruct and apply the concepts which can enhance a child's appreciation for regular physical activity.

According to the literature reviewed, a number of critical theoretical and applied history, philosophy, and sociology of sport concepts actively contribute to a physical educator's instructional effectiveness regarding a student's enjoyment and sustained interest in physical activity. Although, some evidence suggests PETE programs may inadequately prepare prospective physical educators to instruct and apply important concepts in the promotion of 
physically active lifestyles (Bulger \& Housner, 2007). If the physical education profession is to play a more meaningful role in the obesity crisis running rapid within today's youth and the parallel medical conditions that typically develop later in adulthood, PETE professionals need to focus more on preparing prospective physical educators to actively engage in multi-disciplinary approaches to physical activity promotion.

According to Siedentop (2009), sport historians study factors that have affected the development of sport and physical activity across the world. Sport history is much more than studying sporting events of the past. It not only chronicles the past but also interprets the past, relates the past to the present, and provides guidelines to what might be expected or what courses might be taken in the future. Harris (1989) states sport history identifies and describes patterns of change and stability in sport, in particular societies or cultures during specific time periods.

One may wonder, what does philosophy have to do with K-12 teaching and what is the purpose of requiring undergraduate students to take a philosophy of sport course? The K-12 school setting is the best opportunity to teach quality physical activity habits to children. Through teaching philosophy, physical education teacher educators can achieve this goal by helping preservice teachers understand the need, worth, value, and magnitude for physical education in their lives (Cavallini, 2006).

Within the realm of philosophy issues to be considered include sport ethics, values of physical activity, and mind-body relationships (Harris \& Kretchmar, 2005). Philosophical thinking requires a student to develop coherent, general views of involvement in physical activity, to be inquisitive about events which take place at school, to ask about standard procedures, and value commitments most individuals take for granted (Siedentop, 2009). Philosophers complement the facts of history and sociology, when combined together these provide an 
important sociocultural component to PETE. Philosophy of sport involves continual reflection that leads to general views about people and sports (Harris \& Kretchmar, 2005). Topics in a typical philosophy course taught within a kinesiology curriculum include: general overviews of philosophy of physical activity, as well as specialized topics such as ethics in sports, aesthetics of sport, values of physical activity, politics and sport, the mind-body relationship, and the nature of play, games, dance, exercise, and sport. (Hoffman, 2005).

Cavallini (2006) claims a mandatory course within the PETE curriculum should focus on a philosophical perspective of the importance of physical education in an individual's life. Understanding the contribution of philosophy in physical education can mean the difference between a "roll out the ball” mentality and one that will forever change student's physical activity patterns and life. If preservice teachers instill strong physical activity values, beliefs, attitudes, ideas, and viewpoints, they will help their students live a healthier life.

With the increasing popularity of PETE departments changing names to kinesiology or sport studies, sociology of sport finds itself situated within the context of a much broader framework (Sage, 1984). A more varied approach, sport studies, focuses on concepts, theories, and methods from all of the social sciences, and humanities (Harris, 1989). Although sport sociology has in the past primarily focused on sport, there has been a growing interest in the area of exercise, more specifically, how society views and influences perceptions of the body and how it should look (Hoffman, 2005). Through this, sociology of sport now puts itself in the position to assist in the nation's obesity crisis.

\section{Curricular Space}

Based on the results of this study, through the eyes of the history, philosophy, and sociology of sport specialists, it appears as though more of a focus should be brought to these 
three sub-disciplines throughout the PETE curriculum and in more of a condensed way than even the NASPE Sport History, Philosophy, and Sociology Academy thought. This notion is seconded by Zelaznik and Harper (2007) who propose the time is right to "put the sociologicalanthropological and philosophical aspects of movement back into our undergraduate and graduate curricula in order to educate our students on the primacy of movement as an intrinsic activity” (p.164). However, this notion was not mimicked by the physical educators and K-12 physical education teachers who stated they did not see room in the curriculum for this material and time was already an issue when trying to get in the necessary information NCATE mandates. Wiegand, Bulger, and Mohr (2004) suggest the PETE curriculum is an area in need of continual assessment, revision, and refinement. However, the content that should be included and excluded from a curriculum is difficult to determine due to the limited amount of curricular space available in most PETE programs.

What successful teachers need to know and be able to do is not clearly defined. For years, PETE faculty have tried to specifically state this within their own curricular models, thus making decisions regarding the content that should be included or excluded from the PETE curriculum a constant concern. Limitations on curricular space add to this concern due to the continually expanding body of sub-disciplinary knowledge. Arguments can be made regarding the inclusion of large amounts of information versus specific focus on a select few topics. Bulger and Housner (2007) claim students should master designated outcomes or competencies that match the best professional practice within the field, rather than learning a large amount of facts about a broader range of topics.

If history, philosophy, and sociology of sport are not being taught throughout the PETE curriculum due to curricular space, then PETE students are being robbed of important knowledge 
which will prove itself valuable countless times throughout a K-12 physical educator's career. This study can aid PETE programs in looking at the curricular space issue based on the list of competencies that were examined and then reduced to a workable number. PETE programs can therefore, streamline their curriculum by including only the essential information students need to know and be able to do, and thus limit what goes in the curriculum. The PETE curriculum should include only the history, philosophy, and sociology of sport information displayed in the essential competencies list based on the results of this study (see Table 1).

\section{Future Directions}

A notable finding was revealed in the comparison between PETE faculty and K-12 physical education teachers with regard to what history, philosophy, and sociology of sport knowledge is deemed as important and relevant for K-12 physical education gymnasiums. These results mimic McCullick and Chen's (2008) claim that a discrepancy exists in content at the K12 and college levels which has created curriculum misalignment and may have numerous consequences for physical education. To this end the knowledge a PETE faculty member extends to undergraduate physical education majors must be thought about carefully because they promote future PETE effectiveness within their own students. Therefore, future research regarding the PETE curriculum should include knowledge from the K-12 physical education perspective as well as from PETE faculty.

The primary aim of this Delphi investigation was to examine what experts across PETE, sub-discipline area specialists, and public school physical education teachers deemed as both important and relevant history, philosophy, and sociology of sport sub-disciplinary knowledge to the physical education profession. Many programs have recognized that pre-service teachers are not getting what they need in their various curricula related to the sub-disciplines to adequately 
prepare them for their professional roles. As a result, it was important to gain insight across all levels for the purpose of improving the PETE program.

The results of this Delphi investigation revealed 74 original competencies were too broad in nature; therefore, the final list was reduced to 27 competencies. See Table 1 for the final list of history, philosophy, and sociology of sport competencies. Like the Bulger and Housner (2007) study in which $49 \%$ of the 222 original competencies were considered critical in nature, this study revealed $36 \%$ of the original 74 competencies were essential to the PETE curriculum. These studies reveal specific curricular content that is both relevant and important to the PETE curriculum. A final list of recommended history, philosophy, and sociology of sport competencies has been summarized in Table 4. These competencies should prove valuable to PETE curriculum planners and can be used for a variety of purposes: (a) selecting course content; (b) evaluating curricular effectiveness in the areas of history, philosophy, and sociology of sport; (c) aligning courses across the curriculum; (d) focusing student learning around the most essential knowledge, skills, and abilities; and (e) determining the appropriateness of various experiential learning opportunities for students (Bulger \& Housner, 2007). Those items relating to intrinsic and extrinsic motivation, behavior change, personal responsibility, social practices, and sub-cultures, for example, are relevant for prospective physical educators who will be expected to contribute in a meaningful way to help combat obesity in children and physical inactivity.

The findings from this study confirm that experts across the field viewed a more narrow focus on salient concepts and principles and were both important and relevant to better prepare physical education teachers. Likewise, the results can help PETE institutions determine what knowledge, skills, and abilities are most critical for inclusion into the undergraduate PETE 
curriculum. Additionally, the need for this type of interdisciplinary communication becomes more evident as PETE programs seek more innovative curricular models for preparing future physical educators.

The information gleaned from this study can offer PETE programs several options with which to incorporate history, philosophy, and sociology of physical activity (formerly "sport”) content. For example, some PETE programs may determine it is not feasible to include sociocultural content within their undergraduate curriculum do to curricular space issues. Because graduate students who have come from a K-12 background should have a better understanding of sociocultural content due to socialization, perhaps an alternative approach is necessary, that is to incorporate sociocultural content within a PETE graduate program. Future research could be conducted in order to determine if PETE graduate programs are a better fit for such content. It is hoped that the results of this research study will provide a framework upon which PETE faculty members can make future history, philosophy, and sociology of physical activity curricular decisions. 


\section{References}

American Association for Health, Physical Education, and Recreation. (1974). Professional preparation in dance, physical education, recreation education, safety education, and school health education. Washington, DC: AAHPER Publications-Sales.

Andrews, C., \& Allen, J. (2002). Utilization of technology-enhanced Delphi techniques. Workforce Education Forum, 29, 1-15.

Anglin, G. L. (1991). Instructional technology past, present, and future. Englewood, CO: Libraries Unlimited Inc.

Beretta, R. (1996). A critical view of the Delphi technique. Nurse Researcher, 3(4), 79-89.

Bulger, S. M., \& Housner, L. D. (2007). Modified Delphi investigation of exercise science in physical education teacher education. Journal of Teaching in Physical Education, 26, 5780.

Bulger, S. M., Mohr, D. J., Carson, L. M., Robert, D. L., \& Wiegand, R. L. (2000). Preparing prospective physical educators in exercise physiology. Quest, 52, 166-185.

Cavallini, M. F. (2006). Who needs philosophy in physical education? Journal of Physical Education, Recreation, and Dance, 77(8), 28-30.

Clayton, M. J. (1997). Delphi: A technique to harness expert opinion for critical decision-making tasks in education. Educational Psychology, 17, 373-387.

Corbin, C. B., \& McKenzie, T. L. (2008). Physical activity promotion: A responsibility for both K-12 physical education and kinesiology. Journal of Physical Education, Recreation and Dance, 79(6), 47-50.

Cyphert, F. R., \& Gant, W. L. (1971). The Delphi technique: A case study. Phi Delta Kappan, 52, 272-274. 
Dalkey, N. C., \& Helmer, O. (1963). An experimental application of the Delphi method to the use of experts. Management Science, 9, 458-467.

Dalkey, N. C., Rourke, D. L., Lewis, R., \& Snyder, D. (1972). Studies in the quality of life: Delphi and decision making. Lexington, MA: Lexington Books.

Douglas, J. W., \& Wiegand, R. L. (1987). NCATE evaluation: Preparing physical education teacher educators. Journal of Physical Education, Recreation, and Dance, 58, 67-71.

Eitzen, D. S., \& Sage, G. H. (2008). Sociology of North American sport (8 ${ }^{\text {th }}$ ed.). Boulder, CO: Paradigm Publishers.

Fleming, J. L., \& Monda-Amaya, L. E. (2001). Process variables critical for team effectiveness: A Delphi study of wraparound team members. Remedial and Special Education, 22, 158171.

Green, B., Jones, M., Hughes, D., \& Williams, A. (1999). Applying the Delphi technique in a study of GPs information requirement. Health and Social Care in the Community, 7, 198205.

Harris, J. C. (1989). Suited up and stripped down: Perspectives for sociocultural sport studies. Sociology of Sport Journal, 6, 335-347.

Harris, J. C., \& Duncan M. C. (2005). Sociology of physical activity. In S. J. Hoffman (Ed.), Introduction to kinesiology: Studying physical activity (pp. 205-235). Champaign, IL: Human Kinetics.

Harris, J. C., \& Kretchmar, R. S. (2005). Philosophy of physical activity. In S. J. Hoffman (Ed.), Introduction to kinesiology: Studying physical activity (pp. 147-175). Champaign, IL: Human Kinetics.

Henry, F. M. (1964). Physical education-An academic discipline. Journal of Health, Physical 
Education, and Recreation, 35(32), 69-70.

Hoffman, S. J. (2005). Introduction to kinesiology: Studying physical activity $\left(2^{\text {nd }}\right.$ ed.). Champaign, IL: Human Kinetics.

Jacobs, J. M. (1996). Essential assessment criteria for physical education teacher education programs: A Delphi study (Doctoral dissertation, West Virginia University, 1996). Dissertation Abstracts International, 57, 2938.

Kretchmar, S. R. (1990). Commentary: Riding the juggernaut. Quest, 42, 330-334.

Lang, T. (1998). An overview of four futures methodologies. Retrieved November 5, 2008, from http://www.soc.hawaii.edu/future/j7/LANG.html.

Lawson, H. A. (1991). Specialization and fragmentation among faculty as endemic features of academic life. Quest, 43, 280-295.

Ludwig, B. (1997). Predicting the future: Have you considered using the Delphi methodology? Journal of Extension, 35(5), 1-4. Retrieved November 10, 2008 from http://www.joe.org/ joe/1997october/tt2.html.

Marett, J., Siler, W., Pavlacka, J., \& Shapiro, R. (1984). Current status of kinesiology and biomechanics in sports. In R. Shapiro and J. Marett (eds.). Second National Symposium on Teaching Kinesiology and Biomechanics in Sports. DeKalb, Northern Illinois University Press. (Proceedings).

Martino, J. (1993). Technological forecasting for decision making. New York, NY: Elsevier Science Publishing Company.

McCullick, B., \& Chen, A. (2008). Curriculum alignment of K-12 physical education and kinesiology-Part 1: Introduction. Journal of Physical Education, Recreation, and Dance, 79(6), $46 \& 56$. 
Mechikoff, R. A. \& Estes, S. G. (2005). A history and philosophy of sport and physical education: From ancient civilizations to the modern world ( $5^{\text {th }}$ ed). New York, NY: McGraw-Hill.

Mohnsen, B. S. (2003). Concepts and Principles of Physical Education: What Every Student Needs to Know. Reston, VA: NASPE Publications.

National Association for Sport and Physical Education. (2004). Minimum competencies for teaching undergraduate sport philosophy courses. Reston, VA: NASPE Publications.

National Association for Sport and Physical Education. (2008a). Initial physical education program report manual (7th ed.). Reston, VA: NASPE Publications.

National Association for Sport and Physical Education. (2008b). NASPE teacher of the year program. Retrieved October 12, 2008, from http://www.aahperd.org/naspe/ template.cfm?template=naspeawards/toy_t.cfm.

Sage, G. H. (1984). The quest for identity in college physical education. Quest, 36, 115-121.

Shulman, L. (1987). Knowledge and teaching: Foundations of the new reform. Harvard Educational Review, 57, 1-22.

Siedentop, D. (1994). Sport education: Quality PE through positive sport experiences. Champaign, IL: Human Kinetics.

Siedentop, D. (2009). Introduction to physical education, fitness and sport $\left(7^{\text {th }}\right.$ ed.). New York, NY: McGraw-Hill.

United States Department of Health and Human Services. (2000). Promoting better health for young people through physical activity and sports. Atlanta, GA: United States Department of Health and Human Services and Department of Education.

Ward, K. P., \& Kretchmar, R. S. (2008). An integrated approach to an undergraduate kinesiology 
curriculum: A case study about stalling in wrestling. Journal of Physical Education, Recreation, and Dance, 79(9), 40-43.

Weaver, W. T. (1971). The Delphi forecasting method. Phi Delta Kappan, 52, 267-271.

Wiegand, R. L., Bulger, S. M., \& Mohr, D. J. (2004). Curricular issues in physical education teacher education. Journal of Physical Education, Recreation, \& Dance, 75(8), 47-55.

Zelaznik, H. N., \& Harper, W. A. (2007). Skill and physical activity: A central dogma for kinesiology. Quest, 59, 163-169.

Ziglio, E. (1996). The Delphi method and its contribution to decision-making. In M. Adler \& E. Ziglio (Eds.), Gazing into the oracle: The Delphi method and its application to social policy and public health (pp. 3-33). Bristol, PA: Jessica Kingsley Publishers. 
Table 1

Final List of Essential History, Philosophy, and Sociology of Sport Competencies

Essential History, Philosophy, and Sociology of Sport Competencies

History of Sport Competencies

1. Describe \& interpret the relationship of the development of play, games, dance, and sport with that of physical education.

Philosophy of Sport Competencies

1. Understand how sport philosophy contributes to the practice of sport and physical education.

2. Understand why physical education should be valued equally with other academic disciplines.

3. Be familiar with arguments for and against physical education as a valuable discipline and understand why sport and physical education can be viewed as playing an integral role in the educational process.

4. Be familiar with the history of sport and physical education as it relates to the changing values and philosophies in sport and physical education.

5. Understand the cultural significance of games and play and understand how games and play fit within the framework of physical education, sport, and lifespan physical activity.

6. Understand games and play as they relate to designing physical education and sport opportunities for individuals at different developmental times and places (e.g., elementary school physical education vs. youth sport, vs. collegiate sport, vs. adult recreational sport).

7. Understand how social values can affect the practice of sport and physical education (e.g., the win-at-all cost model that is frequently used in sport or the strong emphasis that is placed on science in physical education).

8. Understand that people value participation in physical education and sport for intrinsic \& extrinsic reasons. These reasons may be intrinsically driven (e.g., "I participate in sport because it makes me feel good" or "I participate because I enjoy being outside”) or externally driven (e.g., "I participate because I like to win” or "I participate to burn calories or lose weight”).

9. Understand the difference between intrinsic and extrinsic values in sport and physical education and know how physical education and sport contribute to the "good life" of its participants in multiple, yet highly personal ways.

10. Understand how helping students and athletes recognize the intrinsic and/or extrinsic value of participation is important to the promotion and enjoyment of physical education and sport.

11. Be familiar with a variety of ethical issues in sport and physical education (e.g., intimidation, illicit performance enhancing drugs, commercialization in college athletics, burnout and dropout, sportsmanship, and gender equity).

12. Ability to critically and philosophically examine significant issues in sport and physical education.

13. Ability to cogently argue (verbal and written) for or against a variety of issues in sport and physical education. 
14. Ability to offer new viewpoints on competitive and/or educational practices in sport and physical education in order to ultimately improve practices in sport and physical education.

15. Ability to rationalize and defend physical education as having equal value with other academic disciplines and as being integral to the general educational process.

16. Ability to make sound ethical decisions relative to educational and sport processes and practices.

17. Formulate a personal philosophy of human movement.

\section{Sociology of Sport Competencies}

1. Describe cultural influence upon developmental patterns of play, games, dance, and sport.

2. Describe and interpret the influence of sub-cultures (ethnic, racial, socioeconomic, etc.) on play, games, dance, and sport.

3. Explain how play, games, dance, and sport may be utilized to facilitate change.

4. Identify responsibility as it relates to individual actions, opinions, and outcomes when engaging in sports.

5. Identify current practices and trends in play, games, dance, and sport.

6. Identify the nature and interpret the role and importance of socialization.

7. Describe how socialization takes place through play, games, dance, and sport.

8. Identify and interpret changing social practices as these affect practices in play, games, dance, and sport settings.

9. Describe and interpret the sociological trinity (the way sport interfaces with race, ethnicity, gender, and class).

*Each item had to meet the following criteria for consensus:

(a) The item received a mean rating of at least four or higher in the areas of importance and relevance

(b) The item received at least $75 \%$ of all individual ratings at the four level or higher. 
Table 2

Sub-discipline Delphi Studies

Sub-disciplines

Timeline

Exercise Physiology

Published

History, Philosophy, \& Sociology of Sport

Writing

Biomechanics

Data Collection

Motor Development \& Motor Learning

Data Analysis

Sport \& Exercise Psychology

Planned 
Table 3

Verification Interviews - Course Content

Content Area Expert $\quad$ Interview Data

Sociology of Sport Specialist: $\quad$ History and Philosophy should be taught together. Sociology of Sport should be taught separately. These courses should be taught throughout the curriculum in combination with each other to convey the relationship each has with the other.

PETE Specialist: They should be taught separately but not all three courses separately. A combined history, philosophy, and sociology course is more of what I am referring to. This information should also be reiterated in subsequent courses like a methods course. This sends the message that it is important information.

History of Sport Specialist History and philosophy of sport should be taught together and sociology of sport should be separate, but also discussed throughout the curriculum. This information should be taught in a stand alone but also discussed throughout the curriculum in the senior year is a good time to teach these courses because I have found that later on in life you can better understand and have a better appreciation for these subjects.

Philosophy of Sport Specialist $\quad$ You could teach them all together since they all relate to one another. Philosophy is most 
important; history helps support philosophy, and sociology is there also. Professors usually are trained in history or philosophy or sociology, not all three; therefore, they are specialists in their area and it would be garbage if stranded.

K-12 Physical Education Teacher In either an Introduction to Physical Education course or in a combined course. 
Table 4

Summary of theoretical and applied history, philosophy, and sociology of sport PETE competencies

\section{$\underline{\text { History of Sport }}$}

- Development of play, games, dance, and sport with physical education.

\section{Sociology of Sport}

- Cultural influence on physical activity

- Sub-cultural influence on physical activity

- How physical activity facilitates change

- Responsibility in sports

- Current practices and trends

- Importance of socialization

- How socialization takes place

- How changing social practices affects physical activity settings

- How sport interfaces with race, ethnicity, gender, and class

\section{Philosophy of Sport}

- Sport philosophy's contribute to sport and physical education

- Valuing physical education as an equal with other academic disciplines

- Physical education as an integral role in educational process

- History of sport and physical education with regard to values and philosophies

\section{Philosophy of Sport (cont.)}

- Cultural significance of games and play and how it fits in framework of physical activity

- Games and play in designing opportunities for different developmental times and places

- Affect of social values on practice of sport and physical education

- Intrinsic and extrinsic reasons to value participation in physical education

- Know difference in intrinsic and extrinsic values in sport

- Know importance of intrinsic and extrinsic value of participation in physical activity

- Ethical issues in physical education

- Significant issues in physical education

- Ability to argue for or against a variety of physical activity issues

- Educational practices to improve practice in physical education

- Physical education as valuable to general educational process

- Ethical decision making in sport processes and practices

- Personal philosophy of human movement

\section{$\underline{\text { Verification Interviews }}$}

- Teach history, philosophy, and sociology of sport together within one course as well as reiterate information in methods courses throughout curriculum.

- History, philosophy, and sociology of sport 


\section{APPENDIX A}

History, Philosophy, and Sociology of Sport

Recommendations for Physical Education Teacher Education

Literature Review 
This review of the literature provides a rationale for this study and is organized into the following sections: (a) History of Sport, (b) Philosophy of Sport, (c) Sociology of Sport, (d) Implications for PETE, (e) Delphi Method, and (f) Related Studies.

Scholarly knowledge about physical activity has been organized into sub-disciplines, each provide a different perspective to view the physical activity processes. The sub-disciplines within the kinesiology curriculum as identified by Hoffman (2005) include physiology of physical activity, philosophy of physical activity, history of physical activity, sociology of physical activity, motor behavior, sport and exercise psychology, and biomechanics. Because kinesiology is a rapidly expanding discipline, these sub-disciplines will likely expand also.

The concept of kinesiology involves the understanding that humans are movement oriented. The knowledge and understanding in this discipline are derived from all areas where movement is relevant. The structure of this knowledge involves the theory and practice of the meaning and significance of movement as it is reflected in the sociocultural, historical, and philosophical aspects of movement; the growth and development of the individual; the physical, biological, and behavioral factors influencing movement (American Association for Health, Physical Education, and Recreation, 1974). Each of these sub-disciplines addresses different sets of sport and exercise related questions.

American Association for Health, Physical Education, and Recreation (AAHPER, 1974) states that the primary premises that guided the compilation of history, philosophy, and sociocultural competencies within sport was due to the fact that competencies can be identified, and human movement can be studied through a conceptual approach. The major responsibility of institutions preparing preservice physical education teachers is to design and provide a variety of experiences that will enable students to develop such competencies as the ones from AAHPER 
(1974). Although competencies such as those of AAHPER (now called AAHPERD; dance was later added as a component of this association) are taught within a PETE program, it is up to the preservice student to develop their own particular set of concepts and competencies specific to their own teaching situation and personal background.

The question of why people move and play is related to their culture and remains unique to each individual. Throughout history, people have sought and used many avenues to find meaning and significance within the context of their culture. Human movement has been one of these means with play, games, dance, and sport serving as symbols for the formulations of ideas as well as reflecting human needs (AAHPER, 1974). Each society has developed its own cultural variations and individuals within that society have their own personal philosophy, lifestyle, and needs. In order for children to want to continue to move (play) the physical educator must know each student's thoughts on the meaning and significance of physical activity. The historical perspective along with the cultural context of movement provides the means by which problems and future directions can be understood, which also relates to society in which the physical educator will operate (AAHPER, 1974).

Siedentop (2009) states that over the past four decades, the sub-disciplines of history of sport, philosophy of sport, and sociology of sport have developed into specialized areas of study; each has its own place in undergraduate and graduate curricula (which vary by institution), academic and professional societies, and scholarly journals. Rather than having knowledge in all of the sub-disciplines, most kinesiology professors have received in-depth education in one or two of the sub-disciplines. However, specialization has its downfalls.

Hoffman (2005) suggests separate sub-disciplinary courses can make it difficult for students to develop an integrated knowledge base for use in their professional practice. Although 
the knowledge of history, philosophy, and sociology of sport has been deemed by many specialists as being of vital importance to the physical educator (Eitzen \& Sage, 2008; Harris \& Kretchmar, 2005; Mechikoff \& Estes, 2005), many departments choose to combine these three courses into one introduction to the profession course. Few institutions remain which place such importance on these three sub-disciplines that individual courses are incorporated into the kinesiology curriculum. Hoffman reminds physical educators that dividing up the discipline into separate courses can lead to fragmentation in the student's thinking about physical activity and cause the student to forget that kinesiology is one unified body of knowledge with each part helping students to better understand the discipline as a whole. This will allow students to make correlations as a whole when in their professional practice, since the professional world does not have problems to solve in tidy little boxes the way many curricula are developed but rather the novice physical educator must be able to integrate their knowledge as a whole in order to relate separately taught courses to specific problems. Students who are able to make connections between facts, concepts, and the many sub-disciplines will be best prepared for their professional careers.

Each physical education curriculum model has a different view of the subject matter. Some physical educators believe physical education should focus on sport, or movement education, while others believe more of a focus should be on fitness education or social development (Hoffman, 2005). Siedentop (2009) states the physical education subject matter is so loosely defined that it excludes very little and therefore, will include activities that are not useful or defensible by any criteria. In relation to this, Siedentop also questions what content knowledge teachers need to teach effectively? 


\section{History of Sport}

According to Siedentop (2009), sport historians study factors that have affected the development of sport and physical activity across the world. Sport history is much more than studying sporting events of the past. It not only chronicles the past but also interprets the past, relates the past to the present, and provides guidelines to what might be expected or what courses might be taken in the future. Harris (1989) states sport history identifies and describes patterns of change and stability in sport, in particular societies or cultures during specific time periods. Siedentop (2009) suggests sport history has not grown because few programs place this as an area of emphasis. Many physical educators find it difficult to understand why they should study sport history since it appears to not be of immediate relevance to their professional career. However, sport history causes a physical educator to think critically about what they do and causes an appreciation to develop for the importance and complexity of that work. The very nature of sport history is in its name and subsequently its main interest-sport.

\section{Philosophy of Sport}

Preservice teachers are required to meet national, state, and school district standards. According to the National Association for Sport and Physical Education (NASPE) initial PETE standards, standard number two states, "physical education teacher candidates must know and apply discipline-specific scientific and theoretical concepts critical to the development of physically educated individuals” (NASPE, 2008, p. 6). Accordingly, outcome 2.4 states, "teacher candidates will identify historical, philosophical, and social perspectives of physical education issues and legislation” (NASPE, 2008, p. 6). One may wonder what does philosophy have to do with K-12 teaching and what is the purpose of requiring undergraduate students to take a philosophy of sport course? The K-12 school setting is the best opportunity to teach quality 
physical activity habits to children. Through teaching philosophy, physical education teacher educators can achieve this goal by helping preservice teachers understand the need, worth, value, and magnitude for physical education in their lives (Cavallini, 2006).

Within the realm of philosophy issues to be considered include sport ethics, values of physical activity, and mind-body relationships (Harris \& Kretchmar, 2005). Philosophical thinking requires a student to develop coherent, general views of involvement in physical activity, to be inquisitive about events which take place at school, to ask about standard procedures, and value commitments most individuals take for granted (Siedentop, 2009). Philosophers complement the facts of history and sociology, when combined together these provide an important sociocultural component to PETE. Philosophy of sport involves continual reflection that leads to general views about people and sports (Harris \& Kretchmar, 2005). Topics in a typical philosophy course taught within a kinesiology curriculum include: general overviews of philosophy of physical activity, as well as specialized topics such as ethics in sports, aesthetics of sport, values of physical activity, politics and sport, the mind-body relationship, and the nature of play, games, dance, exercise, and sport. (Hoffman, 2005).

Philosophy of physical activity has two major goals: (1) to clarify thinking about forms of physical activity such as sport, play, games, exercise, and dance, as well as to clarify thinking about the mind-body relationship; and (2) to encourage people to use their insights about physical activities and the mind-body relationship to make positive changes in people's lives. (Harris \& Kretchmar, 2005). Prior to the 1960s, American analysis of the philosophy of physical activity was sporadic. European scholars during this early time period, produced work on the mind-body relationship and on the nature of play, games, and sport, while American physical educators examined the importance of physical education for furthering overall educational goals. 
When scholars began to move beyond educational philosophy and focus more on philosophy of physical activity itself, especially sport, the sub-discipline of philosophy began to take shape. Soon after, a scholarly association (The Philosophic Society for the Study of Sport-PSSS, now

the International Association for the Philosophy of Sport) and a research journal (The Journal of the Philosophy of Sport) was established (Hoffman, 2005).

Cavallini (2006) claims a mandatory course within the PETE curriculum should focus on a philosophical perspective of the importance of physical education in an individual's life. Understanding the contribution of philosophy in physical education can mean the difference between a "roll out the ball" mentality and one that will forever change student's lives. If preservice teachers instill strong physical activity values, beliefs, attitudes, ideas, and viewpoints, they will help their students live a healthier life.

\section{Sociology of Sport}

For more than 100 years, sociology has been an accepted scholarly field whose primary focus has been on social organization, social practices, and social behavior (Massengale \& Swanson, 1997). Sport sociology focuses on socialization, social control, stratification, social conflict, and social change (McPherson, 1981). Coakley (2007) suggests physical activity and sports have to be examined as social constructions; in other words, "aspects of the social world that are created by people as they interact with one another under the social, political, and economic conditions that exist in our society” (p.12). Prior to 1960, if a student looked in course catalogs for sociology of sport courses in the physical education curriculum or in the section where sociology courses were listed, their efforts would fall short of their expectations. Prior to the mid-1960s PETE was focused exclusively on the pedagogical concerns of preparing teachers. However, along with other departments with an applied professional emphasis, physical 
education felt the pressure to demonstrate a basic academic body of knowledge (Sage, 1984). By 1970 sociology of sport courses could be found in many physical education departments as well as in a few sociology departments (Massengale \& Swanson, 1997).

With the increasing popularity of PETE departments changing names to kinesiology or sport studies, sociology of sport finds itself situated within the context of a much broader framework (Sage, 1984). A more varied approach, sport studies, focuses on concepts, theories, and methods from all of the social sciences, and humanities (Harris, 1989). Although sport sociology has in the past primarily focused on sport, there has been a growing interest in the area of exercise, more specifically, how society views and influences perceptions of the body and how it should look (Hoffman, 2005). Through this, sociology of sport now puts itself in position to assist in the nation's obesity crisis.

\section{Implications for PETE}

A physical educator not only utilizes the knowledge within PETE, but also significantly contributes to the knowledge of human movement. The physical educator must have an understanding of the meaning of the growth and development of the individual; the significance of movement; and the practical application of physical, biological, and behavioral sciences to assist individuals in reaching awareness of themselves and others (AAHPER, 1974). PETE programs provide prospective teachers with the subject matter knowledge, pedagogical knowledge, and pedagogical content knowledge (Shulman, 1987) needed to effectively develop the psychomotor, cognitive, and affective characteristics that will enable a child to enjoy a healthy, physically active lifestyle into adulthood (Bulger \& Housner, 2007). The nation’s growing concern for the obesity crisis and the role physical activity plays in the maintenance of good health (U.S. Department of Health and Human Services, 2000) should be used to help 
determine the course content and instructional methodologies employed within the PETE curriculum (McKenzie, 2007). This would in turn better prepare physical educators to instruct and apply the concepts which can enhance a child's appreciation for regular physical activity.

According to the literature reviewed, a number of critical theoretical and applied history, philosophy, and sociology of sport concepts actively contribute to a physical educator's instructional effectiveness regarding a student's enjoyment and sustained interest in physical activity. Although, some evidence suggests PETE programs may inadequately prepare prospective physical educators to instruct and apply important concepts in the promotion of physically active lifestyles (Bulger \& Housner, 2007). If the physical education profession is to play a more meaningful role in the obesity crisis running rapid within today's youth and the parallel medical conditions that typically develop later in adulthood, PETE professionals need to focus more on preparing prospective physical educators to actively engage in multi-disciplinary approaches to physical activity promotion.

\section{Delphi Method}

The PETE curricula transition from theory to practice must incorporate individuals from multiple backgrounds, perspectives, and disciplinary orientations (Sahakian, 1997). The theory to practice dilemma in PETE calls for an alternative research design and the Delphi method may be one such valuable research technique. In situations where group meetings are believed to be unsuitable due to logistical limitations often associated with face-to-face discussion, the Delphi method is a useful research tool in synthesizing expert judgments and deriving consensus (Clayton, 1997). Also, the use of the Delphi method has been recommended when the ambiguity of a problem surpasses the knowledge of a particular decision-maker (Clayton, 1997; Sahakian, 1997). The underlying assumption of the Delphi method is that informed, collective judgment of 
a group of experts is more accurate and reliable than individual judgment (Clayton, 1997; Ziglio, 1996). PETE is like other dynamic environments where effective decision-making is dependent on the "knowledge, resourcefulness, expertise and creativity [of] different types of people" (Sahakian, 1997, p. 2).

The Delphi method was first introduced in 1958 through "Project Delphi” which was developed by the Rand Corporation to predict alternate national defense issues associated with the atomic bomb (Dalkey \& Helmer, 1963). The project was called Delphi due to the mythical oracle of Delphi that was capable of forecasting future events. The predictive power as a forecaster of scientific and technological events is what maintained this method in its early days (Weaver, 1971).

Opposed to other surveys of its time, the Delphi method was set apart because the individuals who were surveyed were experts in the field being investigated, and the survey rounds were repeated until group consensus was reached (Hill \& Fowels, 1975; Weaver, 1971). The traditional Delphi method began the process of census gathering with a questionnaire posing a problem in broad terms and inviting answers and comments which was generally used during the first round of surveying (Murray \& Hammon, 1995; Williams, 1998). The method of census gathering expedites the investigative process and enables the researcher to maintain control over the range and scope of the issues that are being discussed. The structured process of the modified Delphi method utilizes a series of questionnaires (or rounds) to gather information and provide controlled feedback; this process continues until group consensus is obtained (Beretta, 1996; Green, Jones, Hughes, \& Williams, 1999). The Delphi process begins with an initial questionnaire (round one) asking each panel member to rate each item using a Likert scale. The Delphi method is noted as preserving the separate power of each person's opinion, unlike group 
discussion, where one dominant leader might persuade the group member's opinions (Cyphert \& Gant, 1971). Once completed by the expert panel, the questionnaire is returned to the researcher for analyzing. The analyzed responses act as a springboard for the rest of the Delphi process. Feedback from round one is provided in a second questionnaire (round two). In subsequent rounds following round one, expert panel members are provided with their own responses as well as those of the other panelists and the expert is then asked to reconsider (and change if needed) their response based on the responses from the other panel members. This process continues through subsequent rounds until group consensus is obtained. Sumsion (1998) describes the Delphi process as multistage, where each stage builds on the results of the previous one.

Depiction of the results were usually illustrated by tables showing Likert scale scores, with standard deviations included to indicate variances. This depiction of variances makes it obvious for readers to determine group consensus for each item. Also, of equal importance, are those items rejected due to low score ratings. This was also determined by group consensus (Green et al., 1999).

Several advantages of the Delphi technique make it useful. First, Martino (1993) states it is an efficient method to obtain information from educational experts and to reach group consensus, since after each round, each expert panel member is able to compare their ratings with the group mean score and standard deviation on each survey item. According to Lang (1998), this technique helps to avoid the bias of dominant views within group discussions; members can each consider which items they find important. Finally, the Delphi method has the advantage that opinions and ideas are multifaceted and not solely based on critical tasks in which 
only important obvious elements of teaching can be taken into account (Clayton, 1997; Murray \& Hammons, 1995; Williams \& Webb, 1994).

Limitations also accompany the Delphi technique. Lang (1998) suggests limitations with biases introduced by the methods used to select participants, design of the questionnaire, and process results. The expert panel member's professional and personal obligations may also limit the amount of time each panel member can commit to the study (Clayton, 1997); which may result in premature termination from the study by the participant. The information generated in this study will be essentially linked to panel members' personal values, concepts, ideas, experience, and quality of opinions (Woudenberg, 1991). Finally, due to the nature of the Webbased Delphi method, participation will be limited to individuals who have Internet access (Na, 2006).

The Delphi method shares its criticisms along with its advantages. Such criticisms include uncertainty about the future and subjective judgment of experts (Stillwell, 1999). The conventional Delphi method neglects areas of professional standards according to Sackman (1975). These include: questionnaire design, administration, application, and validation. Many researchers agree, despite these neglects, the Delphi method is a valuable tool for educational forecasting and planning (Lang, 1998; Martino, 1993; Ulschak, 1983; Welty, 1973).

Traditional methods of survey distribution and collection that utilize the United States postal system are slow and provide low rates of return (Jacobs, 1996). Internet technology provides an alternative to drastically decrease the amount of time and provides easy follow-up using electronic mail (e-mail) (Turner \& Turner, 1999). Many existing research studies in the area of information technology are utilizing the Internet and the World Wide Web as a method to collect group consensus data (Nesbary, 2000). The World Wide Web extends across the world, 
making geographical boundaries less of an issue in communication. Data collection and analysis are greatly reduced due to advanced online capability, the cost of survey administration for research becoming cheaper, and the amount of work required in survey distribution being lessened. Watt (1999) suggests that despite studies remaining to be done, the validity of webbased survey research is likely to be strongest for researchers who target samples within specific populations. In earlier stages, Internet-based data collection typically involved embedding the necessary instrument directly in the body of an e-mail message and requesting the response be replied to as an attachment or modification of the original message. However, currently researchers are increasingly directing participants to complete survey instruments that have been published as web pages (White \& Dailey, 2001). One such example of a published web page with instrumentation is SurveyMonkey.com. Research study participants can access the online survey via a hyperlink embedded in an e-mail message sent to the participant.

In order to determine the appropriateness of using the Delphi technique, Linstone and Turoff (1975) established the following seven criteria:

1. When the problem does not lend itself to precise analytical techniques but can benefit from subjective judgments on a collective basis.

2. When the individuals who need to contribute to the examination represent diverse backgrounds with respect to experience or expertise.

3. When more individuals are needed than can effectively interact in a face-toface exchange.

4. When the time and cost make group meetings infeasible.

5. When disagreements are so severe or politically unpleasant that the communication process must be refereed and/or anonymity assured. 
6. When the heterogeneity of the participants must be preserved to assure validity of the results and to avoid domination by the strength of certain personalities.

7. When a supplemental group communication process can help the efficiency of face-to-face meetings (p. 59).

The Delphi technique was utilized in this study because it meets most of the aforementioned criteria.

\section{Related Studies}

The Delphi method has been used in identifying competencies and predicting future educational trends (Benjamin, Carroll, Dewar, Lempert, \& Stockly, 2000; Iwu, 1988; McCoy, 2001; Rickman, 1987; Williams, 2000). The Delphi method was utilized in a 10 year research study funded by the Texas Higher Education Coordinating Board to determine future issues for Texas higher education. The results represented how well the higher education system in Texas will meet future challenges if current trends and patterns remain the same. It also identifies the types of changes needed to realign Texas higher education with these issues (Benjamin et al., 2000).

The Better Health 2010 Delphi Study was conducted by the Association of American Medical Colleges (AAMC, 2001) in order to identify changes in organization, operations, roles, and functions that will occur as a result of information technology and the Internet. This threeround, web-based, Delphi study used a 7-point scale to rate the likelihood of 75 statements on how information technology over the next 10 years might change medical education. The study was completely conducted over the Internet and involved 268 participants.

Rickman (1987) used the Delphi method to identify emerging competencies needed in the year 2000 by information processing employees for the automated office environment. Rickman 
expected the competencies determined by the study would be beneficial to business educator curricular decision makers in planning the curriculum for training future employees to be prepared to work in the ever changing professional environment. Expert panel members were used in the study to identify competencies needed by information processing specialists and to determine the degree of importance attributed to these competencies.

A Delphi study was conducted by Iwu (1988) to examine the importance of computer competencies needed for the certification of secondary school business teachers in the United States. The purpose of the study was to: (a) identify important computer competencies, (b) determine the degree of importance of these competencies, and (c) rank the categories of these various competencies. A national panel of business education professors was recommended by Iwu to be used to determine the needs of educators for future training as well as to periodically reassess those determinations to eliminate obsolete business practices.

Williams (2000) compared his research results with those of a previous Delphi study on competencies done by Liz Thach in 1994. Based on the Thach comparison, three Internet related, as well as two pedagogy related competencies emerged from the study. The results from this study represented a need for basic technology competencies across all roles and for sound pedagogical practice in initiatives in distance education. Also, a dual trend emerged related to technology skills. First, the more advanced technical competency, engineering skills, was not as highly rated as before. Secondly, basic technology skills are indispensable across all roles, having become part of the entry-level skill set needed by any staff member. In addition to the general competencies, each role requires other competencies that are role-specific. The role specific competencies on which the expert panel reached a level of group consensus rated the survey items as being very important due to either frequency or being of critical importance. 
The computer competencies needed for business education teachers in the 21st century were identified by McCoy (2001). This three-round Delphi study used electronic mail as the primary means of communication. Twenty-three expert Delphi panel members were nominated by the National Association for Business Teacher Education (NABTE). The survey instrument was the result of responses generated by Round I; Round II involved rating the importance of each competency using a 5-point Likert scale; and finally Round III determined group consensus of the survey items. Based on group consensus, 95 competencies were grouped into five categories: computer hardware, software, computer programming, computer integration, and general computer knowledge. The findings presented nine critically important general knowledge items that should be used to inform the business teacher education curriculum. The Delphi panel believed the two most important competencies about general computer knowledge for business teachers are to be able to readily assess the computer skills/knowledge of students, and to show competency in the fundamentals of computers and information processing.

Bulger and Housner (2007) conducted a modified Delphi study to identify the critical exercise science competencies and associated instructional methods recommended for inclusion in the PETE curriculum. Twenty expert panel members were selected from the following levels of expertise: exercise science, PETE, and K-12 physical education teachers. The panel members were asked to rate on a Likert scale (1-5) each of the 222 initial exercise science competencies. The results of the study indicated 109 out of 222 initial exercise science competencies were both of critical theoretical importance and pedagogical relevance. The present study serves as a replication of the Bulger and Housner study.

The literature reviewed indicates the Delphi method has been used in many studies to identify competencies. Furthermore, with the advanced online capability the Delphi method 
became a very popular educational research method which saves time and cost of conducting research. The Delphi method was selected for this study in order to determine group consensus from a panel of physical education experts and history, philosophy, and sociology of sport specialists. 


\section{Appendix A: Review of Literature References}

American Association for Health, Physical Education, and Recreation. (1974). Professional preparation in dance, physical education, recreation education, safety education, and school health education. Washington, DC: AAHPER Publications-Sales.

Association of American Medical Colleges. (2001). Better Health 2010 Report. Retrieved October 5, 2008, from http://www.aamc.org/programs/betterhealth/start.htm.

Benjamin, R., Carroll, S., Dewar, J., Lempert, R., \& Stockly, S. (2000). Achieving the Texas higher education vision. RAND Corporation. Texas Higher Education Coordinating Board.

Beretta, R. (1996). A critical view of the Delphi technique. Nurse Researcher, 3(4), 79-89.

Bulger, S. M., \& Housner, L. D. (2007). Modified Delphi investigation of exercise science in physical education teacher education. Journal of Teaching in Physical Education, 26, 5780.

Cavallini, M. F. (2006). Who needs philosophy in physical education? Journal of Physical Education, Recreation, and Dance, 77(8), 28-30.

Clayton, M. J. (1997). Delphi: A technique to harness expert opinion for critical decision-making tasks in education. Educational Psychology, 17, 373-387.

Coakley, J. (2007). Sports and society: Issues and controversies ( $9^{\text {th }}$ ed.). New York, NY: McGraw-Hill.

Cyphert, F. R., \& Gant, W. L. (1971). The Delphi technique: A case study. Phi Delta Kappan, 52, $272-274$

Dalkey, N. C., \& Helmer, O. (1963). An experimental application of the Delphi method to the use of experts. Management Science, 9, 458-467. 
Eitzen, D. S., \& Sage, G. H. (2008). Sociology of North American sport $\left(8^{\text {th }}\right.$ ed.). Boulder, CO: Paradigm Publishers.

Green, B., Jones, M., Hughes, D., \& Williams, A. (1999). Applying the Delphi technique in a study of GPs information requirement. Health and Social Care in the Community, 7, 198205.

Harris, J. C. (1989). Suited up and stripped down: Perspectives for sociocultural sport studies. Sociology of Sport Journal, 6, 335-347.

Harris, J. C., \& Kretchmar, R. S. (2005). Philosophy of physical activity. In S. J. Hoffman (Ed.), Introduction to kinesiology: Studying physical activity (pp. 147-175). Champaign, IL: Human Kinetics.

Hill, K. Q., \& Fowles, J. (1975). The methodological worth of the Delphi forecasting technique. Technological Forecasting and Social Change, 7, 193-194.

Hoffman, S. J. (2005). Introduction to kinesiology: Studying physical activity $\left(2^{\text {nd }}\right.$ ed.). Champaign, IL: Human Kinetics.

Iwu, H. O. (1988). Computer competencies needed for the certification of secondary school business teachers. Unpublished doctoral dissertation. University of Nebraska, Lincoln.

Jacobs, J. M. (1996). Essential assessment criteria for physical education teacher education programs: A Delphi study (Doctoral dissertation, West Virginia University, 1996). Dissertation Abstracts International, 57, 2938.

Lang, T. (1998). An overview of four futures methodologies. Retrieved November 5, 2008, from http://www.soc.hawaii.edu/future/j7/LANG.html.

Linstone, H., \& Turoff , M. (1975). The Delphi method: Techniques and applications. Reading, MA: Addison-Wesley Pub. Co. 
Martino, J. (1993). Technological forecasting for decision making. New York, NY: Elsevier Science Publishing Company.

Massengale, J. D., \& Swanson, R. A. (1997). The history of exercise and sport science. Champaign, IL: Human Kinetics.

McCoy, R. (2001). Computer competencies for the 21st century information systems educator. Information Technology, Learning, and Performance Journal, 19(2), 21-35.

McKenzie, T. L. (2007). The preparation of physical educators: A public health perspective. Quest, 59, 346-357.

McPherson, B. (1981). Past, present, and future perspectives for research in sport sociology. In J. Loy, G. Kenyon, \& B. McPherson (Eds.), Sport, culture, and society: A reader on the sociology of sport (pp. 10-22). Philadelphia, PA: Lea \& Febiger.

Mechikoff, R. A., \& Estes, S. G. (2005). A history and philosophy of sport and physical education: From ancient civilizations to the modern world ( $5^{\text {th }}$ ed). New York, NY: McGraw-Hill.

Murray, J., \& Hammons, J. O. (1995). Delphi: A versatile methodology for conducting qualitative research. The Review of Higher Education, 18, 423-436.

Na, S. (2006). A Delphi study to identify teaching competencies of teacher education faculty in 2015. Dissertation, West Virginia University, [On-line Abstract]. Available: https://eidr.wvu.edu/etd/documentdata.eTD?documentid=4543.

National Association for Sport and Physical Education. (2008). Initial physical education program report manual (7th ed.). Reston, VA: NASPE Publications.

Nesbary, D. K. (2000). Survey Research and the World Wide Web. Boston, MA: Allen and Bacon. 
Rickman, L. L. (1987). A Delphi study to identify the emerging competencies needed by the information processing employee for the automated office in the year 2000. Unpublished doctoral dissertation, University of Missouri, Columbia.

Sackman, H. (1975). Delphi critique. Lexington, MA: Lexington Books.

Sahakian, C. E. (1997). The Delphi method. Skokie, IL: The Corporate Partnering Institute.

Shulman, L. (1987). Knowledge and teaching: Foundations of the new reform. Harvard Educational Review, 57, 1-22.

Siedentop, D. (2009). Introduction to physical education, fitness and sport ( $7^{\text {th }}$ ed.). New York, NY: McGraw-Hill.

Stillwell, C. (1999). A Delphi study on critical issues facing higher education for the first decade of the 21st century based on the perspectives of the International Association of University Presidents. Arise Fall 1999 Research Forum. Retrieved from http://www.gwu.edu/ arise/activities/fall99/abstract_stillwell.htm.

Sumsion, T. (1998). The Delphi technique: an adaptive research tool. British Journal of Occupational Therapy 61(4), 153-156.

Thach, E. (1994). Perceptions of distance education experts regarding the roles, outputs, and competencies needed in the field of distance education. Unpublished doctoral dissertation, Texas A\&M University, Educational Human Resource Development Department, College Station, TX.

Turner, J., \& Turner, D. (1999). Using the Internet to perform survey research. Syllabus, 12(5), $55-56$.

Ulschak, F. L. (1983). Human resource development: the theory and practice of need assessment. Reston, Virginia: Reston Publishing Company, Inc. 
United States Department of Health and Human Services. (2000). Promoting better health for young people through physical activity and sports. Atlanta, GA: United States Department of Health and Human Services and Department of Education.

Watt, J. H. (1999). Internet-based surveys. Upgrade: The Magazine for the Software and Information Industry Association, 20, 83-87.

Weaver, W. T. (1971). The Delphi forecasting method. Phi Delta Kappan, 52, 267-271.

Welty, G. (1973). Some problems of selecting Delphi experts for educational planning and forecasting exercises. California Journal of Educational Research, 24(3), 129-134.

White, J., \& Dailey, K. (2001). Web-based instrumentation in educational survey research. WebNet Journal: Internet Technologies, Applications and Issues, 3, 46-50.

Williams, A. (1998). Identification of content, priority, and methods of instructional delivery for a women's health component in an internal medicine residency program. Unpublished doctoral dissertation, West Virginia University, Morgantown.

Williams, P. E. (2000). Roles and competencies for distance education programs in higher education institutions. American Journal of Distance Education, 17, 45-57.

Williams, P., \& Webb, C. (1994). The Delphi technique: A methodological discussion. Journal of Advanced Nursing, 19, 180-186.

Woudenberg, F. (1991). An evaluation of Delphi. Technological Forecasting and Social Change, 40, 131-150.

Ziglio, E. (1996). The Delphi method and its contribution to decision-making. In M. Adler \& E. Ziglio (Eds.), Gazing into the oracle: The Delphi method and its application to social policy and public health (pp. 3-33). Bristol, PA: Jessica Kingsley Publishers. 


\begin{abstract}
APPENDIX B
History, Philosophy, and Sociology of Sport

Recommendations for Physical Education Teacher Education Pilot Study
\end{abstract}




\section{E-mail to Identify Pilot Study Participants for Recruitment}

Hello (insert name here),

I am a doctoral student in physical education teacher education at West Virginia University. I am beginning my dissertation research study titled: History, Philosophy, and Sociology of Sport Recommendations for Physical Education Teacher Education (PETE). The purpose of this study is to establish sport history, philosophy, and sociology course competencies to be used to inform the undergraduate PETE curriculum.

I am in need of sport history, philosophy, and sociology experts for my study; this is where I need your assistance. I know you are an expert in the field of (insert sport history, philosophy, or sociology) and I am in need of finding other experts such as yourself. I am currently contacting other specialists/fellows from the American Academy of Kinesiology and Physical Education (AAKPE) in sport history, philosophy, and sociology. Would you please provide me with a list of individuals you would like to nominate in order to form a panel of experts? Any contact information you can provide on these individuals is much appreciated (e.g., institution employed, e-mail address).

The experts will simply need to use a Likert scale to rate philosophy of sport competencies already established by the National Association for Sport and Physical Education (NASPE). They will have an opportunity to add any additional competencies they believe are relevant to philosophy of sport as well. Also, for the history and sociology of sport sections, the experts will simply need to use a Likert scale to rate competencies suggested by the American Alliance for Health, Physical Education, and Recreation (AAHPER). Experts will have an opportunity at the conclusion of the survey to add any additional competencies they believe are relevant to these areas.

I feel strongly this dissertation will help our profession. Therefore, if you have any information that would help me determine who these experts are, I would greatly appreciate your time and information! Also, I would love for you to be a part of this study as a (insert expert area here) expert panel member; please let me know your thoughts on this.

Thank you for your time and assistance.

Amanda Metcalf

Amanda Metcalf, M.A.

West Virginia University

College of Physical Activity \& Sport Sciences

P.O. Box 6116

Morgantown, WV 26506

(304) 293-0848 


\section{E-mail for Pilot Study Participant Recruitment}

Hello (insert name here),

I am a doctoral student in physical education teacher education at West Virginia University. I am contacting you to request your participation as an expert panel member for the pilot test of my dissertation titled: History, Philosophy, and Sociology of Sport Recommendations for Physical Education Teacher Education. This research study will involve the administration of a Delphi procedure to determine the history, philosophy, and sociology of sport competencies that should be included in the physical education teacher education curriculum.

For your contribution to this research study, I simply need you to critique the survey items using a rating scale that will eventually be employed to justify the validity and completeness of each competency for future use in the physical education teacher education curriculum.

Would you be interested in participating as an expert for this pilot study? Please let me know your thoughts.

Thank you for your time, Amanda Metcalf

Amanda Metcalf, M.A.

West Virginia University

College of Physical Activity \& Sport Sciences

P.O. Box 6116

Morgantown, WV 26506

(304) 293-0848 


\section{Phone Script for Pilot Study Participant Recruitment}

"Hello, my name is Amanda Metcalf and I am calling to request your participation as an expert panel member for the pilot test of my dissertation titled: History, Philosophy, and Sociology of Sport Recommendations for Physical Education Teacher Education.

This research study will involve the administration of a Delphi procedure to determine the history, philosophy, and sociology of sport competencies that should be included in the physical education teacher education curriculum. For your contribution to this research study, I simply need you to critique the survey items using a rating scale that will eventually be employed to justify the validity and completeness of each competency for future use in the physical education teacher education curriculum.

- You must be 18 years of age or older to participate.

- Your participation is entirely voluntary, you can choose to stop participation at any time and you do not have to answer any questions you do not want to answer.

- Your responses will be kept as confidential as legally possible. All data will be erased once my dissertation is complete. At no time will your name be revealed during reporting.

- Your job status will not be affected if you decide either not to participate or to withdraw.

- West Virginia's University's Institutional Review Board acknowledgement of this project is on file.

Would you be interested in participating as an expert for this pilot study?”

\section{YES/NO (IF “NO” GO TO 1 / IF “YES” GO TO 2)}

1. "Thank you for your time and consideration."

2. “Thank you for agreeing to participate; your time and efforts are greatly appreciated. Next

week I will e-mail more information in regard to your participation in this research study, as well as a link to the online survey instrument. Thank you for agreeing to participate. Your expert contribution is vital to the success of this research project.” 


\section{West VirginiaUniversity}

College of Physical Activity and Sport Sciences

Dear

Thank you for agreeing to serve as an expert panel member for my pilot study. My name is Amanda Metcalf and I am conducting this research study under the supervision of Reagan Curtis, Ph.D., an Associate Professor in the College of Human Resources and Education at West Virginia University. The purpose of this research study is to determine the history, philosophy, and sociology of sport competencies that should be included in the undergraduate physical education teacher education curriculum. The results of this study will be used to fulfill the requirements for my doctoral dissertation at West Virginia University titled: History, Philosophy, and Sociology of Sport Recommendations for Physical Education Teacher Education.

Before taking part in this study I want to make sure you understand the following:

- You must be 18 years of age or older to participate.

- Your participation is entirely voluntary, you can choose to stop participation at any time and you do not have to answer any questions you do not want to answer.

- Your responses will be kept as confidential as legally possible. All data will be erased once all research interests are exhausted. At no time will your name be revealed during reporting.

- Your job status will not be affected if you decide to either not participate or withdraw.

- West Virginia's University's Institutional Review Board (IRB) acknowledgement of this project is on file.

Thank you again for your willingness to participate in this study.

Sincerely,

Amanda Metcalf, M.A.

(304) 293-0848

Amanda.Metcalf@mail.wvu.edu

Reagan Curtis, Ph.D.

(304) 293-2098

reagan.curtis@mail.wvu.edu 


\section{E-mail to Provide Pilot Study Detailed Information}

Dear

Thank you for agreeing to participate as an expert panel member for the pilot test of my dissertation titled: History, Philosophy, and Sociology of Sport Recommendations for Physical Education Teacher Education. The results of this research study will be used to fulfill the requirements for my doctoral dissertation at West Virginia University. You were selected as an expert panel member for this study due to your expertise in (insert history, philosophy, and/or sociology of sport or its eventual application in K12 physical education programs).

The purpose of this study is to determine a list of history, philosophy, and sociology of sport competencies that should be included in the physical education teacher education curriculum. The Delphi panel members in later rounds will be asked to rate these competencies in terms of their importance and relevance for prospective K-12 physical education teachers. The panel members participating in this phase of the study will consist of three history, philosophy, and sociology of sport experts, two physical education teacher educators, and two K-12 physical education teachers. As a panel member, I simply need for you to rate the survey items in terms of their importance for undergraduate physical education teacher education students, as well as provide any additional competencies you feel should be added to the current list.

Your participation in this phase of the research process is entirely voluntary and you do not need to respond to every item on the questionnaire. You can be assured of complete confidentiality regarding all of your responses. I will send you the final results upon completion of the study.

If possible, I would greatly appreciate if you would please complete the online survey by December 5, 2008. This will allow you two full weeks to complete the survey. Instructions on completing the online survey will appear once you access the survey hyperlink below.

The following hyperlink will direct you to the online survey: www.surveymonkey.com/PETEDelphi

Thank you again for agreeing to participate in this study. If you have any questions, please feel free to contact me at (304) 293-0848 or Amanda.Metcalf@mail.wvu.edu.

Sincerely, Amanda A. Metcalf

West Virginia University Doctoral Candidate

\footnotetext{
${ }^{1}$ National Association for Sport and Physical Education. (2004). Minimum Competencies for Teaching Undergraduate Sport Philosophy Courses. Approved by the Sport Philosophy Academy and The National Association for Sport and Physical Education. Reston, VA.

${ }^{2}$ American Association for Health, Physical Education, and Recreation. (1974). Professional Preparation in Dance, Physical Education, Recreation Education, Safety Education, and School Health Education. AAHPER PublicationsSales: Washington, DC.
} 


\section{Pilot Study}

\section{Survey I ntroduction}

Welcome and thank you for agreeing to participate as an expert panel member in this Delphi investigation!

Your input regarding these competencies will have the potential to influence future curricular decision making in physical education teacher education. The survey will be used to generate consensus of expert opinion regarding the history, philosophy, and sociology of sport competencies prospective physical educators should "know" and be able to "do" as a result of the physical education teacher education curriculum.

The Delphi Method will be used to address this research inquiry, allowing you the opportunity to share your feedback and provide recommendations. The Delphi Method is a research protocol that involves (a) the identification and selection of a small panel of experts on a specific topic, (b) the use of multiple rounds of surveying as a means to collect expert opinion, and (c) the attainment of group consensus through regular feedback.

Your practical experience, insight, and judgment are vital to the success of this project because you are helping to identify the survey items that will eventually be considered by the actual Delphi panel members during Round II of this research study.

The survey items were adapted directly from the National Association for Sport and Physical Education (2004) and the American Alliance for Health, Physical Education, Recreation, and Dance (AAHPERD). Each are reproduced with the permission of the Sport Philosophy Academy within NASPE; as well as AAHPERD.

Please remember the final date for survey completion is December 5th. I greatly appreciate your assistance in the timely completion of this project.

Thank you for your time and input! Please feel free to call or e-mail me with any questions you may have.

Amanda Metcalf

West Virginia University

Amanda.Metcalf@mail.wvu.edu

(304) 293- 0848 


\section{Pilot Study}

\section{Survey I nstructions}

The following survey contains 30 concepts followed by key competencies you will need to judge in regard to their importance in the physical education teacher education curriculum.

Please do the following:

1) Rate each competency individually using the scale contained within the survey. A rating of (5) or (4) means the item should be kept; a rating of (3) means that you are neutral or undecided; and a rating of (2) or (1) means that item should be dropped from the study because it is not a relevant history, philosophy, or sociology of sport competency.

2) In the space provided, make any suggestions for improvement regarding the competencies identified within each concept area. For example, provide any suggestions that would enhance the clarity or add to the completeness of the competency. When making suggestions, please be as specific as possible and refer to each item by their corresponding letter ( $a, b, c$, etc). Your critique will serve to improve the quality of this survey in subsequent rounds.

3) Following each section, a space has been provided for writing any additional competencies you deem important for inclusion to the next round of the survey.

4) Following the competency rating, please answer two additional questions (yes or no answers) in regard to the survey instrument's overall quality.

5) Finally, please answer the five questions (yes or no answers) related to the use of SurveyMonkey as a tool for this study.

A few reminders:

1-You must enter your name on the first page of the survey in order to continue with the survey. This is the only must answer question.

2-You will not be allowed to go back into the survey once you have accessed the website link.

Therefore, if you are reading this message you are committed to completing the survey at this time.

3-You may return to the instructions page at any time by using the "Prev" buttons at the bottom of the survey pages. There is complete freedom (once you have entered your name) to go to any page within the survey and change your responses if necessary.

4- A survey completion bar will be at the top of each page in order to show your progress through the survey. 


\section{Pilot Study}

\section{Table of Contents}

Section 1: Participant Information (Question 1)

Section 2: History of Sport (Questions 2-6)

Section 3: Philosophy of Sport (Questions 7-24)

Section 4: Sociology of Sport (Questions 25-34)

Section 5: Survey Instrument's Overall Quality (Questions 35-36)

Section 6: Use of SurveyMonkey (Questions 37-41) 


\section{Pilot Study}

\section{Section 1: Participant I nformation}

* 1. Please enter your name:

Name: 


\section{Pilot Study}

\section{Section 2: History of Sport}

2. The development of play, games, dance, sport, and physical education closely parallels the historical development of man.

a) Identify and interpret the importance of historical influences.

b) Relate the events and ideas of the history of human movement to society.



- Neutral
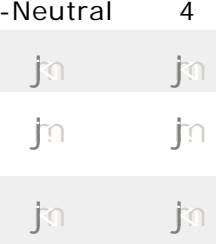

5-Keep

c) Identify and interpret the development of play, games, and sport in the American culture.

Suggestions for Improvement:

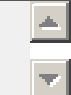

3. Understanding man's historical involvement with play, games, dance, and sport affords the individual dimensions for acquiring meaning and better understanding of man's past.
a) Identify the origin and development of significant forms of play,
games, dance, and sport served in past cultures.

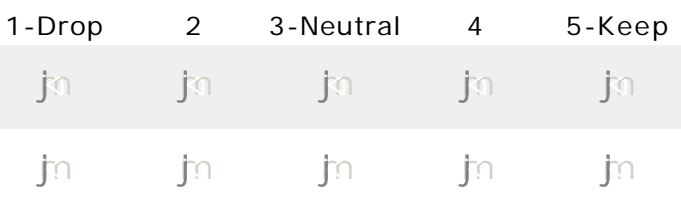
and sport served in past cultures.

Suggestions for Improvement:

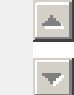

4. An understanding of contemporary forms of play, games, dance, and sport is influenced through knowledge of significant forms of human movement growing from past cultures.

a) Identify the social, political, economic, philosophical, and religious conditions in past cultures which have influences forms and purposes

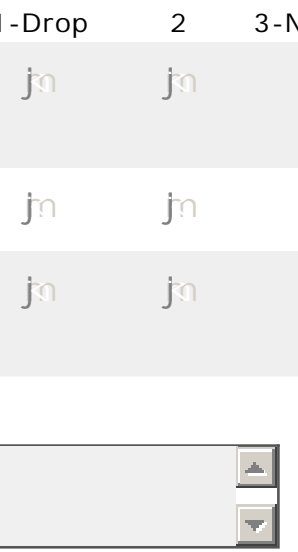
of contemporary play, games, dance, and sport.

b) Relate past forms, purposes, and cultural conditions to present-day conceptions of play, games, dance, and sport.

c) Identify significant persons, institutions, and events which contributed to the evolvement of present-day play, games, dance, and sport.

Suggestions for Improvement: 


\section{Pilot Study}

5. Play, games, dance, and sport have each had a historical development. Physical education has developed as a profession and is intimately related to the development of play, games, dance, and sport.

a) Trace and relate the relationship of the development of play, 1-Drop games, dance, sport, and physical education. 


\section{Pilot Study}

\section{Section 2: History of Sport}

Completeness

6. Please list any additional competencies you deem relevant to the history of sport in order to add to the completeness of the survey.

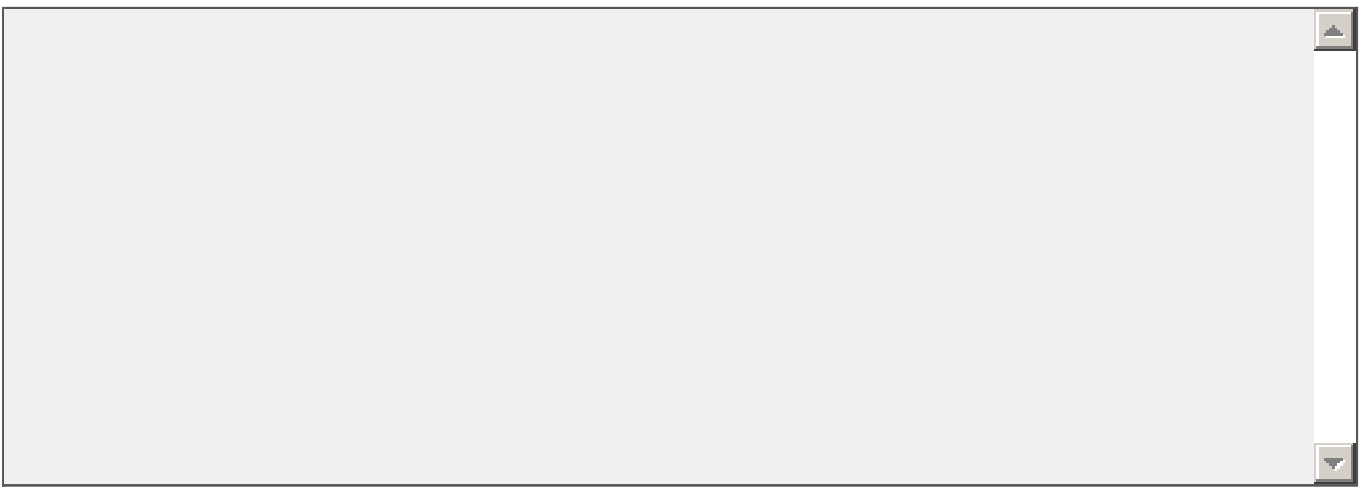




\section{Section 3: Philosophy of Sport}

\section{I dentifying the Nature of Philosophy and Sport Philosophy}

a) Understand philosophy as a formal field of study and understand the discipline of sport philosophy.

b) Understand how sport philosophy contributes to the practice of sport and physical education.

c) Understand the difference between philosophy and empiricism. Know that philosophy involves asking questions, posing challenges, and searching for deeper meanings of various issues, while empiricism involves the search for factual evidence that can be seen, heard, felt, measured, etc.

d) Understand that being a philosopher involves contemplating the differences between the "real world," where knowledge and truth rest in 1-Drop concrete material existence and the "ideal world," where knowledge and truth rest in what the mind and spirit perceive as real.



\section{Branches of Philosophy and Asking Philosophical Questions}

a) Understand the relationship between sport and physical education and the branches of philosophy, including metaphysics (focusing on questions about the nature of reality), epistemology (focusing on questions about what people know), and axiology (focusing on questions related to the value of things).

b) Understand the difference between a philosophical question and an empirical question and should understand that philosophical questions<smiles>c1ccccc1</smiles>

Suggestions for Improvement:

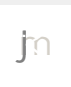

$\bigcirc$
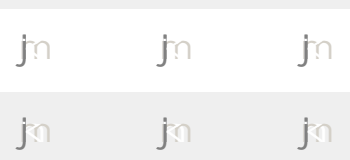

$\bigcirc$
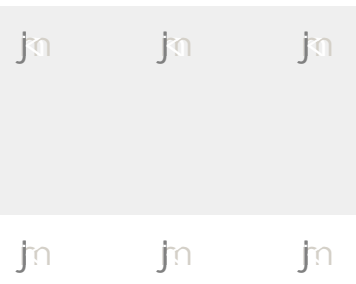
can be answered from a variety of disciplines/perspectives. For example, an empirical question is asked in the form of: How does physical activity improve one's health? Or, a philosophical question is asked in the form of: What does it mean to be healthy?

c) Be able to ask a variety of philosophical questions that span the branches of philosophy (i.e., metaphysical, axial, and epistemological). For example, a question from a metaphysical standpoint could be in the form of: How should winning be defined in an athletic contest? Or from an epistemological standpoint: How do people come to know themselves as movers? Or from an axiological standpoint: Is competition in school physical education classes a good and healthy thing for elementary age students?

Suggestions for Improvement: 1-Drop
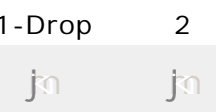

3-Neutra
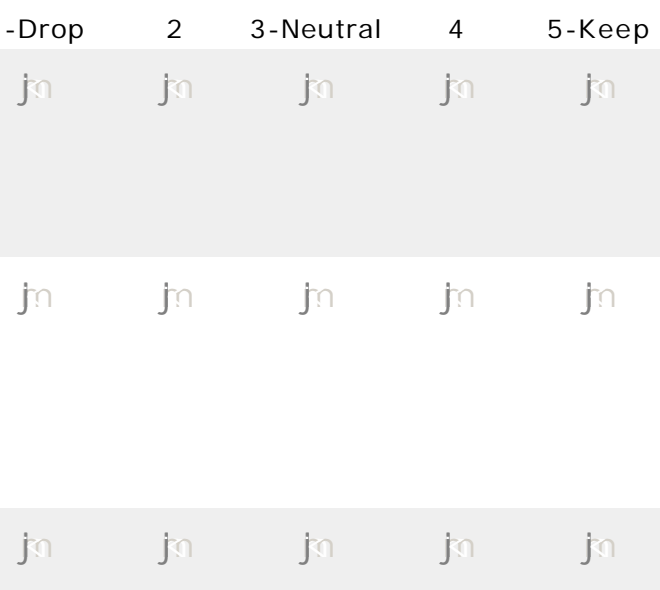


\section{Familiarity with a Variety of Philosophers of Science, Education, and Physical Education (past and present)}

a) Be familiar with philosophers of science (Galileo Galilei, Francis Bacon, I saac Newton, Thomas Hobbes), education (J ean Jacques 1-Drop
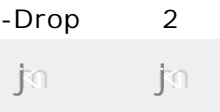

Rousseau, Johan Bernhard Basedow, John Dewey), and physical education (J. B. Nash, Jessie Feiring-Williams, Charles McCloy, Rosalind Cassidy, and Eleanor Methany). Students should also understand how the works of these philosophers are significant to issues in sport and physical education (e.g., conceptualizations of exercise science and/or the purposes, outcomes, and educational strategies used in physical education and sport).

Suggestions for Improvement:

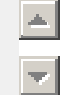

\section{I dentifying the I mportance of Sport and Physical Education to the Educational Process}

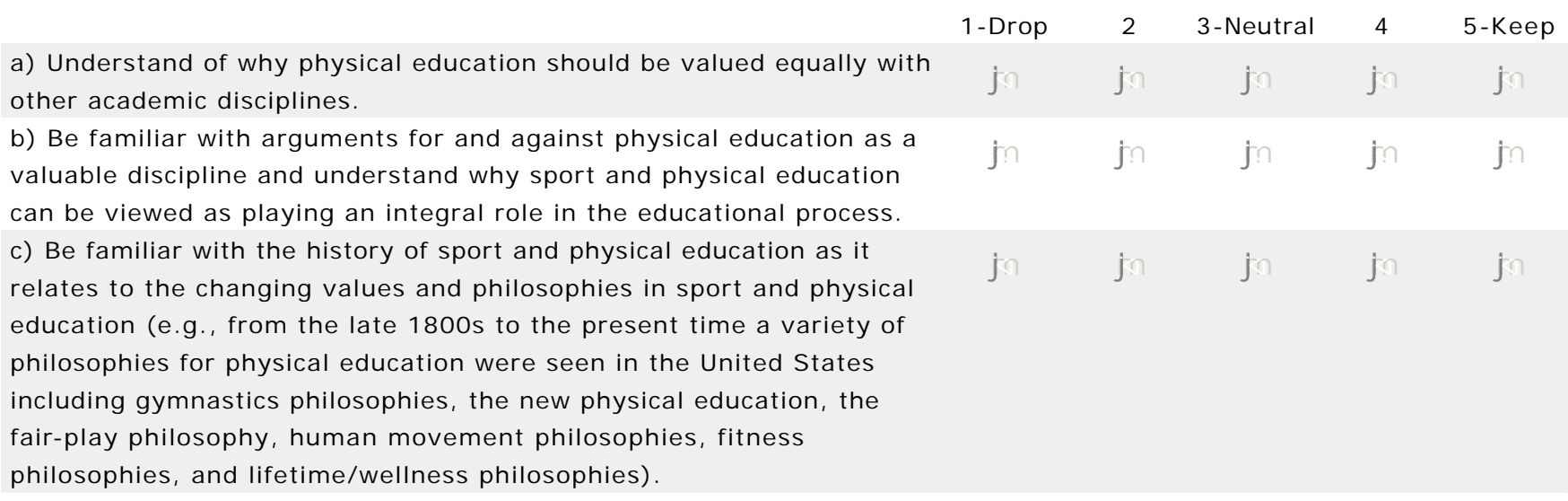

Suggestions for Improvement: 


\section{Section 3: Philosophy of Sport}

\section{The Discipline of Physical Education: Understanding the Difference Between the Professional Discipline and the Academic Discipline}

a) Be familiar with the historical debate between the academic and professional disciplines of physical education (i.e., Is the purpose of the discipline of physical education to generate new "scientific" knowledge to advance the academic discipline or to generate "applied knowledge" to serve the public's need for school physical education and/or sport opportunities?).

b) Have an understanding of why physical education has been renamed with new identifiers such as exercise science, human movement, sport science, and kinesiology.

Suggestions for Improvement:
1-Drop
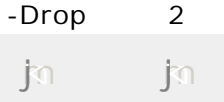

3-Neutra

$\bigcirc$

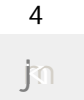

5-Keep

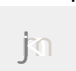

\section{Mind versus Body Argument}

a) Understand the "mind versus body" argument and how this argument is: (1) historically tied to the philosophies of sport and physical education endorsed by the Greeks and Ancient Romans (with a key focus on the philosophical thinking of Plato and Aristotle) and (2) significant to sport and physical education in that modern day practices often extend from dualistic and holistic thinking about the mind and body.

b) Understand the various ways in which our society thinks from a dualistic perspective (e.g., viewing sports competition as part mental and part physical; measuring physical fitness solely in terms of the components of fitness represent dualistic ways of thinking about the mind and body).

c) Develop a familiarity with various types of dualistic and holistic arguments, such as whether the body can be trained and/or educated

1-Drop
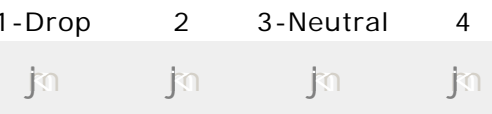

5-Keep

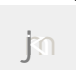
without impacting the mind and vice- versa. Another example is how a holistic argument of education can be used to establish a place for school physical education.

Suggestions for Improvement: 


\section{I dentifying Games and Play and its Significance to Society}
a) Understand the philosophical difference between games and play.
b) Understand the cultural significance of games and play and understand how games and play fit within the framework of physical education, sport, and lifespan physical activity.
c) Understand games and play as they relate to designing physical education and sport opportunities for individuals at different
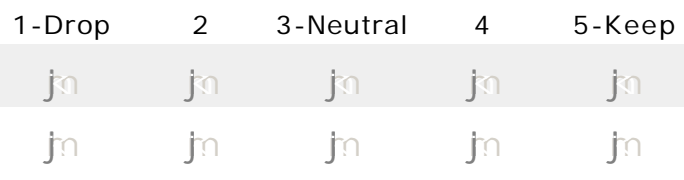 developmental times and places (e.g., elementary school physical
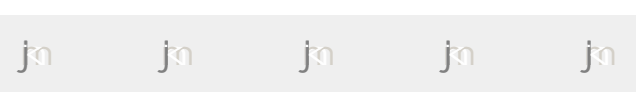 education vs. youth sport, vs. collegiate sport, vs. adult recreational sport).

Suggestions for Improvement:

\section{The Role of Society in Sport}

a) Understand the importance of considering societal values in relationship to their philosophical thinking. For example, how does one

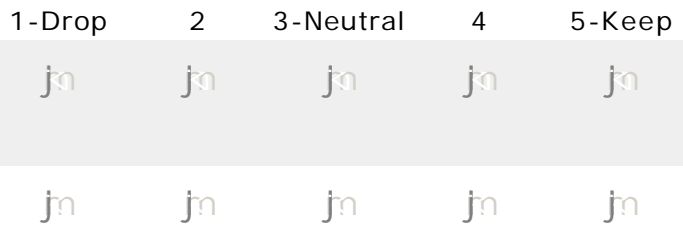
b) Understand how societal values can affect the practice of sport and physical education (e.g., the win-at-all cost model that is frequently used in sport or the strong emphasis that is placed on science in physical education).

Suggestions for Improvement:
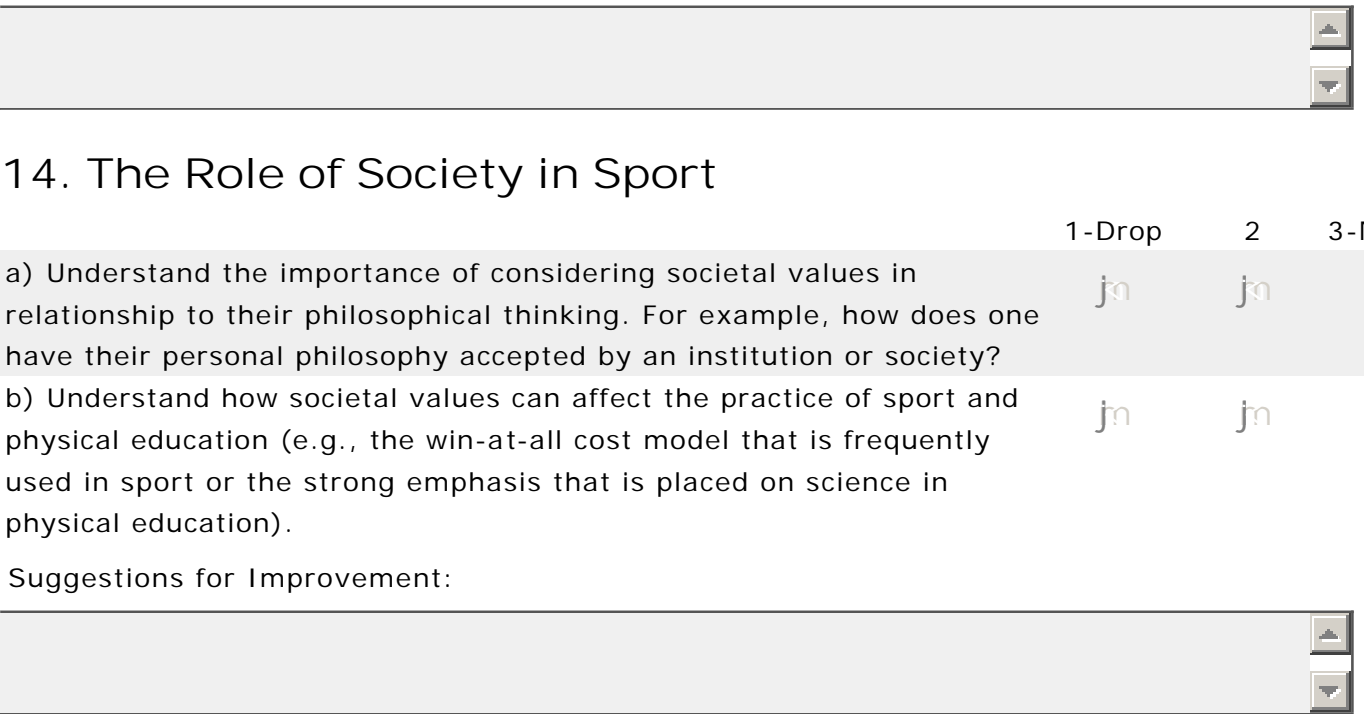


\section{Section 3: Philosophy of Sport}

\section{I dentifying the Difference Between I ntrinsic and Extrinsic Values}

a) Understand that people value participation in physical education and sport for different reasons. These reasons may be intrinsically


3-Neutral
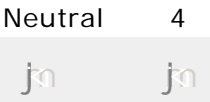

5-Keep

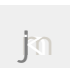
driven (e.g., "I participate in sport because it makes me feel good" or "I participate because I enjoy being outside") or externally driven (e.g., "I participate because I like to win" or "I participate to burn calories or lose weight").

b) Understand the difference between intrinsic and extrinsic values in sport and physical education and know how physical education and sport contribute to the "good life" of its participants in multiple, yet highly personal ways.

c) Understand how helping students and athletes recognize the intrinsic and/or extrinsic value of participation is important to the promotion and enjoyment of physical education and sport.

Suggestions for Improvement:

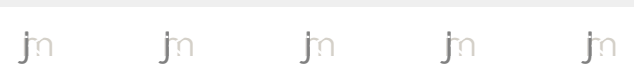

00

\section{Ethical Aspects of Sport}

a) Understand ethics and ethical theories such as universality, paternalism, teleological ethics, and deontological ethics.

b) Be familiar with a variety of ethical issues in sport (e.g., intimidation, illicit performance enhancing drugs, commercialization in
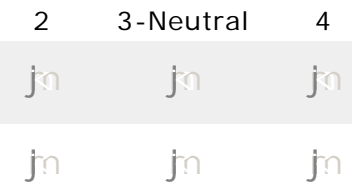

5-Keep college athletics, burnout and dropout, sportsmanship, and gender equity).

Suggestions for Improvement:

\section{General Skills As a Result of Knowledge}

a) Ability to read and comprehend philosophical writings.

b) Ability to critically and philosophically examine significant issues in sport and physical education.

c) Ability to cogently argue (verbal and written) for or against a variety of issues in sport and physical education.

d) Ability to offer new viewpoints on competitive and/or educational practices in sport and physical education in order to ultimately improve practices in sport and physical education.

e) Ability to rationalize and defend physical education as having equal value with other academic disciplines and as being integral to the general educational process.

f) Ability to make sound ethical decisions relative to educational and sport processes and practices.

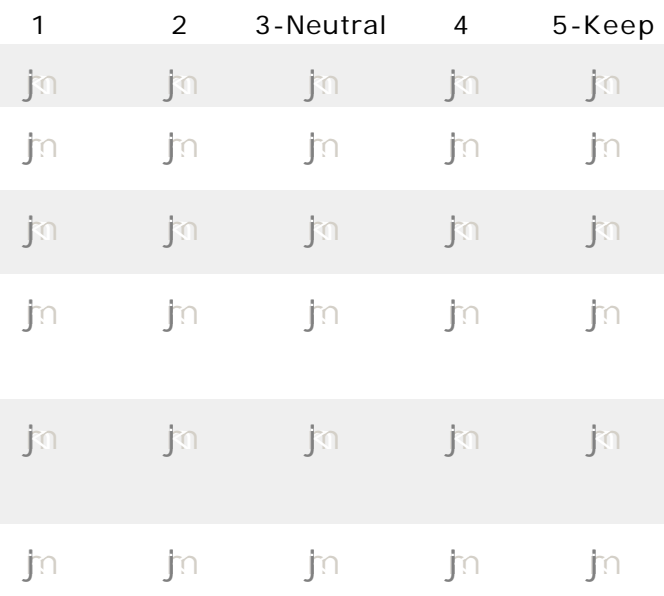

Suggestions for Improvement:

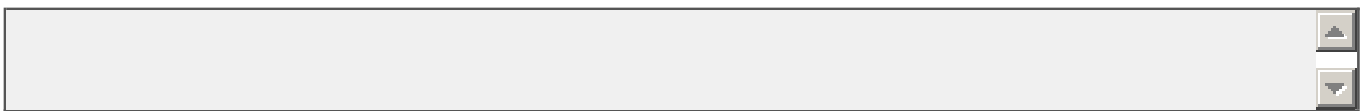




\section{Pilot Study}

18. Human movement has meaning which may be examined through philosophic inquiry.

a) Identify philosophic systems of thought and their relationship to human movement.

1-Drop

$\bigcirc$

2

3-Neutral

$\bigcirc$

$0^{4}$

5-Keep

b) Describe the processes of inquiry and apply to human movement.

c) Formulate a personal philosophy of human movement.

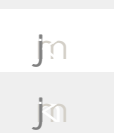

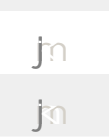

$\bigcirc$ $\bigcirc$

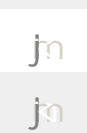

Suggestions for Improvement:






\section{Pilot Study}

\section{Section 3: Philosophy of Sport}

19. Play, games, dance, and sport afford opportunity for man to inquire and discover his own nature.

a) Identify ways that persons realize and express individuality and

uniqueness through play, games, dance, and sport.

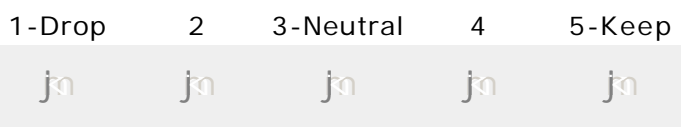

Suggestions for Improvement:

20. Play, games, dance, and sport afford opportunity for man to inquire into and discover the nature of the relationship between himself and others.

a) Identify one's human condition which makes him similar to other

human beings, leading to the development of a rationale for

1-Drop
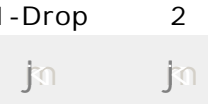

3-Neutral

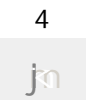

5-Keep

interdependence.

Suggestions for Improvement:

\section{Human movement reflects the nature of the universe.}

a) Identify and discuss the theories concerning the nature of the

universe as they relate to play, games, dance, and sport.
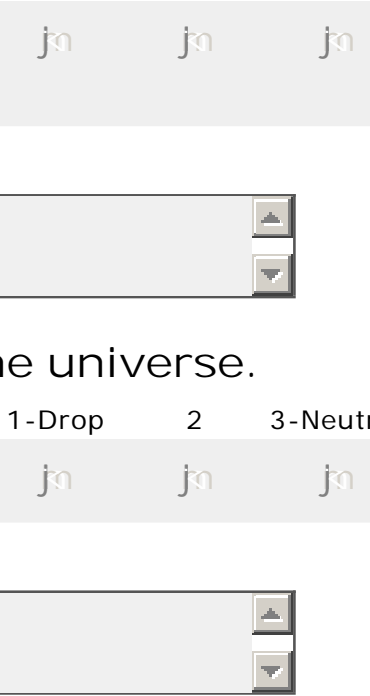

Suggestions for Improvement:

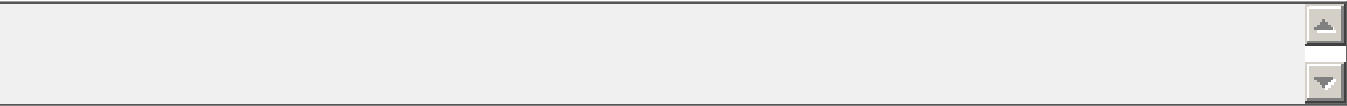

\section{The individual is a co-participator, co-controller, and co-creator of both} the self and the universe within which he exists.

a) Compare the relationships between man and the universe through

1-Drop
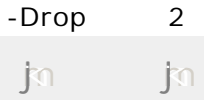

3-Neutral

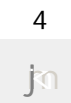

5-Keep

his play, games, dance, and sport.

$\bigcirc$

Suggestions for Improvement:

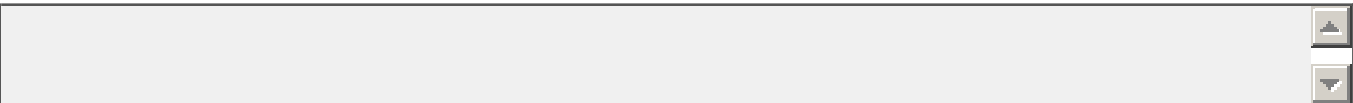




\section{Pilot Study}

23. Behaviors reflect philosophical attitudes. a) Identify several types of behaviors exhibited in play, games, dance,
and sport in Contemporary societies.
b) Identify the need for human individuality and worth in relation to
societal need and requirements as expressed in play, games, dance, and sport.

Suggestions for Improvement:






\section{Pilot Study}

\section{Section 3: Philosophy of Sport}

Completeness

24. Please list any additional competencies you deem relevant to the philosophy of sport in order to add to the completeness of the survey.

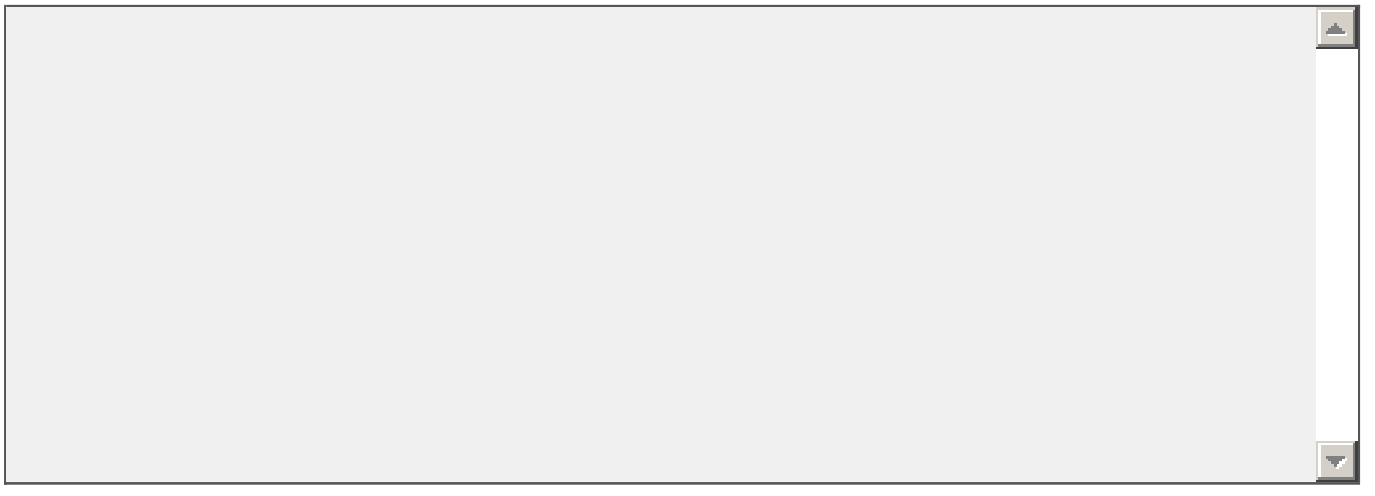




\section{Pilot Study}

\section{Section 4: Sociology of Sport}

\section{Play, games, dance, and sport are fundamental forms of human expression.}

a) Interpret modes of expression as they influence play, games,

dance, and sport.

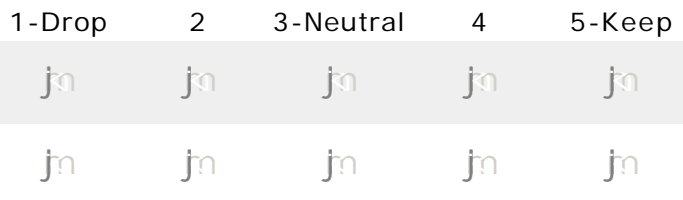

b) Distinguish and identify variations in modes of expression as they occur in play, games, dance, and sport.

Suggestions for Improvement:

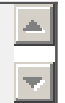

\section{Play, games, dance, and sport are elements of all cultures.}

a) Identify cultural elements.

b) Identify the nature of social institutions and the reciprocal influences of play, games, dance, and sport and other cultural

1-Drop elements, such as politics and economics.

c) Describe cultural influence upon developmental patterns of play, games, dance, and sport.

Suggestions for Improvement:
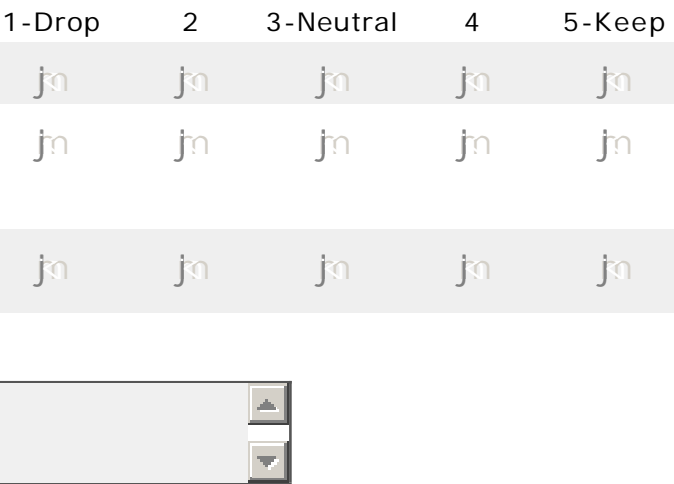

\section{Play, games, dance, and sport reflect society.}

a) Identify, describe, and interpret theories of play.

b) Identify, describe, and interpret theories of play as they are reflected in practice, in play, games, dance, and sport.

1-Drop


3-Neutral
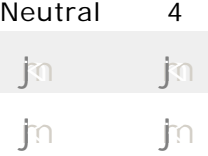

5-Keep

c) Identify work ethics and their influence on play, games, dance, and sport in America.
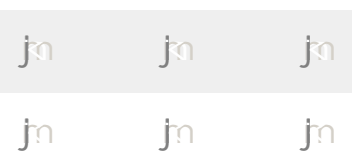

$\bigcirc$

d) Describe and interpret the influence of sub-cultures (ethnic, racial, socioeconomic, etc.) on play, games, dance, and sport.

Suggestions for Improvement: 


\section{Pilot Study}

28. Societal change may be brought about through play, games, dance, and sport.

a) Explain how social forces operate to bring about change.

b) Explain how play, games, dance, and sport may be utilized to facilitate change.

c) Predict the possible social change which may be brought about through play, games, dance, and sport.
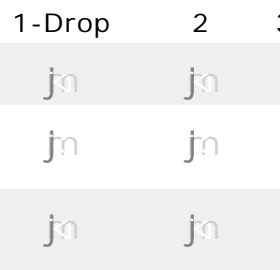

Suggestions for Improvement:
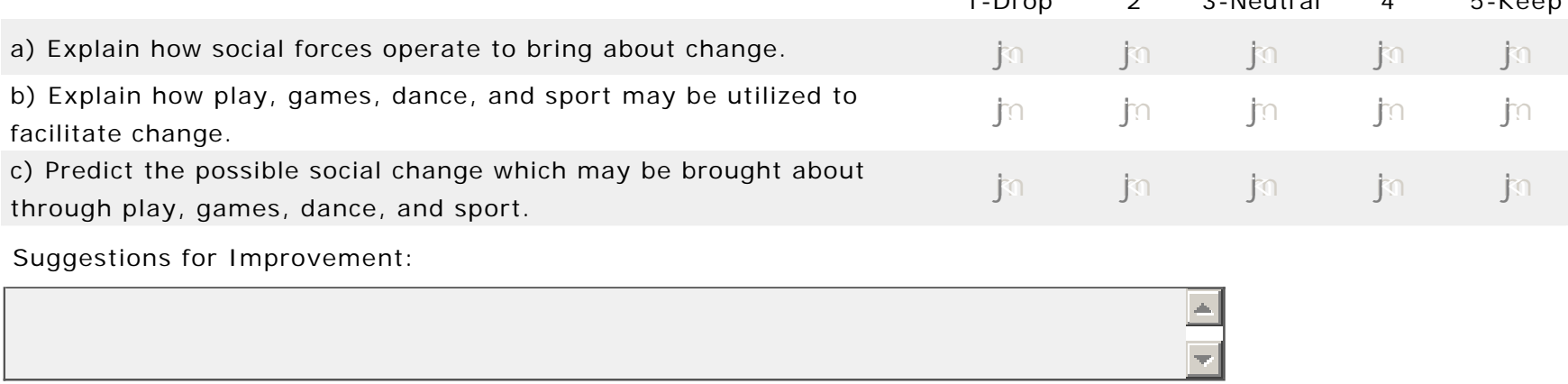


\section{Pilot Study}

\section{Section 4: Sociology of Sport}

\section{Cultural values are transmitted through play, games, dance, and sport.}

a) Identify, describe, and evaluate the role, background, and expectations of social behavior demonstrating values and ethics of 1-Drop
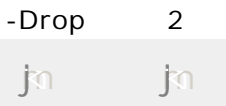
3-Neutral
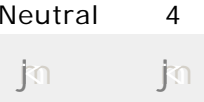

5-Keep society (e.g., sportsmanship, fair play, codes of etiquette).

Suggestions for Improvement:

30. Physical education is a medium for transmitting play, games, dance, and sport.

a) Identify current practices and trends in play, games, dance, and

1-Drop

sport.
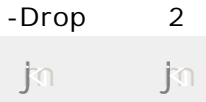

3-Neutra

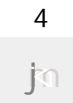

5-Keep

Suggestions for Improvement:

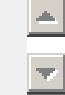

\section{Socialization takes place through play, games, dance, and sport.}

a) Identify the nature and interpret the role and importance of socialization.

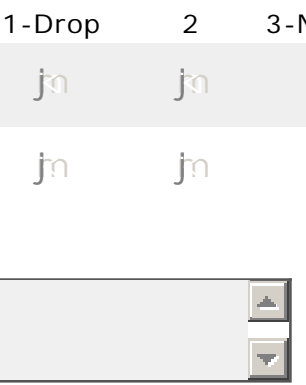

b) Describe how socialization takes place through play, games, dance, and sport.

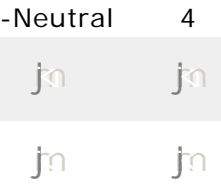

Suggestions for Improvement:

\begin{tabular}{lll}
2 & -10 \\
\hline
\end{tabular}

\section{Social values, practices, and attitudes are constantly changing.}

a) Identify recent findings in sociology and social psychology and relate these to play, games, dance, and sport.

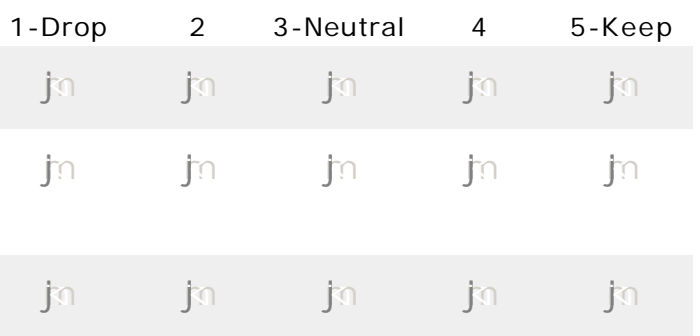
practices in play, games, dance, and sport settings.

Suggestions for Improvement: 


\section{Pilot Study}

33. Group movement experiences involve competitive and cooperative processes which may resolve or intensify social problems.

a) Identify and evaluate the problems which arise in cooperation and competition in group movement experiences.

1-Drop

$\bigcirc$

b) Demonstrate and evaluate various roles in group movement activities (e.g., facilitator, blocker, information source, recorder).

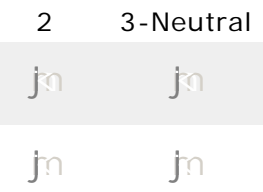

0 5-Keep

Suggestions for Improvement:






\section{Pilot Study}

\section{Section 4: Sociology of Sport}

Completeness

34. Please list any additional competencies you deem relevant to the sociology of sport in order to add to the completeness of the survey.

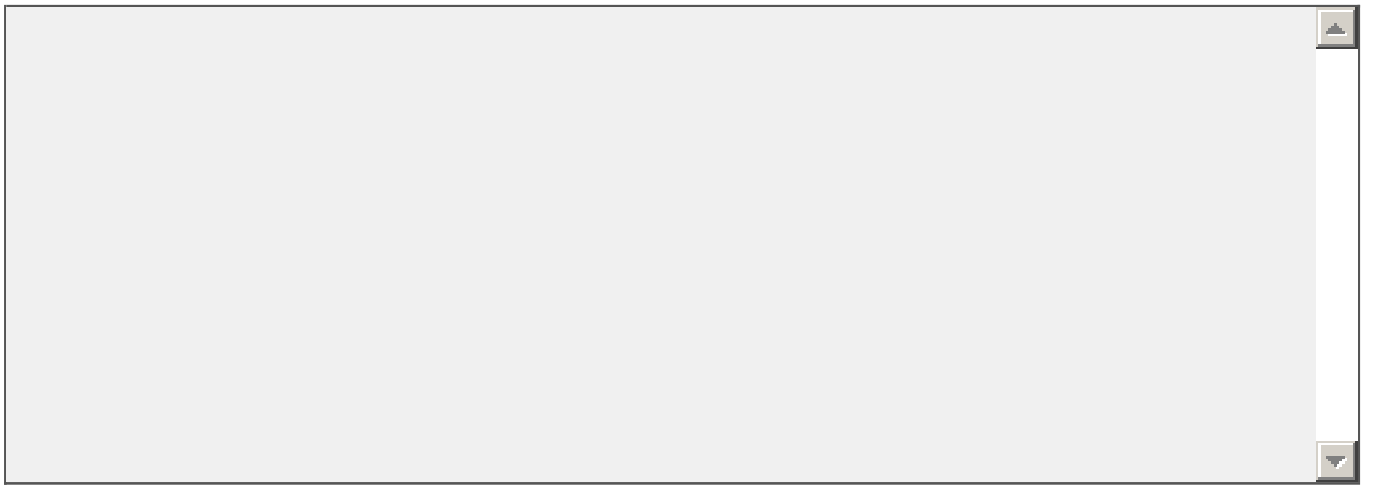




\section{Pilot Study}

\section{Section 5: Survey I nstrument's Overall Quality}

35. In your opinion, does the instrument (as amended) represent valid competencies for use in the physical education teacher education curriculum?

$\bigcirc$ Yes

$\bigcirc$ No

If No, please explain:

36. In your opinion, does the instrument (as amended) represent a comprehensive overview of the history, philosophy, and sociology of sport competencies that should be included in the physical education teacher education undergraduate program?

$\bigcirc$ Yes

$\bigcirc \mathrm{No}$

If No, please explain: 


\section{Pilot Study}

\section{Section 6: Use of SurveyMonkey}

Please answer the following questions in order to help aid in future rounds of the survey.

37. Do you feel SurveyMonkey is the best means of gathering data for this pilot study?

Yes

No

If No, please explain:

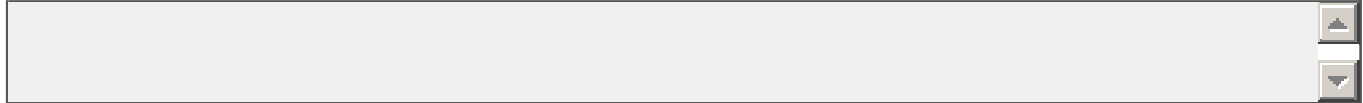

38. Did you experience any difficulties in using SurveyMonkey in taking the survey?

Yres

No

If Yes, please explain:

39. Were the instructions clear on how to use the online format?

Yes

No

If No, please explain:

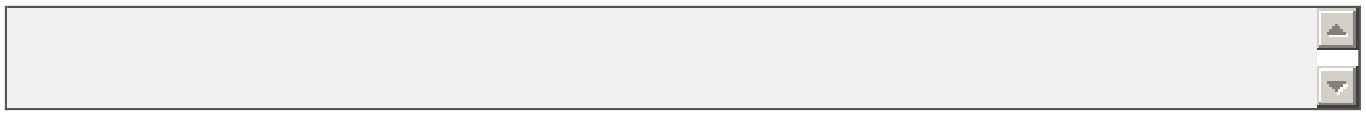

40. Please identify any improvements you view necessary for using this online format in future rounds, other than those mentioned in the space provided at the end of each section.

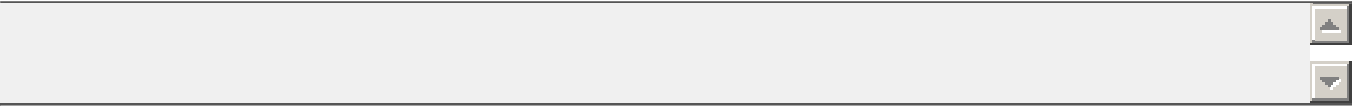

41. Would you have preferred a hard copy instead of utilizing the SurveyMonkey online format?

Yyes

No 


\section{Pilot Study}

Thank you for taking the survey, your input is greatly appreciated!

I will be in touch to let you know the results of the study once all surveys are complete and the data are analyzed.

You will know you are completely finished with the survey once you are redirected to my West Virginia University webpage. This will occur once you click the "Done" button below.

Amanda Metcalf

West Virginia University

Amanda.Metcalf@mail.wvu.edu

(304) 293- 0848 


\section{APPENDIX C}

History, Philosophy, and Sociology of Sport

Recommendations for Physical Education Teacher Education

Round I 


\section{E-mail for Round I Participant Recruitment}

Hello (insert name here),

I am writing to request your participation as an expert judge for my dissertation research project being conducted at West Virginia University, titled History, Philosophy, and Sociology of Sport Recommendations for Physical Education Teacher Education. You were selected to participate because of your high degree of expertise in the area of sport history.

For your contribution to this research study, I simply need you to critique the survey items using a rating scale (1-5) that will be used to justify the validity and completeness of each competency for future use in the physical education teacher education curriculum. The survey will involve two rounds and will be conducted using an online survey engine.

Would you be willing to participate in this study? Below is the tentative time line in order for you to determine if this study will fit into your schedule:

May 11, 2009 - Round 1 survey sent to participants (will have two weeks to complete) June 1, 2009 - Round 2 survey sent to participants (will have two weeks to complete) Once these data are analyzed, a copy of the completed survey will be sent to you. Also, should you decide to do so, your name will be included as part of the study as being an expert panel member. It is very important for you to be able to participate in both rounds of the survey in order to obtain group consensus.

Please feel free to contact me at (304) 293-0848 if you have any immediate questions regarding this e-mail. Please reply by Friday, May 1, 2009. Your prompt response is greatly appreciated!

Thank you for your consideration, I look forward to hearing from you soon!

Amanda Metcalf

Amanda Metcalf, M.A.

West Virginia University

College of Physical Activity \& Sport Sciences

P.O. Box 6116

Morgantown, WV 26506

(304) 293-0848 


\section{Phone Script for Round I Participant Recruitment}

"Hello, my name is Amanda Metcalf and I am calling to request your participation as an expert panel member for my dissertation research study titled History, Philosophy, and Sociology of Sport Recommendations for Physical Education Teacher Education. This research study will involve the administration of a Delphi procedure to determine the history, philosophy, and sociology of sport competencies that should be included in the physical education teacher education curriculum. For your contribution to this research study, I simply need you to critique the survey items using a rating scale that will be employed to justify the validity and completeness of each competency for future use in the physical education teacher education curriculum.

- You must be 18 years of age or older to participate.

- Your participation is entirely voluntary, you can choose to stop participation at any time and you do not have to answer any questions you do not want to answer.

- Your responses will be kept as confidential as legally possible. All data will be erased once my dissertation is complete. At no time will your name be revealed during reporting.

- Your job status will not be affected if you decide either not to participate or to withdraw.

- West Virginia's University's Institutional Review Board acknowledgement of this project is on file.

Would you be interested in participating as an expert for this pilot study?”

\section{YES/NO (IF “NO” GO TO 1 / IF “YES” GO TO 2)}

1. “Thank you for your time and consideration.”

2. "Thank you for agreeing to participate; your time and efforts are greatly appreciated. Next week I will e-mail more information in regard to your participation in this research study, as well as a link to the online survey instrument. Thank you for agreeing to participate. Your expert contribution is vital to the success of this research project.” 


\section{Delphi Round I}

\section{Survey I ntroduction}

Welcome and thank you for agreeing to participate as an expert panel member in this Modified Delphi investigation!

As a panel member, you are asked to rate a list of history, philosophy, and sociology of sport concepts in terms of their theoretical importance and pedagogical relevance for prospective physical educators. Your input regarding these competencies will have the potential to influence future curricular decision making in physical education teacher education. The survey will be used to generate consensus of expert opinion regarding the history, philosophy, and sociology of sport competencies prospective physical educators should "know" and be able to "do" as a result of the physical education teacher education curriculum. Your practical experience, insight, and judgment are vital to the success of this project.

The survey items were adapted directly from the National Association for Sport and Physical Education (NASPE, 2004) and the American Alliance for Health, Physical Education, Recreation, and Dance (AAHPER, 1974). Each are reproduced with the permission of the Sport Philosophy Academy within NASPE; as well as AAHPERD.

Please remember the final date for Round I survey completion is May $22 \mathrm{nd}$. Round II will be sent out once all results are tabulated. I greatly appreciate your assistance in the timely completion of this project.

Thank you for your time and input! Please feel free to call or e-mail me with any questions you may have.

Amanda Metcalf

West Virginia University

Amanda.Metcalf@mail.wvu.edu

(304) 293- 0848

* National Association for Sport and Physical Education. (2004). Minimum Competencies for Teaching Undergraduate Sport Philosophy Courses. Approved by the Sport Philosophy Academy and The National Association for Sport and Physical Education. Reston, VA.

*American Association for Health, Physical Education, and Recreation. (1974). Professional Preparation in Dance, Physical Education, Recreation Education, Safety Education, and School Health Education. AAHPER Publications-Sales: Washington, DC. 


\section{Delphi Round I}

\section{Survey I nstructions}

The following survey contains 30 concepts followed by key competencies you will need to judge in regard to their theoretical importance and pedagogical relevance in the physical education teacher education curriculum.

Please do the following:

1- Rate each of the questionnaire items separately in the areas of IMPORTANCE and RELEVANCE. For the purpose of this study, IMPORTANCE will refer to the item's value as a theoretical underpinning of the physical education profession. RELEVANCE will refer to the item's practical or applied value to the K-12 physical educator.

2- A rating of (5) or (4) in BOTH IMPORTANCE and RELEVANCE means that you consider the item to be essential in the preparation of prospective K- 12 physical education teachers.

3- A rating of (3) means you are neutral or undecided regarding the IMPORTANCE and RELEVANCE of the item.

4- A rating of (2) or (1) on EITHER IMPORTANCE or RELEVANCE means the item is not essential for the preparation of prospective K-12 physical education teachers.

5-If you choose not to respond to a particular item, please leave it blank.

A few reminders:

1-You must enter your name on the first page of the survey in order to continue. This is the only question you must answer.

2-You will not be allowed to go back into the survey once you have accessed the website link. Therefore, if you are reading this message you are committed to completing the survey at this time.

3-You may return to the instructions page at any time by using the "Prev" buttons at the bottom of the survey pages. There is complete freedom (once you have entered your name) to go to any page within the survey and change your responses if necessary.

4- A survey completion bar will be at the top of each page in order to show your progress through the survey. 


\section{Delphi Round I}

\section{Table of Contents}

Section 1: Participant Information (Question 1)

Section 2: History of Sport (Questions 2-6)

Section 3: Philosophy of Sport (Questions 7-22)

Section 4: Sociology of Sport (Questions 23-31) 


\section{Delphi Round I}

\section{Section 1: Participant I nformation}

* 1. Please enter your name:

Name: 


\section{Delphi Round I}

\section{Section 2: History of Sport}

2. The development of play, games, dance, sport, and physical education closely parallels the historical development of humankind.

mportance

Relevance

a) Identify and interpret the importance of historical influences.

b) Relate the events and ideas of the history of human movement to society.

c) Describe and interpret the development of play, games, dance, and sport in American and other cultures.
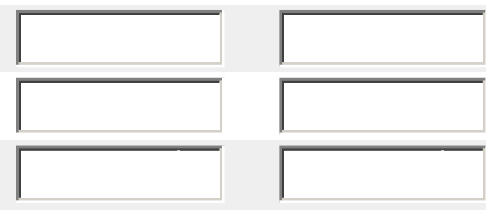

3. Understanding humankind's historical involvement with play, games, dance, and sport affords the individual dimensions for acquiring meaning and better understanding of humankind's past.

Importance

a) Describe \& interpret the development of significant forms of play, games, dance, and sport in past cultures.
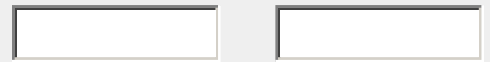

b) Identify the purposes that the various forms of play, games, dance, and sport served in past cultures.
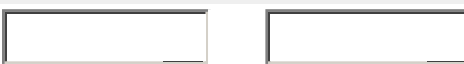

4. An understanding of contemporary forms of play, games, dance, and sport is influenced through knowledge of significant forms of human movement growing from past cultures.

a) Identify the social, political, economic, philosophical, and religious conditions in past cultures which have influenced forms and purposes of contemporary play, games, dance, and sport.

b) Relate past forms, purposes, and cultural conditions to those of present-day play, games, dance, and sport.

c) Identify significant persons, institutions, and events which contributed to the evolution of present-day play, games, dance, and sport.
Importance

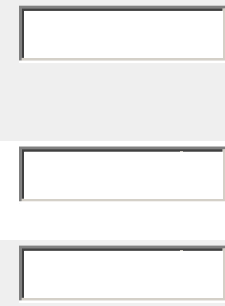
Relevance
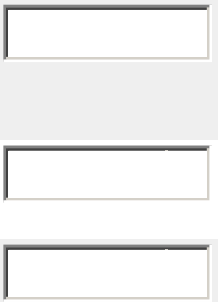

5. Play, games, dance, and sport have each had a historical development. Physical education has developed as a profession and is intimately related to the development of play, games, dance, and sport.

Describe \& interpret the relationship of the development of play, games, dance, and sport with that of physical education.

Importance

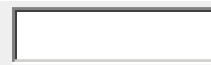

Relevance

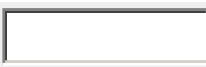

\section{Understanding the influence of human movement on historical societies.}

Understand the influence of human movement on the development of political, social, economic, and cultural patterns of historical societies.
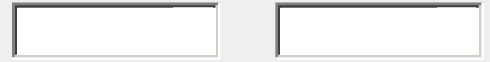


\section{Section 3: Philosophy of Sport}

\section{I dentifying the Nature of Philosophy and Sport Philosophy}

a) Understand philosophy as a formal field of study and understand the discipline of sport philosophy.

b) Understand how sport philosophy contributes to the practice of sport and physical education.

c) Understand the difference between philosophy and empiricism. Know that philosophy involves asking questions, posing challenges, and searching for deeper meanings of various issues, while empiricism involves the search for factual evidence that can be seen, heard, felt, measured, etc.

d) Understand that being a philosopher involves contemplating the differences between the "real world," where knowledge and truth rest in concrete material

Importance

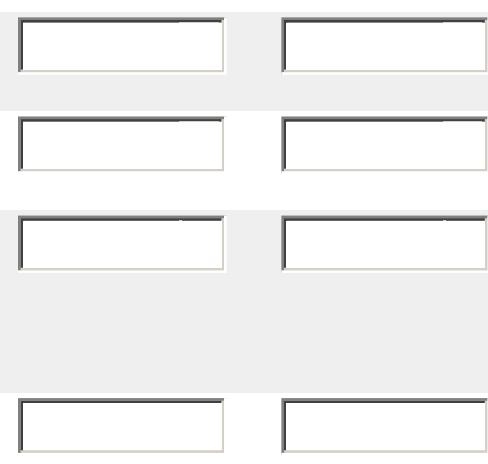
existence and the "ideal world," where knowledge and truth rest in what the mind and spirit perceive as real.

\section{Branches of Philosophy and Asking Philosophical Questions}

Importance

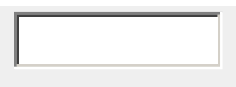

a) Understand the relationship between sport and physical education and the branches of philosophy, including metaphysics (focusing on questions about the nature of reality), epistemology (focusing on questions about what people know), and axiology (focusing on questions related to the value of things).

b) Understand the difference between a philosophical question and an empirical question, as well as understand that philosophical questions can be answered from a variety of disciplines/perspectives.

c) Be able to ask a variety of philosophical questions that span the branches of philosophy (i.e., metaphysical, axial, and epistemological).

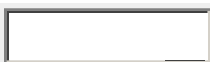

Relevance
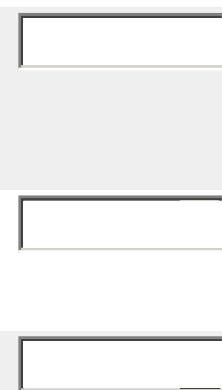

\section{Familiarity with a Variety of Philosophers of Science, Education, and Physical Education (past and present)}

Be familiar with the works of important philosophers of physical education, and understand how these works are significant to issues in sport and physical
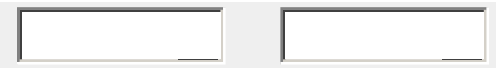
education?

\section{I dentifying the I mportance of Sport and Physical Education to the Educational Process}

a) Understand why physical education should be valued equally with other academic disciplines.

Importance

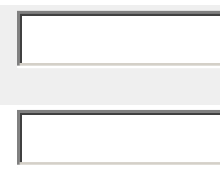

b) Be familiar with arguments for and against physical education as a valuable discipline and understand why sport and physical education can be viewed as playing an integral role in the educational process.

c) Be familiar with the history of sport and physical education as it relates to the changing values and philosophies in sport and physical education.

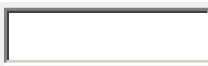

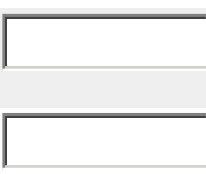

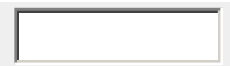




\section{Section 3: Philosophy of Sport}

\section{The Discipline of Physical Education: Understanding the Difference Between the Professional Discipline and the Academic Discipline}

a) Be familiar with the historical debate between the academic and professional disciplines of physical education (i.e., Is the purpose of the discipline of physical education to generate new "scientific" knowledge to advance the academic discipline or to generate "applied knowledge" to serve the public's need for school physical education and/or sport opportunities?).

b) Understand why physical education has been renamed with new identifiers such as exercise science, human movement, sport science, and kinesiology.

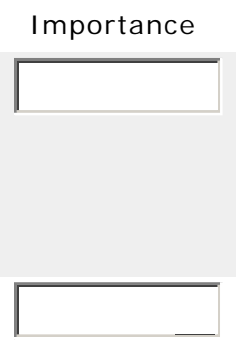

\section{Mind versus Body Argument}

a) Understand the "mind versus body" argument and how this argument is: (1) historically tied to the philosophies of sport and physical education endorsed by the Greeks and Ancient Romans (with a key focus on the philosophical thinking of Plato and Aristotle) and (2) significant to sport and physical education in that modern day practices often extend from dualistic and holistic thinking about the mind and body.

b) Understand the various ways in which our society thinks from a dualistic perspective (e.g., viewing sports competition as part mental and part physical; measuring physical fitness solely in terms of the components of fitness represent dualistic ways of thinking about the mind and body).

c) Develop a familiarity with various types of dualistic and holistic arguments, such as whether the body can be trained and/or educated without impacting the mind and vice- versa. Another example is how a holistic argument of education can be used to establish a place for school physical education.

\section{I dentifying Games and Play and its Significance to Society}

a) Understand the philosophical difference between games and play.

b) Understand the cultural significance of games and play and understand how games and play fit within the framework of physical education, sport, and lifespan physical activity.

c) Understand games and play as they relate to designing physical education and sport opportunities for individuals at different developmental times and places (e.g., elementary school physical education vs. youth sport, vs. collegiate sport, vs. adult recreational sport).

\section{The Role of Society in Sport}

Importance
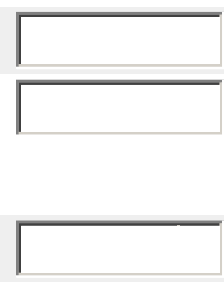



Relevance
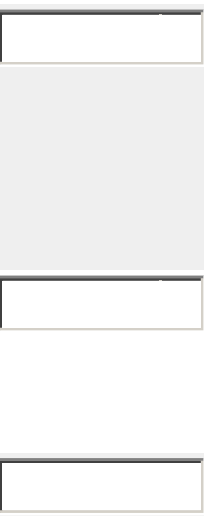


\section{Section 3: Philosophy of Sport}

\section{I dentifying the Difference Between Intrinsic and Extrinsic Values}

a) Understand that people value participation in physical education and sport for intrinsic \& extrinsic reasons. These reasons may be intrinsically driven (e.g., "I participate in sport because it makes me feel good" or "I participate because I enjoy being outside") or externally driven (e.g., "I participate because I like to win" or "I participate to burn calories or lose weight").

b) Understand the difference between intrinsic and extrinsic values in sport and physical education and know how physical education and sport contribute to the "good life" of its participants in multiple, yet highly personal ways.

c) Understand how helping students and athletes recognize the intrinsic and/or extrinsic value of participation is important to the promotion and enjoyment of physical education and sport.

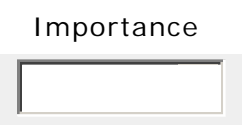

\section{Ethical Aspects of Sport}

a) Understand ethics and ethical theories such as paternalism, teleological ethics, and deontological ethics.

b) Be familiar with a variety of ethical issues in sport and physical education (e.g., intimidation, illicit performance enhancing drugs, commercialization in college athletics, burnout and dropout, sportsmanship, and gender equity).

\section{General Skills As a Result of Knowledge}


a) Ability to read and comprehend philosophical writings.

b) Ability to critically and philosophically examine significant issues in sport and physical education.

c) Ability to cogently argue (verbal and written) for or against a variety of issues in sport and physical education.

d) Ability to offer new viewpoints on competitive and/or educational practices in sport and physical education in order to ultimately improve practices in sport and physical education.

e) Ability to rationalize and defend physical education as having equal value with other academic disciplines and as being integral to the general educational process.

f) Ability to make sound ethical decisions relative to educational and sport processes and practices.

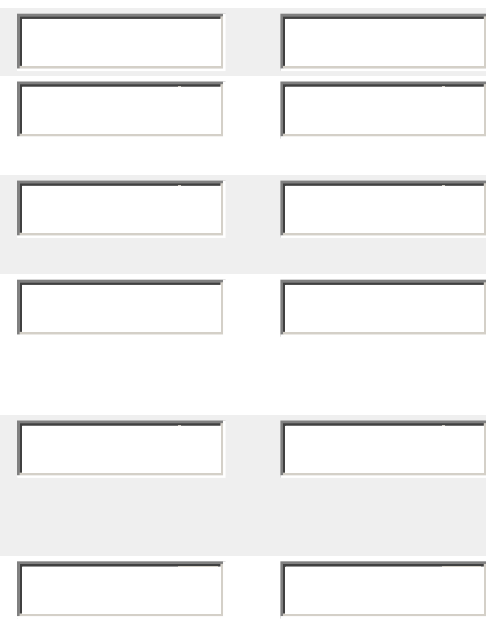

\section{Human movement has meaning which may be examined through philosophic inquiry.}

a) Identify philosophic systems of thought and their relationship to human movement.

b) Describe the processes of inquiry and apply to human movement.

c) Formulate a personal philosophy of human movement.
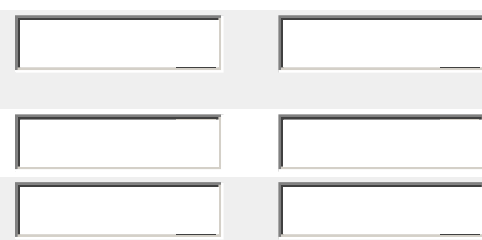


\section{Delphi Round I}

\section{Section 3: Philosophy of Sport}

19. Play, games, dance, and sport afford opportunities for individuals to inquire and discover their own nature.

Importance

Relevance

I dentify ways that individuals realize and express individuality and uniqueness

through play, games, dance, and sport.


20. Play, games, dance, and sport afford opportunity for individuals to inquire into and discover the nature of the relationship between themselves and others.

Importance

Relevance

I dentify one's human condition which makes him/her similar to other individuals,

leading to the development of a rationale for interdependence.
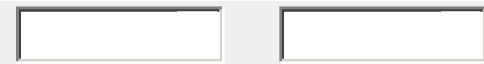

\section{Human movement reflects the nature of the universe.}

Identify and discuss the theories concerning the nature of the universe as they relate to play, games, dance, and sport.

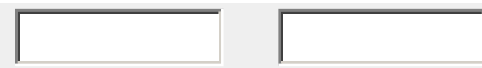

22. The individual is a co-participator, co-controller, and co-creator of both the self and the universe within which he exists.

Importance

Compare the relationships between man and the universe through his play,

games, dance, and sport.
Relevance

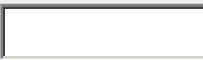

\section{Behaviors reflect philosophical attitudes.}

a) Identify several types of behaviors exhibited in play, games, dance, and sport in Contemporary societies.



b) Identify the need for human individuality and worth in relation to societal need and requirements as expressed in play, games, dance, and sport. 


\section{Delphi Round I}

\section{Section 4: Sociology of Sport}

\section{Play, games, dance, and sport are fundamental forms of human expression.}

Importance

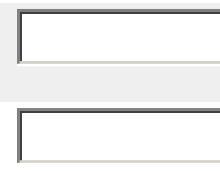

Relevance

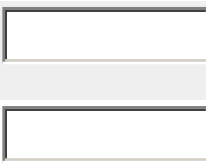

a) Interpret modes of expression as they influence play, games, dance, and sport.

b) Distinguish and identify variations in modes of expression as they occur in play, games, dance, and sport.

\section{Play, games, dance, and sport are elements of all cultures.}

Importance

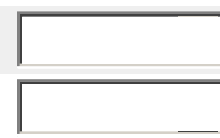

b) Identify the nature of social institutions and the reciprocal influences of play, games, dance, and sport and other cultural elements, such as politics and economics.

c) Describe cultural influence upon developmental patterns of play, games, dance, and sport.

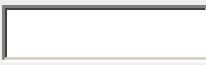

Relevance
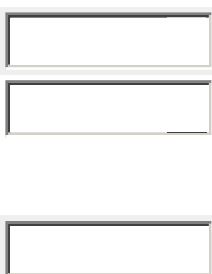

\section{Play, games, dance, and sport reflect society.}

a) Identify, describe, and interpret theories of play.

b) Identify, describe, and interpret theories of play as they are reflected in practice, in play, games, dance, and sport.

c) Identify work ethics and their influence on play, games, dance, and sport in America.
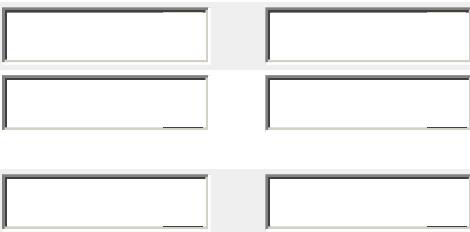

d) Describe and interpret the influence of sub-cultures (ethnic, racial, socioeconomic, etc.) on play, games, dance, and sport.
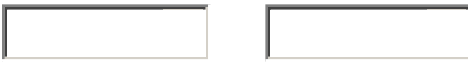

\section{Social change may be brought about through play, games, dance, and sport.}

a) Explain how social forces operate to bring about change.

b) Explain how play, games, dance, and sport may be utilized to facilitate change.

c) Predict the possible social change which may be brought about through play, games, dance, and sport.
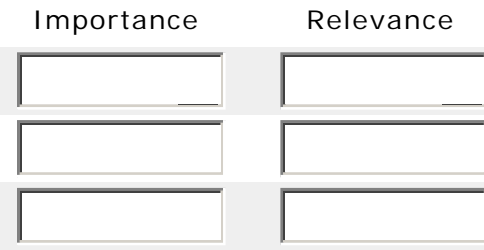


\section{Delphi Round I}

\section{Section 4: Sociology of Sport}

\section{Cultural values are transmitted through play, games, dance, and sport.}

\footnotetext{
a) Describe \& interpret how social behavior demonstrates the values and ethics in sport and society.

b) Identify responsibility as it relates to individual actions, opinions, and outcomes when engaging in sports.
}

Importance

Relevance
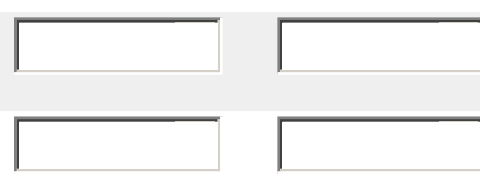

29. Physical education is a medium for transmitting play, games, dance, and sport.

mportance

Relevance

Identify current practices and trends in play, games, dance, and sport.

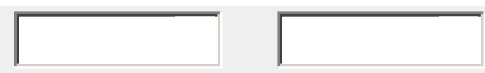

\section{Socialization takes place through play, games, dance, and sport.}
a) Identify the nature and interpret the role and importance of socialization.
b) Describe how socialization takes place through play, games, dance, and sport.



\section{Social values, practices, and attitudes are constantly changing.}

a) Identify recent findings in sociology and social psychology and relate these to play, games, dance, and sport.

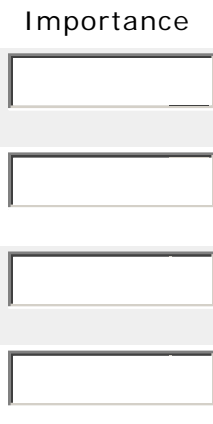

b) Describe and interpret the process by which social attitudes are changed and relate these processes in play, games, dance, and sport settings.

c) Identify and interpret changing social practices as these affect practices in play, games, dance, and sport settings.

d) Describe and interpret the sociological trinity (the way sport interfaces with race ethnicity, gender, and class).

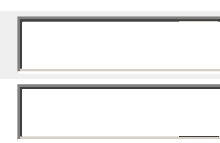

\section{Group movement experiences involve competitive and cooperative processes which may resolve or intensify social problems.}

Importance
a) Identify and evaluate the problems which arise in cooperation and competition in group movement experiences.
b) Demonstrate and evaluate various roles in group movement activities (e.g., facilitator, blocker, information source, recorder).

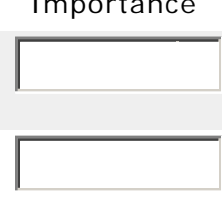






\section{Delphi Round I}

Thank you for taking the survey, your input is greatly appreciated!

Once all Round I surveys have been completed and analyzed I will e-mail you the website link to Round II of the study. I anticipate this taking place on or around June 1st.

You will know you are completely finished with the survey once you are redirected to my West Virginia University webpage. This will occur once you click the "Done" button below.

Amanda Metcalf

West Virginia University

Amanda.Metcalf@mail.wvu.edu

(304) 293- 0848 


\section{APPENDIX D \\ History, Philosophy, and Sociology of Sport \\ Recommendations for Physical Education Teacher Education}

Round II 


\section{Round II E-mail}

Hello (insert name here),

Welcome to the final round of this modified Delphi investigation!

I have attached a document that includes both your individual rating (IR) and the group mean rating (GR) for each survey item. Please use this document when making your selection for this final round. Feel free to either select your Round I score or make a different selection based on the group mean.

In order for the item to be kept and group consensus achieved, the following criteria must be met: (a) The item needs to receive a mean rating of at least four or higher in the areas of importance AND relevance; and (b) the item needs to receive at least $75 \%$ of all individual ratings at the four level or higher.

The following hyperlink will take you to Round II of the survey:

http://www.surveymonkey.com/s.aspx?sm=QR4OuN5Vnanv_2fiVbx1wnEA_3d_3d

If possible, please complete the online survey prior to midnight on Monday, June 22nd.

Thank you once again for your assistance!

Amanda

Amanda Metcalf, M.A.

West Virginia University

College of Physical Activity \& Sport Sciences

P.O. Box 6116

Morgantown, WV 26506

(304) 293-0848 
History, Philosophy, and Sociology of Sport Recommendations for Physical Education Teacher Education Round II

*Below you will find your individual rating (IR) and the average group rating (GR) from the previous round of investigation.

Please use this information in making your selection on SurveyMonkey.

*Please keep in mind the following definitions of importance and relevance as they relate to this study:

IMPORTANCE - ITEM SHOULD BE UNDERSTOOD BY ALL PROSPECTIVE K-12 PHYSICAL EDUCATION TEACHERS. RELEVANCE - ITEM IS APPLICABLE TO THE INSTRUCTION OF PHYSICAL EDUCATION IN A K-12 SETTING.

\begin{tabular}{l|c|c|}
\hline \multicolumn{1}{c|}{ Concepts \& Competencies } & Importance & Relevance \\
\hline Section 1: History of Sport & IR & GR \\
\hline $\begin{array}{l}\text { IR } \\
\text { 1. The development of play, games, dance, sport, and physical education closely parallels } \\
\text { the historical development of humankind. }\end{array}$ & 3 & 3.88 \\
\hline $\begin{array}{l}\text { a. Identify and interpret the importance of historical influences. } \\
\text { b. Relate the events and ideas of the history of human movement to society. } \\
\text { c. Describe and interpret the development of play, games, dance, and sport in } \\
\text { American and other cultures. }\end{array}$ & 3 & 3.64 \\
\hline $\begin{array}{l}\text { 2. Understanding humankind's historical involvement with play, games, dance, and sport affords } \\
\text { the individual dimensions for acquiring meaning and better understanding of humankind's past. }\end{array}$ & 2 \\
\hline $\begin{array}{l}\text { a. Describe and interpret the development of significant forms of play, games, } \\
\text { dance, and sport served in past cultures. }\end{array}$ & 5.04 \\
$\begin{array}{l}\text { b. Identify the purposes that the various forms of play, games, dance, and sport } \\
\text { served in past cultures. }\end{array}$ & 2.60 \\
\hline $\begin{array}{l}\text { 3. An understanding of contemporary forms of play, games, dance, and sport is influenced } \\
\text { through } \text { knowledge of significant forms of human movement growing from past cultures. }\end{array}$ & 3.48 \\
\hline $\begin{array}{l}\text { a. Identify the social, political, economic, philosophical, and religious conditions } \\
\text { in past cultures which have influences forms and purposes of contemporary } \\
\text { play, games, dance, and sport. }\end{array}$ & 3.76 \\
\hline
\end{tabular}




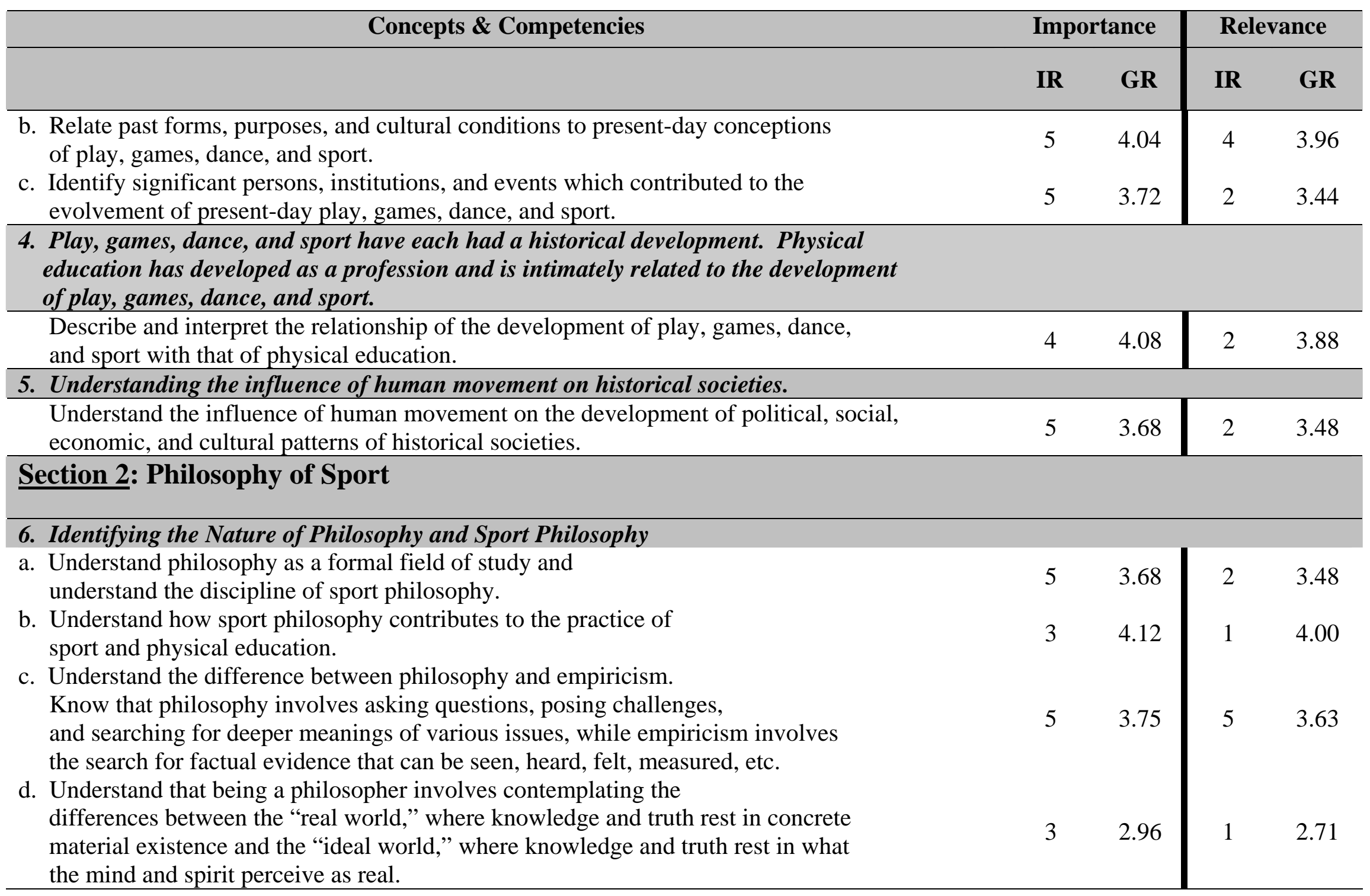




\begin{tabular}{|c|c|c|c|c|}
\hline \multirow[t]{2}{*}{ Concepts \& Competencies } & \multicolumn{2}{|c|}{ Importance } & \multicolumn{2}{|c|}{ Relevance } \\
\hline & IR & GR & IR & GR \\
\hline \multicolumn{5}{|l|}{ 7. Branches of Philosophy and Asking Philosophical Questions } \\
\hline $\begin{array}{l}\text { a. Understand the relationship between sport and physical education } \\
\text { and the branches of philosophy, including metaphysics (focusing on questions } \\
\text { about the nature of reality), epistemology (focusing on questions about what } \\
\text { people know), and axiology (focusing on questions related to the value of things). }\end{array}$ & 3 & 3.21 & 1 & 2.96 \\
\hline $\begin{array}{l}\text { b. Understand the difference between a philosophical question and } \\
\text { an empirical question and should understand that philosophical questions can be } \\
\text { answered from a variety of disciplines/perspectives. }\end{array}$ & 5 & 3.75 & 5 & 3.63 \\
\hline $\begin{array}{l}\text { c. Be able to ask a variety of philosophical questions that span the } \\
\text { branches of philosophy (i.e., metaphysical, axial, and epistemological). }\end{array}$ & 4 & 3.59 & 3 & 3.17 \\
\hline \multicolumn{5}{|l|}{$\begin{array}{l}\text { 8. Familiarity with a Variety of Philosophers of Science, Education, and Physical Education } \\
\text { (past and present) }\end{array}$} \\
\hline $\begin{array}{l}\text { Be familiar with philosophers of science, education, and physical education. } \\
\text { Students should also understand how the works of these philosophers are significant } \\
\text { to issues in sport and physical education. }\end{array}$ & 5 & 3.88 & 4 & 3.80 \\
\hline \multicolumn{5}{|l|}{ 9. Identifying the Importance of Sport and Physical Education to the Educational Process } \\
\hline $\begin{array}{l}\text { a. Understand of why physical education should be valued equally with other academic } \\
\text { disciplines. }\end{array}$ & 5 & 4.84 & 5 & 4.80 \\
\hline $\begin{array}{l}\text { b. Be familiar with arguments for and against physical education as a valuable discipline } \\
\text { and understand why sport and physical education can be viewed as playing an } \\
\text { integral role in the educational process. }\end{array}$ & 5 & 4.92 & 5 & 4.88 \\
\hline $\begin{array}{l}\text { c. Be familiar with the history of sport and physical education as it relates to the changing } \\
\text { values and philosophies in sport and physical education. }\end{array}$ & 5 & 4.2 & 4 & 4.04 \\
\hline
\end{tabular}




\begin{tabular}{|c|c|c|c|c|}
\hline \multirow[t]{2}{*}{ Concepts \& Competencies } & \multicolumn{2}{|c|}{ Importance } & \multicolumn{2}{|c|}{ Relevance } \\
\hline & IR & GR & IR & GR \\
\hline \multicolumn{5}{|l|}{$\begin{array}{l}\text { 10. The Discipline of Physical Education: Understanding the Difference Between the Professional } \\
\text { Discipline and the Academic Discipline }\end{array}$} \\
\hline $\begin{array}{l}\text { a. Be familiar with the historical debate between the academic and professional disciplines } \\
\text { of physical education (i.e., Is the purpose of the discipline of physical education to generate } \\
\text { new "scientific" knowledge to advance the academic discipline or to generate "applied } \\
\text { knowledge" to serve the public's need for school physical education and/or sport } \\
\text { opportunities?). }\end{array}$ & 5 & 4.12 & 5 & 3.88 \\
\hline $\begin{array}{l}\text { b. Understand why physical education has been renamed with new } \\
\text { identifiers such as exercise science, human movement, sport science, and kinesiology. }\end{array}$ & 5 & 4.24 & 5 & 3.96 \\
\hline \multicolumn{5}{|l|}{ 11. Mind versus Body Argument } \\
\hline $\begin{array}{l}\text { a. Understand the "mind versus body" argument and how this argument is: } \\
\text { (1) historically tied to the philosophies of sport and physical education endorsed by the } \\
\text { Greeks and Ancient Romans (with a key focus on the philosophical thinking of Plato } \\
\text { and Aristotle) and (2) significant to sport and physical education in that modern day } \\
\text { practices often extend from dualistic and holistic thinking about the mind and body. }\end{array}$ & 5 & 4.04 & 5 & 3.92 \\
\hline $\begin{array}{l}\text { b. Understand the various ways in which our society thinks from a dualistic perspective } \\
\text { (e.g., viewing sports competition as part mental and part physical; measuring physical } \\
\text { fitness solely in terms of the components of fitness represent dualistic ways of thinking } \\
\text { about the mind and body). }\end{array}$ & 5 & 4.00 & 5 & 4.00 \\
\hline $\begin{array}{l}\text { c. Develop a familiarity with various types of dualistic and holistic arguments, such as } \\
\text { whether the body can be trained and/or educated without impacting the mind and } \\
\text { vice- versa. Another example is how a holistic argument of education can be used to } \\
\text { establish a place for school physical education. }\end{array}$ & 5 & 3.92 & 5 & 3.88 \\
\hline
\end{tabular}




\begin{tabular}{|c|c|c|c|c|}
\hline \multirow[t]{2}{*}{ Concepts \& Competencies } & \multicolumn{2}{|c|}{ Importance } & \multicolumn{2}{|c|}{ Relevance } \\
\hline & IR & GR & IR & GR \\
\hline \multicolumn{5}{|l|}{ 12. Identifying Games and Play and its Significance to Society } \\
\hline $\begin{array}{l}\text { a. Understand the philosophical difference between games and play. } \\
\text { b. Understand the cultural significance of games and plav and understand how games }\end{array}$ & 5 & 3.88 & 5 & 3.80 \\
\hline $\begin{array}{l}\text { and play fit within the framework of physical education, sport, and lifespan physical } \\
\text { activity. }\end{array}$ & 5 & 4.32 & 5 & 4.28 \\
\hline $\begin{array}{l}\text { c. Understand games and play as they relate to designing physical education and sport } \\
\text { opportunities for individuals at different developmental times and places } \\
\text { (e.g., elementary school physical education vs. youth sport, vs. collegiate sport, vs. } \\
\text { adult recreational sport). }\end{array}$ & 5 & 4.48 & 5 & 4.40 \\
\hline \multicolumn{5}{|l|}{ 13. The Role of Society in Sport } \\
\hline $\begin{array}{l}\text { a. Understand the importance of considering societal values in relationship to their } \\
\text { philosophical thinking. }\end{array}$ & 4 & 3.96 & 2 & 3.79 \\
\hline $\begin{array}{l}\text { b. Understand how societal values can affect the practice of sport and physical education } \\
\text { (e.g., the win-at-all cost model that is frequently used in sport or the strong emphasis } \\
\text { that is placed on science in physical education). }\end{array}$ & 5 & 4.54 & 5 & 4.54 \\
\hline \multicolumn{5}{|l|}{ 14. Identifying the Difference Between Intrinsic and Extrinsic Values } \\
\hline $\begin{array}{l}\text { a. Understand that people value participation in physical education and sport for } \\
\text { different reasons. These reasons may be intrinsically driven (e.g., "I participate in } \\
\text { sport because it makes me feel good" or "I participate because I enjoy being outside”) } \\
\text { or externally driven (e.g., "I participate because I like to win” or "I participate to burn } \\
\text { calories or lose weight”). }\end{array}$ & 5 & 4.48 & 4 & 4.40 \\
\hline $\begin{array}{l}\text { b. Understand the difference between intrinsic and extrinsic values in sport and } \\
\text { physical education and know how physical education and sport contribute to the } \\
\text { "good life" of its participants in multiple, yet highly personal ways. }\end{array}$ & 5 & 4.64 & 5 & 4.60 \\
\hline $\begin{array}{l}\text { c. Understand how helping students and athletes recognize the intrinsic and/or extrinsic } \\
\text { value of participation is important to the promotion and enjoyment of physical } \\
\text { education and sport. }\end{array}$ & 5 & 4.40 & 4 & 4.36 \\
\hline
\end{tabular}




\begin{tabular}{|c|c|c|c|c|}
\hline \multirow[t]{2}{*}{ Concepts \& Competencies } & \multicolumn{2}{|c|}{ Importance } & \multicolumn{2}{|c|}{ Relevance } \\
\hline & IR & GR & IR & GR \\
\hline \multicolumn{5}{|l|}{ 15. Ethical Aspects of Sport } \\
\hline $\begin{array}{l}\text { a. Understand ethics and ethical theories such as universality, paternalism, } \\
\text { teleological ethics, and deontological ethics. }\end{array}$ & 5 & 3.50 & 4 & 3.38 \\
\hline $\begin{array}{l}\text { b. Be familiar with a variety of ethical issues in sport (e.g., intimidation, illicit } \\
\text { performance enhancing drugs, commercialization in college athletics, burnout } \\
\text { and dropout, sportsmanship, and gender equity). }\end{array}$ & 5 & 4.33 & 5 & 4.33 \\
\hline \multicolumn{5}{|l|}{ 16. General Skills As a Result of Knowledge } \\
\hline a. Ability to read and comprehend philosophical writings. & 5 & 3.50 & 2 & 3.29 \\
\hline $\begin{array}{l}\text { b. Ability to critically and philosophically examine significant issues in sport and } \\
\text { physical education. }\end{array}$ & 5 & 4.36 & 5 & 4.28 \\
\hline $\begin{array}{l}\text { c. Ability to cogently argue (verbal and written) for or against a variety of issues in } \\
\text { sport and physical education. }\end{array}$ & 5 & 4.08 & 5 & 4.04 \\
\hline $\begin{array}{l}\text { d. Ability to offer new viewpoints on competitive and/or educational practices in sport } \\
\text { and physical education in order to ultimately improve practices in sport and physical } \\
\text { education. }\end{array}$ & 5 & 4.24 & 5 & 4.24 \\
\hline $\begin{array}{l}\text { e. Ability to rationalize and defend physical education as having equal value with other } \\
\text { academic disciplines and as being integral to the general educational process. }\end{array}$ & 5 & 4.84 & 5 & 4.76 \\
\hline $\begin{array}{l}\text { f. Ability to make sound ethical decisions relative to educational and sport processes } \\
\text { and practices. }\end{array}$ & 5 & 4.56 & 5 & 4.60 \\
\hline \multicolumn{5}{|l|}{ 17. Human movement has meaning which may be examined through philosophic inquiry. } \\
\hline a. Identify philosophic systems of thought and their relationship to human movement. & 4 & 3.40 & 2 & 3.20 \\
\hline b. Describe the processes of inquiry and apply to human movement. & 4 & 3.52 & 2 & 3.32 \\
\hline c Formulate a personal philosophy of human movement. & 3 & 3.92 & 3 & 3.88 \\
\hline \multicolumn{5}{|l|}{$\begin{array}{l}\text { 18. Play, games, dance, and sport afford opportunity for humankind to inquire and discover } \\
\text { his/her own nature. }\end{array}$} \\
\hline $\begin{array}{l}\text { Identify ways that persons realize and express individuality and uniqueness through } \\
\text { play, games, dance, and sport. }\end{array}$ & 5 & 4.16 & 4 & 4.08 \\
\hline
\end{tabular}




\begin{tabular}{|c|c|c|c|c|}
\hline \multirow[t]{2}{*}{ Concepts \& Competencies } & \multicolumn{2}{|c|}{ Importance } & \multicolumn{2}{|c|}{ Relevance } \\
\hline & IR & GR & IR & GR \\
\hline \multicolumn{5}{|l|}{$\begin{array}{l}\text { 19. Play, games, dance, and sport afford opportunity for man to inquire into and discover } \\
\text { the nature of the relationship between himself and others. }\end{array}$} \\
\hline $\begin{array}{l}\text { Identify one's human condition which makes him/her similar to other human beings, } \\
\text { leading to the development of a rationale for interdependence. }\end{array}$ & 3 & 3.60 & 3 & 3.60 \\
\hline \multicolumn{5}{|l|}{ 20. Human movement reflects the nature of the universe. } \\
\hline $\begin{array}{l}\text { Identify and discuss the theories concerning the nature of the universe as they relate } \\
\text { to play, games, dance, and sport. }\end{array}$ & 3 & 2.75 & 3 & 2.54 \\
\hline \multicolumn{5}{|l|}{$\begin{array}{l}\text { 21. The individual is a co-participator, co-controller, and co-creator of both the self and the } \\
\text { universe within which he exists. }\end{array}$} \\
\hline $\begin{array}{l}\text { Compare the relationships between man and the universe through his play, games, } \\
\text { dance, and sport. }\end{array}$ & 3 & 3.08 & 3 & 2.92 \\
\hline \multicolumn{5}{|l|}{ 22. Behaviors reflect philosophical attitudes. } \\
\hline $\begin{array}{l}\text { a. Identify several types of behaviors exhibited in play, games, dance, and sport in } \\
\text { contemporary societies. }\end{array}$ & 5 & 3.72 & 3 & 3.56 \\
\hline $\begin{array}{l}\text { b. Identify the need for human individuality and worth in relation to societal need } \\
\text { and requirements as expressed in play, games, dance, and sport. }\end{array}$ & 3 & 3.76 & 3 & 3.76 \\
\hline \multicolumn{5}{|l|}{ Section 3: Sociology of Sport } \\
\hline \multicolumn{5}{|l|}{ 23. Play, games, dance, and sport are fundamental forms of human expression. } \\
\hline \multirow{2}{*}{$\begin{array}{l}\text { a. Interpret modes of expression as they influence play, games, dance, and sport. } \\
\text { b. Distinguish and identify variations in modes of expression as they occur in } \\
\text { play, games, dance, and sport. }\end{array}$} & 5 & 3.32 & 5 & 3.28 \\
\hline & 5 & 3.36 & 5 & 3.28 \\
\hline \multicolumn{5}{|l|}{ 24. Play, games, dance, and sport are elements of all cultures. } \\
\hline a. Identify cultural elements. & 5 & 3.84 & 2 & 3.84 \\
\hline $\begin{array}{l}\text { b. Identify the nature of social institutions and the reciprocal influences of play, } \\
\text { games, dance, and sport and other cultural elements, such as politics and economics. }\end{array}$ & 5 & 3.64 & 2 & 3.60 \\
\hline $\begin{array}{l}\text { c. Describe cultural influence upon developmental patterns of play, games, dance, } \\
\text { and sport. }\end{array}$ & 5 & 4.40 & 2 & 4.24 \\
\hline
\end{tabular}




\begin{tabular}{|c|c|c|c|c|}
\hline \multirow[t]{2}{*}{ Concepts \& Competencies } & \multicolumn{2}{|c|}{ Importance } & \multicolumn{2}{|c|}{ Relevance } \\
\hline & IR & GR & IR & GR \\
\hline \multicolumn{5}{|l|}{ 25. Play, games, dance, and sport reflect society. } \\
\hline a. Identify, describe, and interpret theories of play. & 5 & 3.48 & 2 & 3.24 \\
\hline $\begin{array}{l}\text { b. Identify, describe, and interpret theories of play as they are reflected in practice, } \\
\text { in play, games, dance, and sport. }\end{array}$ & 5 & 3.68 & 4 & 3.58 \\
\hline $\begin{array}{l}\text { c. Identify work ethics and their influence on play, games, dance, and sport in } \\
\text { America. }\end{array}$ & 4 & 3.64 & 4 & 3.64 \\
\hline $\begin{array}{l}\text { d. Describe and interpret the influence of sub-cultures (ethnic, racial, } \\
\text { socioeconomic, etc.) on play, games, dance, and sport. }\end{array}$ & 5 & 4.32 & 5 & 4.32 \\
\hline \multicolumn{5}{|l|}{ 26. Societal change may be brought about through play, games, dance, and sport. } \\
\hline a. Explain how social forces operate to bring about change. & 5 & 3.92 & 4 & 3.80 \\
\hline b. Explain how play, games, dance, and sport may be utilized to facilitate change. & 4 & 3.96 & 4 & 3.92 \\
\hline $\begin{array}{l}\text { c. Predict the possible social change which may be brought about through play, } \\
\text { games, dance, and sport. }\end{array}$ & 5 & 3.72 & 4 & 3.60 \\
\hline \multicolumn{5}{|l|}{ 27. Cultural values are transmitted through play, games, dance, and sport. } \\
\hline $\begin{array}{l}\text { a. Describe \& interpret how social behavior demonstrates the values and ethics } \\
\text { in sport and society. }\end{array}$ & 5 & 3.80 & 2 & 3.72 \\
\hline $\begin{array}{l}\text { b. Identify responsibility as it relates to individual actions, opinions, and outcomes } \\
\text { when engaging in sports. }\end{array}$ & 5 & 4.17 & 4 & 4.04 \\
\hline \multicolumn{5}{|l|}{ 28. Physical education is a medium for transmitting play, games, dance, and sport. } \\
\hline Identify current practices and trends in play, games, dance, and sport. & 5 & 4.32 & 5 & 4.32 \\
\hline \multicolumn{5}{|l|}{ 29. Socialization takes place through play, games, dance, and sport. } \\
\hline a. Identify the nature and interpret the role and importance of socialization. & 5 & 4.00 & 4 & 3.96 \\
\hline b. Describe how socialization takes place through play, games, dance, and sport. & 5 & 4.36 & 4 & 4.28 \\
\hline \multicolumn{5}{|l|}{ 30. Social values, practices, and attitudes are constantly changing. } \\
\hline $\begin{array}{l}\text { a. Identify recent findings in sociology and social psychology and relate these to } \\
\text { play, games, dance, and sport. }\end{array}$ & 5 & 3.72 & 5 & 3.72 \\
\hline $\begin{array}{l}\text { b. Describe and interpret the process by which social attitudes are changed and } \\
\text { relate these processes in play, games, dance, and sport settings. }\end{array}$ & 5 & 3.64 & 4 & 3.52 \\
\hline
\end{tabular}




\begin{tabular}{|c|c|c|c|c|}
\hline \multirow[t]{2}{*}{ Concepts \& Competencies } & \multicolumn{2}{|c|}{ Importance } & \multicolumn{2}{|c|}{ Relevance } \\
\hline & IR & GR & IR & GR \\
\hline $\begin{array}{l}\text { c. Identify and interpret changing social practices as these affect practices in play, } \\
\text { games, dance, and sport settings. }\end{array}$ & 5 & 4.08 & 4 & 4.04 \\
\hline $\begin{array}{l}\text { d. Describe and interpret the sociological trinity (the way sport interfaces with race, } \\
\text { ethnicity, gender, and class). }\end{array}$ & 5 & 4.12 & 5 & 4.08 \\
\hline \multicolumn{5}{|l|}{$\begin{array}{l}\text { 31. Group movement experiences involve competitive and cooperative processes which may } \\
\text { resolve or intensify social problems. }\end{array}$} \\
\hline $\begin{array}{l}\text { a. Identify and evaluate the problems which arise in cooperation and competition } \\
\text { in group movement experiences. }\end{array}$ & 5 & 4.12 & 5 & 4.12 \\
\hline $\begin{array}{l}\text { b. Demonstrate and evaluate various roles in group movement activities (e.g., facilitator, } \\
\text { blocker, information source, recorder). }\end{array}$ & 5 & 3.64 & 5 & 3.68 \\
\hline
\end{tabular}




\section{Delphi Round II}

\section{Survey I ntroduction}

Welcome to Round II of the modified Delphi investigation!

Thank you for your assistance in completing this research project. It is my hope that this study will result in the generation of a comprehensive list of critical theoretical and applied history, philosophy, and sociology of sport competencies that are recommended for inclusion in the physical education teacher education curriculum.

Please remember the final date for Round II survey completion is Monday, June 22nd. I greatly appreciate your assistance in the timely completion of this project. Your practical experience, insight, and judgment are vital to the success of this project.

Thank you for your time and input! Please feel free to call or e-mail me with any questions you may have.

Amanda

Amanda Metcalf

West Virginia University

Amanda.Metcalf@mail.wvu.edu

(304) 293- 0848

*The survey items were adapted directly from the National Association for Sport and Physical Education (NASPE, 2004) and the American Alliance for Health, Physical Education, Recreation, and Dance (AAHPER, 1974). Each are reproduced with the permission of the Sport Philosophy Academy within NASPE; as well as AAHPERD. 


\section{Delphi Round II}

\section{Survey I nstructions}

The following survey contains 30 concepts followed by key competencies you will need to judge in regard to their theoretical importance and pedagogical relevance in the physical education teacher education curriculum.

Please do the following:

1- Rate each of the survey items separately in the areas of IMPORTANCE and RELEVANCE. For the purpose of this study, IMPORTANCE means the item should be understood by all prospective physical education teachers. RELEVANCE means the item is applicable to the instruction of physical education in a K-12 setting. Please note the attachment to the e- mail that brought you to this survey. The average GROUP RATING (GR) for each item was included to provide you with some additional information concerning the relationship between your INDIVIDUAL RATING (IR) from the previous round and the group mean response.

2- A rating of (5) or (4) in BOTH IMPORTANCE and RELEVANCE means that you consider the item to be essential in the preparation of prospective K- 12 physical education teachers.

3- A rating of (3) means you are neutral or undecided regarding the IMPORTANCE and RELEVANCE of the item.

4- A rating of (2) or (1) on EITHER IMPORTANCE or RELEVANCE means the item is not essential for the preparation of prospective K-12 physical education teachers.

5-If you choose not to respond to a particular item, please leave it blank.

A few reminders:

1-You must enter your name on the first page of the survey in order to continue. This is the only question you must answer.

2-You will not be allowed to go back into the survey once you have accessed the website link.

Therefore, if you are reading this message you are committed to completing the survey at this time.

3- You may return to the instructions page at any time by using the "Prev" buttons at the bottom of the survey pages. There is complete freedom (once you have entered your name) to go to any page within the survey and change your responses if necessary.

4- A survey completion bar will be at the top of each page in order to show your progress through the survey. 


\section{Delphi Round II}

\section{Table of Contents}

Section 1: Participant Information (Question 1)

Section 2: History of Sport (Questions 2-6)

Section 3: Philosophy of Sport (Questions 7-23)

Section 4: Sociology of Sport (Questions 24-31) 


\section{Delphi Round II}

\section{Section 1: Participant I nformation}

* 1. Please enter your name:

Name: 


\section{Delphi Round II}

\section{Section 2: History of Sport}

2. The development of play, games, dance, sport, and physical education closely parallels the historical development of humankind.

Importance

Relevance
a) Identify and interpret the importance of historical influences.
b) Relate the events and ideas of the history of human movement to society.
c) Describe and interpret the development of play, games, dance, and sport in American and other cultures.
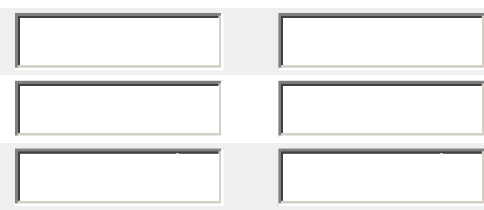

3. Understanding humankind's historical involvement with play, games, dance, and sport affords the individual dimensions for acquiring meaning and better understanding of humankind's past.
a) Describe \& interpret the development of significant forms of play, games, dance, and sport in past cultures.
b) Identify the purpose
served in past cultures.


4. An understanding of contemporary forms of play, games, dance, and sport is influenced through knowledge of significant forms of human movement growing from past cultures.
a) Identify the social, political, economic, philosophical, and religious conditions in past cultures which have influenced forms and purposes of contemporary play, games, dance, and sport.
b) Relate past forms, purposes, and cultural conditions to those of present-day play, games, dance, and sport.
c) Identify significant persons, institutions, and events which contributed to the evolution of present-day play, games, dance, and sport.

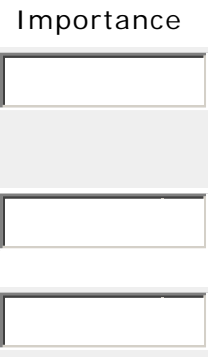

5. Play, games, dance, and sport have each had a historical development. Physical education has developed as a profession and is intimately related to the development of play, games, dance, and sport.

Describe \& interpret the relationship of the development of play, games, dance, and sport with that of physical education.

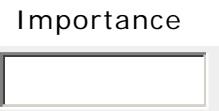

Relevance

\section{Understanding the influence of human movement on historical societies.}

Understand the influence of human movement on the development of political, social, economic, and cultural patterns of historical societies.
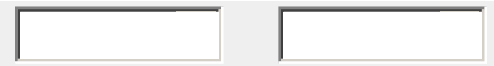


\section{Delphi Round II}

\section{Section 3: Philosophy of Sport}

\section{I dentifying the Nature of Philosophy and Sport Philosophy}

a) Understand philosophy as a formal field of study and understand the discipline of sport philosophy.

b) Understand how sport philosophy contributes to the practice of sport and physical education.

c) Understand the difference between philosophy and empiricism. Know that philosophy involves asking questions, posing challenges, and searching for deeper meanings of various issues, while empiricism involves the search for factual evidence that can be seen, heard, felt, measured, etc.

d) Understand that being a philosopher involves contemplating the differences between the "real world," where knowledge and truth rest in concrete material

Importance

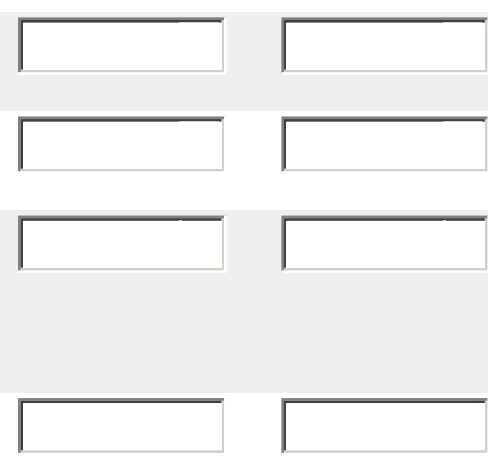
existence and the "ideal world," where knowledge and truth rest in what the mind and spirit perceive as real.

\section{Branches of Philosophy and Asking Philosophical Questions}

Importance

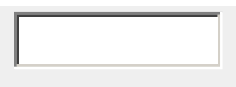

a) Understand the relationship between sport and physical education and the branches of philosophy, including metaphysics (focusing on questions about the nature of reality), epistemology (focusing on questions about what people know), and axiology (focusing on questions related to the value of things).

b) Understand the difference between a philosophical question and an empirical question, as well as understand that philosophical questions can be answered from a variety of disciplines/perspectives.

c) Be able to ask a variety of philosophical questions that span the branches of philosophy (i.e., metaphysical, axial, and epistemological).

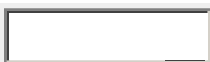

Relevance
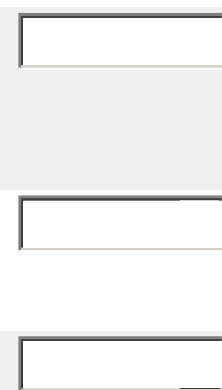

\section{Familiarity with a Variety of Philosophers of Science, Education, and Physical Education (past and present)}

Be familiar with the works of important philosophers of physical education, and understand how these works are significant to issues in sport and physical
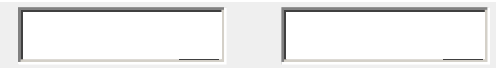
education.

\section{I dentifying the I mportance of Sport and Physical Education to the Educational Process}

a) Understand why physical education should be valued equally with other academic disciplines.

Importance

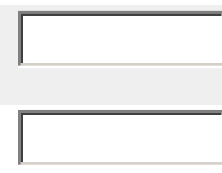

b) Be familiar with arguments for and against physical education as a valuable discipline and understand why sport and physical education can be viewed as playing an integral role in the educational process.

c) Be familiar with the history of sport and physical education as it relates to the changing values and philosophies in sport and physical education.

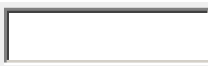



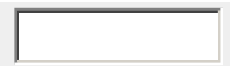




\section{Delphi Round II}

\section{Section 3: Philosophy of Sport}

\section{The Discipline of Physical Education: Understanding the Difference Between the Professional Discipline and the Academic Discipline}

a) Be familiar with the historical debate between the academic and professional disciplines of physical education (i.e., Is the purpose of the discipline of physical education to generate new "scientific" knowledge to advance the academic discipline or to generate "applied knowledge" to serve the public's need for school physical education and/or sport opportunities?).

b) Understand why physical education has been renamed with new identifiers such as exercise science, human movement, sport science, and kinesiology.

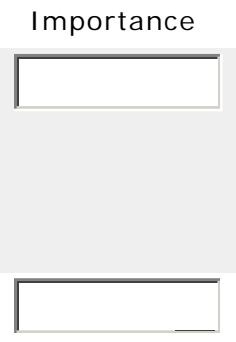

\section{Mind versus Body Argument}

a) Understand the "mind versus body" argument and how this argument is: (1) historically tied to the philosophies of sport and physical education endorsed by the Greeks and Ancient Romans (with a key focus on the philosophical thinking of Plato and Aristotle) and (2) significant to sport and physical education in that modern day practices often extend from dualistic and holistic thinking about the mind and body.

b) Understand the various ways in which our society thinks from a dualistic perspective (e.g., viewing sports competition as part mental and part physical; measuring physical fitness solely in terms of the components of fitness represent dualistic ways of thinking about the mind and body).

c) Develop a familiarity with various types of dualistic and holistic arguments, such as whether the body can be trained and/or educated without impacting the mind and vice- versa. Another example is how a holistic argument of education can be used to establish a place for school physical education.

\section{I dentifying Games and Play and its Significance to Society}

a) Understand the philosophical difference between games and play.

b) Understand the cultural significance of games and play and understand how games and play fit within the framework of physical education, sport, and lifespan physical activity.

c) Understand games and play as they relate to designing physical education and sport opportunities for individuals at different developmental times and places (e.g., elementary school physical education vs. youth sport, vs. collegiate sport, vs. adult recreational sport).

\section{The Role of Society in Sport}

Importance
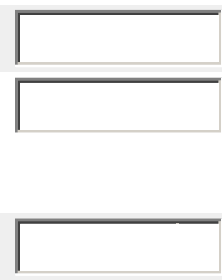

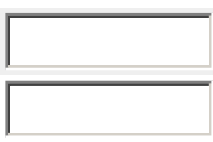

Relevance
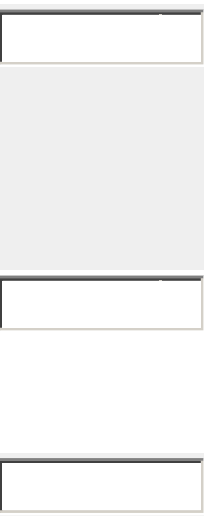


\section{Delphi Round II}

\section{Section 3: Philosophy of Sport}

\section{I dentifying the Difference Between I ntrinsic and Extrinsic Values}

a) Understand that people value participation in physical education and sport for intrinsic \& extrinsic reasons. These reasons may be intrinsically driven (e.g., "I participate in sport because it makes me feel good" or "I participate because I enjoy being outside") or externally driven (e.g., "I participate because I like to win" or "I participate to burn calories or lose weight").

b) Understand the difference between intrinsic and extrinsic values in sport and physical education and know how physical education and sport contribute to the "good life" of its participants in multiple, yet highly personal ways.

c) Understand how helping students and athletes recognize the intrinsic and/or extrinsic value of participation is important to the promotion and enjoyment of physical education and sport.

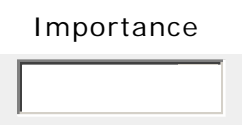

\section{Ethical Aspects of Sport}

a) Understand ethics and ethical theories such as paternalism, teleological ethics, and deontological ethics.

b) Be familiar with a variety of ethical issues in sport and physical education (e.g., intimidation, illicit performance enhancing drugs, commercialization in college athletics, burnout and dropout, sportsmanship, and gender equity).

\section{General Skills As a Result of Knowledge}

Importance

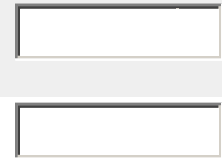

Relevance

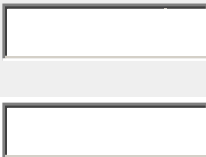

Importance

Relevance
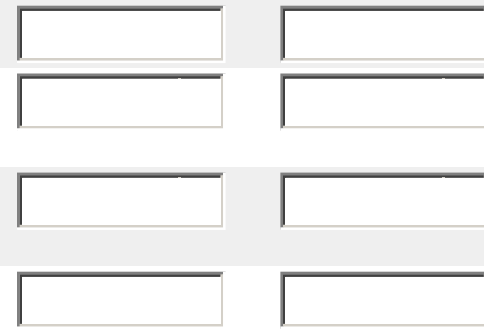

physical education.

c) Ability to cogently argue (verbal and written) for or against a variety of issues in sport and physical education.

d) Ability to offer new viewpoints on competitive and/or educational practices in sport and physical education in order to ultimately improve practices in sport and physical education.

e) Ability to rationalize and defend physical education as having equal value with other academic disciplines and as being integral to the general educational process.

f) Ability to make sound ethical decisions relative to educational and sport processes and practices.
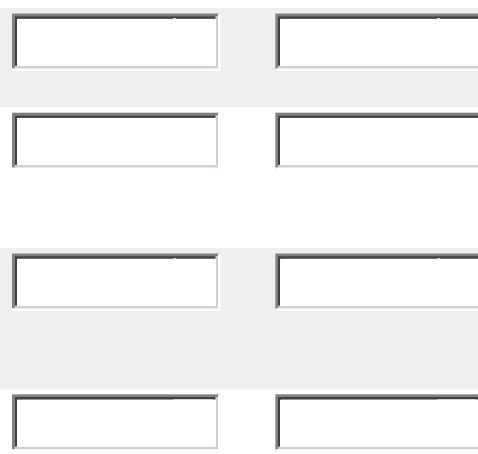

\section{Human movement has meaning which may be examined through philosophic inquiry.}

a) Identify philosophic systems of thought and their relationship to human movement.

b) Describe the processes of inquiry and apply to human movement.

c) Formulate a personal philosophy of human movement.
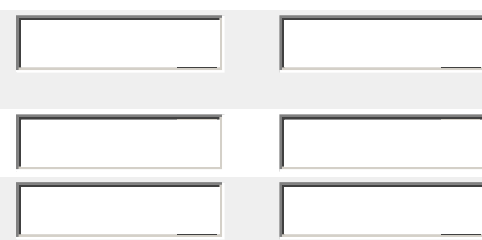


\section{Delphi Round II}

\section{Section 3: Philosophy of Sport}

19. Play, games, dance, and sport afford opportunities for individuals to inquire and discover their own nature.

Importance

Relevance

I dentify ways that individuals realize and express individuality and uniqueness

through play, games, dance, and sport.
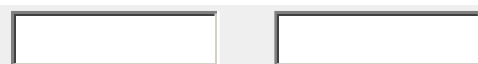

20. Play, games, dance, and sport afford opportunity for individuals to inquire into and discover the nature of the relationship between themselves and others.

Importance

Relevance

I dentify one's human condition which makes him/her similar to other individuals,

leading to the development of a rationale for interdependence.
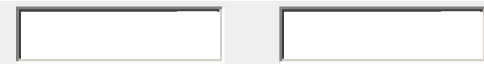

\section{Human movement reflects the nature of the universe.}

Identify and discuss the theories concerning the nature of the universe as they relate to play, games, dance, and sport.

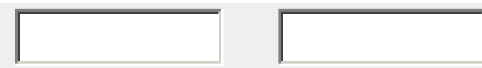

22. The individual is a co-participator, co-controller, and co-creator of both the self and the universe within which he exists.

Importance

Compare the relationships between man and the universe through his play,

games, dance, and sport.
Relevance

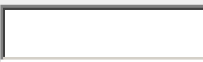

\section{Behaviors reflect philosophical attitudes.}

a) Identify several types of behaviors exhibited in play, games, dance, and sport in contemporary societies.

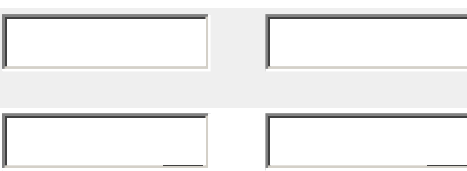

b) Identify the need for human individuality and worth in relation to societal need and requirements as expressed in play, games, dance, and sport. 


\section{Delphi Round II}

\section{Section 4: Sociology of Sport}

\section{Play, games, dance, and sport are fundamental forms of human expression.}

Importance

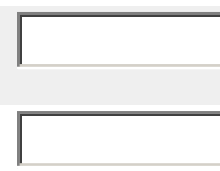

Relevance

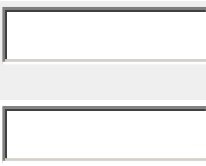

a) Interpret modes of expression as they influence play, games, dance, and sport.

b) Distinguish and identify variations in modes of expression as they occur in play, games, dance, and sport.

\section{Play, games, dance, and sport are elements of all cultures.}

Importance

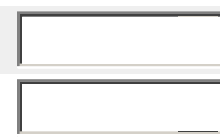

b) Identify the nature of social institutions and the reciprocal influences of play, games, dance, and sport and other cultural elements, such as politics and economics.

c) Describe cultural influence upon developmental patterns of play, games, dance, and sport.

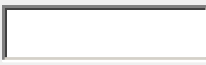

Relevance


\section{Play, games, dance, and sport reflect society.}

a) Identify, describe, and interpret theories of play.

b) Identify, describe, and interpret theories of play as they are reflected in practice, in play, games, dance, and sport.

c) Identify work ethics and their influence on play, games, dance, and sport in America.
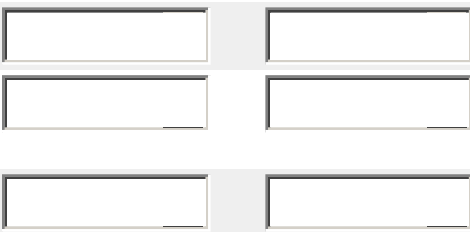

d) Describe and interpret the influence of sub-cultures (ethnic, racial, socioeconomic, etc.) on play, games, dance, and sport.
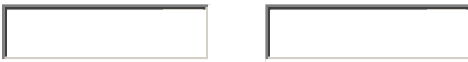

\section{Social change may be brought about through play, games, dance, and sport.}

a) Explain how social forces operate to bring about change.

b) Explain how play, games, dance, and sport may be utilized to facilitate change.

c) Predict the possible social change which may be brought about through play, games, dance, and sport.

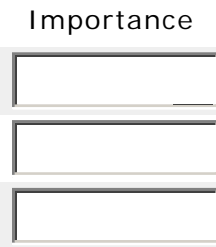

Relevance

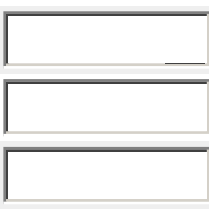




\section{Delphi Round II}

\section{Section 4: Sociology of Sport}

\section{Cultural values are transmitted through play, games, dance, and sport.}

\footnotetext{
a) Describe and interpret how social behavior demonstrates the values and ethics

in sport and society.

b) Identify responsibility as it relates to individual actions, opinions, and outcomes when engaging in sports.
}

Importance

Relevance
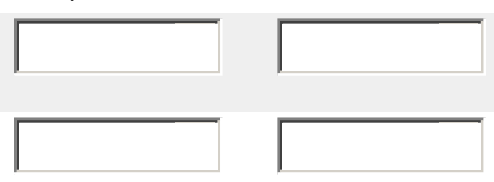

\section{Physical education is a medium for transmitting play, games, dance, and} sport.

dentify current practices and trends in play, games, dance, and sport.

Importance

Relevance

30. Socialization takes place through play, games, dance, and sport.

a) Identify the nature and interpret the role and importance of socialization.

b) Describe how socialization takes place through play, games, dance, and sport.

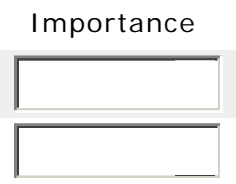

Relevance

\section{Social values, practices, and attitudes are constantly changing.}

a) Identify recent findings in sociology and social psychology and relate these to play, games, dance, and sport.

Importance

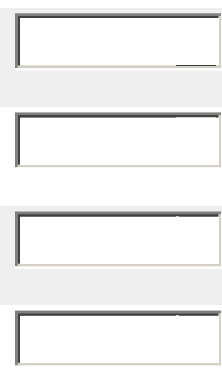

Relevance
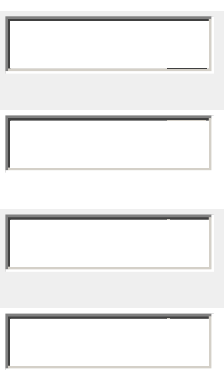

d) Describe and interpret the sociological trinity (the way sport interfaces with race/ethnicity, gender, and class).

\section{Group movement experiences involve competitive and cooperative processes which may resolve or intensify social problems.}

Importance
a) Identify and evaluate the problems which arise in cooperation and competition in group movement experiences.
b) Demonstrate and evaluate various roles in group movement activities (e.g., facilitator, blocker, information source, recorder).



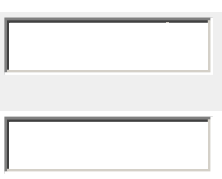




\section{Delphi Round II}

Thank you for taking this survey and playing a significant role in this study! Your input is greatly appreciated!

Completion of this round concludes your participation in the study. Final results of the study will be reported to all expert panel members in the form of an executive summary.

You will know you are completely finished with the survey once you are redirected to my West Virginia University webpage. This will occur once you click the "Done" button below.

Amanda Metcalf

West Virginia University

Amanda.Metcalf@mail.wvu.edu

(304) 293- 0848 


\section{APPENDIX E}

History, Philosophy, and Sociology of Sport

Recommendations for Physical Education Teacher Education Verification Interview Protocol 


\section{Verification Interview_E-mail to Potential Telephone Interviewees}

Hello (insert name here),

First, I would like to thank you once again for you participation as an expert panel member in the Delphi study examining what history, philosophy, and sociology of sport can contribute to physical education teacher education.

Second, would you be willing to participate in a telephone interview in order to discuss your thoughts on the final results of the study and the integration of these final history, philosophy, and sociology of sport competencies into the PETE curriculum? Please let me know as soon as possible if you would be willing to participate in a telephone interview. As soon as I hear back from you we will set up an interview date and time.

Thank you for your support of this study!

Amanda

Amanda Metcalf, M.A.

West Virginia University

College of Physical Activity \& Sport Sciences

P.O. Box 6116

Morgantown, WV 26506

(304) 293-0848 


\section{Verification Interview-Telephone Protocol}

Hello, this is Amanda Metcalf from West Virginia University. You assisted in my dissertation research study this summer examining what history, philosophy, and sociology of sport can contribute to physical education teacher education. I would like to ask you a few questions regarding the final results of the study and the integration of this knowledge into the PETE curriculum. But first, tell me a little about yourself.

\section{Lead-up Questions}

(History, Philosophy, and Sociology of Sport Specialists and PETE Faculty)

1) How long have you taught at the college level (philosophy of sport, etc.)?

2) Do you currently teach history, philosophy, and/or sociology of sport courses? If so, do the results of this study coincide with the information you present in your class(es)? If not, do you currently teach any courses that present this type of information?

3) What other types of courses do you teach?

4) Have you or are you currently involved in any research in history, philosophy, and/or sociology of sport?

\section{(K-12 Teachers)}

1) How long have you been a K-12 physical education teacher?

2) Do you currently incorporate history, philosophy, or sociology of sport into your physical education classes?

\section{Interview Questions}

1) How should history, philosophy, and sociology of sport be taught? Should they be taught together or separately?

2) Should these three areas be taught as stand alone courses or stranded throughout the PETE curriculum?

3) If stand alone courses, where in the sequence of the PETE curriculum do these subjects fit? If stranded, how should these subjects be integrated throughout the PETE curriculum?

4) Are there competencies you would have added to the final list that are not currently included? (If yes, make sure competencies are clearly stated and specific.)

5) Why do you feel these competencies should be added?

6) Are there competencies you would remove from the current list?

7) Is there anything else you would like to discuss relative to this study? 